\title{
THE BENEFITS OF ADULT PIANO STUDY AS SELF-REPORTED BY SELECTED ADULT PIANO STUDENTS
}

Peter J. Jutras, B.M., M.M.

\author{
Dissertation Prepared for the Degree of \\ DOCTOR OF PHILOSOPHY
}

\section{UNIVERSITY OF NORTH TEXAS}

May 2003

APPROVED:

Warren Henry, Major Professor, Chair

Music Education Department Robert Fred Kern, Committee Member Debbie Rohwer, Committee Member Dave Shrader, Committee Member James C. Scott, Dean of the College of Music C. Neal Tate, Dean of the Robert B.

Toulouse School of Graduate Studies 
Jutras, Peter J. The benefits of adult piano study as self-reported by selected adult piano students. Doctor of Philosophy (Music Education), May, 2003, 237 pp., 26 tables, references, 105 titles.

The purpose of this study was to assess the benefits that selected adult piano students reported receiving from their study. Adult piano students $(N=711)$ from 24 states representing all geographic regions of the U.S. each completed a questionnaire containing 31 individual benefit items. These benefits were organized into three categories: Personal, Skill, and Social/Cultural. The demographic characteristics of the study population were consistent with the findings of other adult music research. Students indicated the existence (yes or no) of each benefit and rated the importance of existing benefits on a scale of 1-10.

The category of Skill Benefits was the most agreed upon and highest rated category in the study, with over $90 \%$ agreement for each of the seven Skill Benefits. The 14 Personal Benefits were also rated highly, particularly benefits related to selfactualization and fun. Self-related Personal Benefits were rated moderately, while more introverted Personal Benefits such as Imagination/Creativity, Spirituality, and Aesthetic Appreciation were lower rated benefits. The 10 Social/Cultural benefits were the lowest rated and least important benefits in the study.

The most agreed upon benefits were Skill Improvement, Musical Knowledge, Musicianship, Accomplishment, Skill Refinement, Technique, Play/Fun, Escape from Routine, and Music Listening. The highest rated benefits in terms of importance were Dream Fulfilled, Technique, Accomplishment, Escape from Routine, Skill Improvement, Musicianship, Musical Knowledge, Play/Fun, Skill Refinement, and Personal Growth. 
Copyright 2003

by

Peter J. Jutras 


\section{ACKNOWLEDGEMENTS}

I wish to express my gratitude to the following people:

To Dr. Warren Henry, who served as chair and major professor. His tireless work and encouragement helped to make this document a reality.

To Dr. Hildegard Froehlich, who inspired me to ask questions and investigate areas I would have otherwise taken for granted.

To my committee members, Dr. Robert Fred Kern, Dr. Debbie Rohwer, and Dr. David Shrader, who provided invaluable suggestions, assistance, and support.

To Dr. Howard Tinsley, who graciously provided information about his research and a copy of the PAL questionnaire for use in the study.

To all of the teachers and students across the country who unselfishly devoted time away from their busy schedules to complete and return the questionnaires.

To Sam Holland and Tony Caramia, who have inspired me to pursue pedagogy as a highest form of both art and science.

To all of my adult piano students, who have taught me much more than they realize.

Finally, to my wife Kristin, who has provided unwavering love, patience, encouragement, and support. 


\section{TABLE OF CONTENTS}

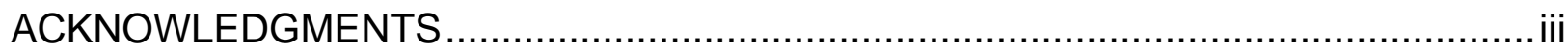

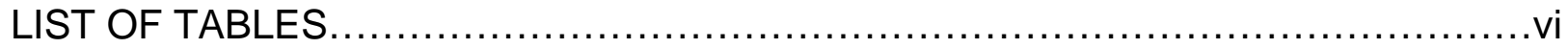

Chapter

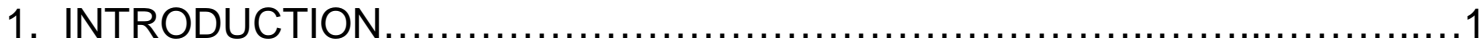

Rationale

Leisure Benefits Research

Adult Music Research

Leisure and Adult Music Research

Purpose

A Benefits Based Approach to Adult Music Research

Definitions

Adult

Benefit

Leisure

2. REVIEW OF RELATED LITERATURE.

Leisure Research

Researching Leisure Benefits

Measuring Leisure Benefits

Benefit Categories in Leisure Research

Adult Music Research

Demographic Characteristics

Motivations of Adult Musicians

Benefits of Adult Music

Summary of the Adult Music Research

Adult Education Research

Summary

3. METHODOLOGY

Questionnaire Development

Initial Questionnaire Construction

Questionnaire Revision

Pilot Study

Pilot Study Demographics

Pilot Study Results

Main Study Procedure

Location of Main Study Subjects

Main Study Demographics

Reliability

Data Collection

Data Analysis 
4. RESULTS

Benefit Data

Existence of Benefits

Importance of Benefits

Summary

Personal Benefits

Skill Benefits

Social/Cultural Benefits

5. CONCLUSIONS AND RECOMMENDATIONS 160

Conclusions

Personal Benefits

Skill Benefits

Social/Cultural Benefits

Recommendations

APPENDIX A....... 188

Content Validity Items

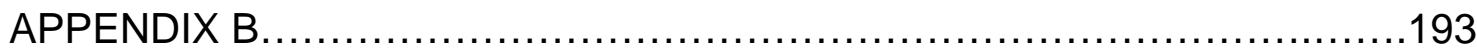

Field Test Cover Sheet and Instructions

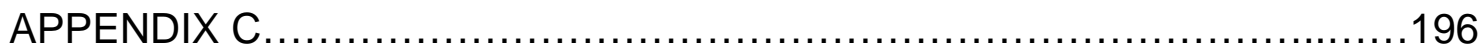

Pilot Test Questionnaire

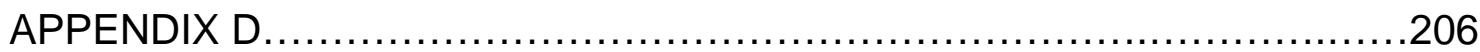

Factor Analysis of Pilot Test Items

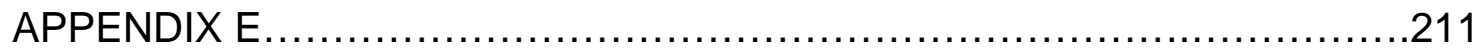

Main Study Questionnaire

APPENDIX F.

Cover Letter, Instructions, Response Sheet, and

Follow-Up Letter

REFERENCES. 


\section{LIST OF TABLES}

TABLE 1

Psychological Needs Identified by Tinsley et al.

TABLE 2.

Benefit Items Included for Content Validity Review, Field Test, and Pilot Test

TABLE 3 105

Benefit Items Included on Main Study Questionnaire

TABLE 4 108

Pilot Study Internal Consistency Coefficients

TABLE 5. 109

Pilot Study Benefit Item Ratings - Percentage Agreeing the Benefit Exists

TABLE 6

Pilot Study Benefit Item Ratings - Mean Importance of Benefits

TABLE 7

Location of Main Study Subjects

TABLE 8

Distribution of Subjects by Gender

TABLE 9 121

Distribution of Subjects by Age

TABLE 10.

Distribution of Subjects by Reported Annual Income Level

TABLE 11

Distribution of Subjects by Region and Sub-Region

TABLE 12. 124

Distribution of Subjects by State

TABLE 13. 126

Distribution of Subjects by Education Level

TABLE 14. 127

Occupations of Subjects 
TABLE 15.

Distribution of Subjects by Instructional Setting

TABLE 16.

Repertoire Genres Studied

TABLE 17.

Main Study Internal Consistency Coefficients

TABLE 18.

Benefit Item Ratings - Percentage Agreeing the Benefit Exists, Grouped by Item

TABLE 19. 147

Benefit Item Ratings - Percentage Agreeing the Benefit Exists, Grouped by Category

TABLE 20.

Mean Percentages of Agreement, by Category

TABLE 21

Benefit Item Ratings - Mean Rating of Importance,

Grouped by Item

TABLE 22. 154

Benefit Item Ratings - Mean Rating of Importance, Grouped by Category

TABLE 23.

Summed Mean Ratings of Importance

TABLE 24. 207

Factor Analysis Results for Pilot Questionnaire Personal Benefit Items

TABLE 25. 209

Factor Analysis Results for Pilot Questionnaire Skill Benefit Items

TABLE 26. 210

Factor Analysis Results for Pilot Questionnaire Social/Cultural Benefit Item 


\section{CHAPTER 1 \\ INTRODUCTION}

\section{Rationale}

While the field of education has focused traditionally on the instruction of children, adults represent a growing population of students interested in learning. American society has witnessed a growth in the adult population over recent decades. In 1987 , for the first time in history, Americans over the age of 65 outnumbered those under the age of 25 (Merriam \& Caffarella, 1999a). The median age of the United States population increased from 30.0 years in 1980 to 35.2 in 1998, and it is expected to further rise to 38.0 by the year 2025 (U.S. Census Bureau, 1999). Adults as a group are living longer, healthier lives, and today they find themselves wealthier and more educated than at any previous time in history (Merriam \& Caffarella, 1999a).

The increase in the adult population, along with dramatic increases in free time and disposable income, has led to greater adult participation in education. The percentage of adults participating in some form of organized instruction has increased from $10 \%$ in 1969 to $40 \%$ in 1995 (Valentine, 1997). Adults of all ages are seeking learning experiences in many areas of education, including the field of music. 
A 1997 survey conducted by the National Endowment for the Arts (NEA) found that 25.8 million adults in the United States over the age of 18 were involved with the public or private playing of jazz or classical music at least once in the last 12 months. Additionally, 38.9 million adults reported singing publicly or privately at least once in the previous year, and 7.2 million adults reported being involved with music composition at least once in the same period (National Endowment for the Arts, 1997). Adult musicians are also seeking out formal instruction. The 1997 NEA survey found that approximately $12 \%$ of a sample of the respondents to the larger survey $(n=5,467)$ reported participation in some form of music lesson or instructional activity in the previous year. Approximately $6 \%$ of this sample reported participation in a music appreciation class at some point during the same year.

The concept of teaching music to adult students is not new to the profession of music education. Indeed, the very roots of American music education can be traced to the singing schools of colonial America, whose purpose was to teach and improve the musical principles of church congregations (Mark \& Gary, 1992). The Music Educators National Conference (MENC) has been interested in the role of community music since its early days as the Music Supervisors National Conference, when Peter Dykema promoted community singing. Mueller (1958) proposed that the philosophical foundations of music education should be designed to promote music making in adulthood. In a discussion of music education, Charles Leonhard noted that MENC has emphasized the need for lifelong learning and adult music education since its inception (Black, 1997). 
Major initiatives in the music education profession have discussed the importance of teaching adults. The Tanglewood Declaration from the landmark 1967 MENC symposium stated that music teachers should be "equipped to work with the very young, with adults, with the disadvantaged, and with the emotionally disturbed" (Murphy \& Sullivan, 1968, p. 56). MENC's Goals and Objectives (GO) Project of 1970 advocated the involvement of people of all ages in the learning of music, and it recommended the "expansion of music for adults both in and out of school" (Andrews, 1970, p. 24). In 1974, the MENC National Commission on Instruction suggested various ways to promote adult music education (Music Educators National Conference, 1974).

Recent times have also seen the music education profession take an active interest in the teaching of adults. In 1992, MENC devoted an entire issue of the Music Educators Journal to the topic of lifelong learning in music (Blakslee, 1992). In 1994, the International Society for Music Education (ISME) launched an initiative in the field of adult and community music, devoting a series of journal articles, meetings, and symposia to the topic. This increased focus on adult music education led ISME to place the concept of music education throughout the lifespan in its official Declaration of Beliefs (International Journal of Music Education, 1994).

Piano study is an area of choice to which adult music students are drawn. Cooper (1996) reported that approximately 20 million adult amateur pianists continue to play. Bowles (1988) surveyed adults and found that keyboard was the most frequently chosen instrument of study, with $72 \%$ of adult respondents expressing some level of 
desire to study piano. Price (2001) noted that the fastest growing group of piano students was made up of pupils from age 25 to 55 .

One approach to the study of why people choose to pursue certain activities involves an examination of the benefits those activities provide. This approach has been prevalent in the field of leisure research for the last three decades (Driver, Brown, \& Peterson, 1991). When adults choose of their own free will to invest time, money, and effort into certain activities, understanding the benefits involved can provide insight into why these activities were chosen. The field of leisure research has focused on activities that involve free choice, and because most forms of adult music participation (including adult piano study) involve free choice, they can be considered leisure pursuits. The following section will present brief highlights from the existing leisure benefits research.

\section{Leisure Benefits Research}

The study of leisure activity benefits has been an active line of research for the past 25 years. Psychologists, sociologists, recreation planners, and leisure researchers have conducted numerous studies outlining the physiological, psychological, sociological, economic, and environmental benefits of leisure activities ranging from sports to participation in the arts (Driver, Brown, et al., 1991). According to Iso-Ahola (1999), "to understand the essence or the true meaning of leisure is to understand why people participate (or fail to participate) and what they strive to get from their involvement" (p. 35).

Driver, Brown, et al. (1991) noted that since participation in leisure activities is voluntary, it is logical to assume that people participate because there is some sort of 
benefit to them. The question, according to Driver, Brown, et al., is not of the existence of benefits, but of the identification of certain activities' benefits, the variance of benefits among participants, and the relative value or worth of these benefits to the participants.

Tinsley, Barrett, and Kass (1977) identified 45 psychological needs that could potentially be satisfied by leisure activities. The satisfaction of these needs was empirically tested on participants in six different leisure activities, and this research was replicated and extended by Tinsley and Kass (1978). These studies established an empirical method for measuring the benefits of various leisure activities. Further studies extended the research and documented the validity and reliability of the instruments used to gather the data (Tinsley \& Bowman, 1986; Tinsley \& Kass, 1979, 1980a, 1980b).

The research studies by Tinsley and Kass (Tinsley et al., 1977; Tinsely \& Kass, $1978,1979,1980 a, 1980 \mathrm{~b})$ led to the conclusion that some benefits were reported to be present to some extent in all leisure activities, while the presence of other benefits varied from leisure activity to leisure activity. From the original list of items, it was determined that 27 benefits were leisure activity specific and were present more in some leisure activities than others. Examples of these benefits included achievement, affiliation, creativity, getting along with others, play, and self-esteem. It was also found that 17 benefits were leisure activity general, and present to approximately the same degree in all leisure activities. Examples of these benefits included moral values, relaxation, and self-control (Driver, Tinsley, \& Manfredo, 1991).

Further research by Tinsley and Johnson (1984) led to an eight-factor structure which characterized the various benefits of leisure activities. Using factor analysis, 
Tinsley and Johnson organized the benefits of leisure into eight broad categories: SelfExpression (also titled Self-Actualization), Companionship, Power, Compensation (noneconomic or personal compensation), Security, Service, Intellectual Aestheticism, and Solitude.

In similar research on leisure benefits, Driver and Brown (1986) constructed a taxonomy of the probable benefits of outdoor leisure experiences. This taxonomy included the category headings of Personal Development, Social Bonding, Stimulation, and Independence. Driver and Bruns (1999) examined leisure benefit research and reported broad categories of Personal Benefits, Social and Cultural Benefits, Economic Benefits, and Environmental Benefits. In a book detailing research on the benefits of leisure, Driver, Brown, et al. (1991) organized chapters according to three broad categories of benefits: Psychological Benefits, Sociological Benefits, and Economic/Environmental Benefits.

The published leisure literature has demonstrated that the benefits of leisure are often grouped into broad categories, with personal and social/cultural benefits being the most frequently cited categories. In addition, studies of leisure benefits (Driver, Brown, et al., 1991; Driver \& Bruns, 1999; Tinsley \& Kass, 1978, 1979) often mentioned skillrelated benefits. Benefits from all three of these categories (personal, skill, and social/cultural) were also cited frequently by researchers in the field of adult music education. The following section will present brief highlights from the existing adult music research. 
Adult Music Research

A survey of music education books, journals, and periodicals yielded many articles on the topic of adult music education. Authors have devoted entire books to the topic (Adams, 1996; Holt, 1978; Maris, 2001), and music education trade journals have included articles about teaching adult music students (Blakslee, 1992; Coffman, 1996; Dillon, 1998, 1999; Holland, 1999). Newspapers have also published articles discussing the endeavors of adult music students (Ivry, 2002; Price, 2001). Most of these writings, however, were anecdotal or opinion-based and did not follow any method of systematic inquiry or research.

Before 1980 , systematic inquiry into issues relating to adult music education had been sparse, with few research studies on adult music education in existence. Since 1980, the body of knowledge concerning adult music education has been growing, with a number of studies conducted in the last fifteen years. Mark $(1995,1996)$ has been a vocal proponent for further research in the area of adult music education, noting that throughout our profession the needs of adult students have been largely ignored. Recent authors of studies on adult music participation (Chiodo, 1997; Conda, 1997; Cooper, 1996; Spencer, 1996) have also noted the lack of systematic research on adult music students, and these authors have emphasized the need for further research in this field.

Descriptive research has been the dominant mode of inquiry used in the existing adult music research literature. Most of the studies have sought to describe the adult music population, typically including discussions of demographic data. Many of the studies have also discussed motivational factors related to adult music participation 
(Conda, 1997; Cooper, 1996; Heintzelman, 1989; Hinkle, 1988; Seago, 1993; Spell, 1989), and two studies (Chiodo, 1997; Stebbins, 1992) have investigated the benefits of adult music participation. Examples of quantitative studies about adult music participants which were primarily descriptive in nature included those by Cooper (1996), Heintzelman (1989), Spell, (1989), and Spencer (1996). Qualitative studies describing adult music participants included those by Chiodo (1997), Conda (1997), Larson (1983), Rybak (1995), and Stebbins (1992). The following sections will detail the demographic characteristics and motivational factors found in these studies.

Demographics. A number of studies have reported demographic data, surveying large populations of adult music participants to ascertain their age, gender, income, geographic location, level of education, and prior experience with music. Among the studies that reported demographic data were those by Cooper (1996), Darrough (1990), Heintzelman (1989), Hinkle (1988), Patterson (1985), Seago (1993), Spell (1989), and Spencer (1996). Overall trends of the demographic data from these studies indicated that more females than males participated, most participants were employed in professional or white collar occupations, and participants tended to earn middle to upper level incomes.

The demographic characteristics of adult music participants reported in the studies listed above were consistent with the characteristics of the broader adult education population as reported by writers in that field. Valentine (1997) summarized the United States' component of a major study sponsored by the UNESCO Institute for Education on adult participation in education. This survey showed that adult students in the U.S. tended to be employed, highly educated, and born in the United States. 
Similarly, in a synthesis of adult education literature, Merriam and Caffarella (1999a) reported that adult education participants tended to be "white, middle class, employed, younger, and better educated than the non-participant" (p. 71). Merriam and Caffarella (1999a) also noted that throughout the last 40 years, studies on adult education have shown that this profile of the adult learner remains "remarkably consistent" (p. 70).

One additional factor cited by many of the studies on adult music education was the tendency of adult music students to report having some prior experience, either formal or informal, with music (Cooper, 1996; Patterson, 1985; Spell, 1989; Spencer, 1996; Vincent, 1997). In addition to providing demographic data, many of the above studies also investigated motivational factors influencing adult music participation.

Motivational factors. To fully understand the decision behind adult music participation, it is important that educators understand why adult music students continue to study and participate. The term motivation refers to "an internal factor that arouses and directs human behavior" (Iso-Ahola, 1999, p. 35). The study of benefits is based on a similar premise, as it seeks to determine the improved conditions which people receive from their participation in various activities (Driver, Brown, et al., 1991). While motivation study tends to focus more on the initial decision to participate, benefit research tends to examine what is gained once participation has begun. Both terms, however, examine factors that cause participants to persist and continue in a given endeavor.

Adult music studies investigating motivational factors included those by Chiodo (1997), Conda (1997), Cooper (1996), Heintzelman (1989), Hinkle (1988), Kaltoft (1990), Patterson (1985), Seago (1993), Spell (1989), and Spencer (1996). These 
studies surveyed adult music participants and asked them about various factors related to their motivation. The collective data indicated that there was not one clear motivational factor among adult music participants, but rather a combination of factors which motivated adults to participate in music. These motivational factors can be organized into three broad groups which are consistent with categories of benefits identified by the leisure researchers: Personal factors, Skill-related factors, and Social/Cultural factors.

Personal motivational factors reported in these studies included factors such as self-esteem (Conda, 1997), Personal Pleasure (Cooper, 1996), the experience of joy and happiness (Hinkle, 1988), Self-Expression (Chiodo, 1997), and Fun (Chiodo, 1997). Some of the studies (Chiodo, 1997; Conda, 1997; Hinkle, 1988) mentioned personal factors related to Maslow's concept of self-actualization, which centers on a person's desire to achieve one's highest sense of accomplishment and personal fulfillment (Maslow, 1968).

Skill-related factors cited as motivators in these studies included the enrichment of musical knowledge (Seago, 1993), the development of musical talent (Seago, 1993), the training of the ear (Seago, 1993), the enjoyment of musical challenges (Spell, 1989), the improvement of skill (Spencer, 1996), the development of performance skills (Patterson, 1985), and the opportunity to participate in music making (Heintzelman, 1989).

In outlining social and cultural motivational factors, studies on adult music participants have cited concepts such as socialization (Conda, 1997), shared accomplishment (Conda, 1997), Group Interaction (Chiodo, 1997), Ethnic Heritage 
(Hinkle, 1988), Social Improvement and Social Relationships (Heintzelman, 1989), and social and cultural emancipation (Kaltoft, 1990).

Collectively, these adult music studies provided a rich description of adult music students, including demographic profiles as well as indications of motivating factors which influenced adult participation in music. These studies identified motivating factors and benefits that were personal, skill-related, and social/cultural in nature.

Leisure and Adult Music Research

When the results of the leisure studies are taken collectively with the results of the adult music research, there is evidence of common ground between the two fields. Both fields report broad categories of personal and social/cultural benefits or motivational factors. In addition, both fields have noted the presence of skill-related motivating factors and benefits. Leisure research has investigated pursuits which involve free choice by the participant; this is also characteristic of both adult music participation and adult piano study.

Many of the personal benefits reported by leisure researchers were identical or similar to personal motivational factors cited in the adult music research. Two of Tinsley's eight factors, Self-Actualization and Self-Expression (Tinsley \& Johnson, 1984), were also cited in the adult music literature (Chiodo, 1997; Conda 1997; Hinkle, 1988). In addition, aspects of Tinsley's Compensation factor, which was defined as the satisfaction of the individual's need to experience things that are new, fresh, and unusual (Tinsley \& Johnson, 1984) were similar to personal motivating factors such as Personal Pleasure and Personal Growth cited in the adult music literature (Cooper, 1996; Spencer, 1996). Furthermore, Driver and Bruns (1999) listed a number of 
personal leisure benefits which were also cited in studies on adult music participation, including self-actualization (Chiodo, 1997; Conda, 1997; Hinkle, 1988), Flow (Rybak, 1997), freedom (Kaltoft, 1990), and enjoyment (Conda, 1997).

Among the skill-based benefits of cited by Driver and Bruns (1999) were learning, cognitive efficiency, challenge, stimulation, and improved cognitive performance. These factors and similar concepts have also been cited in the adult music literature (Patterson, 1985; Seago, 1993; Spell, 1989; Spencer, 1996). Tinsley's factor of Intellectual Aestheticism, defined as the need of the individual for intellectual stimulation and aesthetic experiences (Tinsley \& Johnson, 1984), has parallels in the adult music research with some of the cited skill-related motivating factors such as the need for challenge, musical growth, and learning (Seago, 1993; Spell, 1989, Spencer, 1996).

In a factor analysis which classified leisure benefits, Tinsley and Johnson (1984) identified four factors (Companionship, Power, Service, and Solitude) related to social concepts. These factors were similar to the concepts of socialization, social interaction, and social relationships cited as motivators for adult music participants (Chiodo, 1997; Conda, 1997; Heintzelman, 1989). Driver and Bruns (1999) reported similar social benefits of leisure, including social interaction, social support, and socialization. They also suggested that cultural awareness, ethnic identity, cultural identity, and cultural continuity were benefits of leisure; similar cultural concepts have also been cited in the adult music research literature (Hinkle, 1988; Kaltoft, 1990).

While there is considerable overlap between the fields of leisure research and adult music research, the field of adult music research has not investigated the specific concept of benefits as intensively as the field of leisure research. There are, however, 
two existing studies that did investigate specifically the benefits of adult music participation.

A Benefits-Based Approach to Adult Music Research

Studies by Stebbins (1992) and Chiodo (1997) may serve as examples to demonstrate that a benefits-based approach adapted from leisure research is a viable means for investigating adult music study. Both of these studies were qualitative in nature, and both investigated benefits reflective of the broad categories (personal, skill, and social/cultural) outlined by the reviewed literature in the fields of leisure and adult music research.

Stebbins, a sociologist and leisure researcher, used a benefits-based approach to examine the costs and rewards of barbershop singing. He developed a list of nine benefits or rewards that he found to be consistently present in a variety of leisure activities. This list included: Personal Enrichment, Self-Actualization, Self-Expression, Self-Image, Enjoyment or Fun, Re-create Oneself, Social Attraction, Group Accomplishment, and Financial Return. This list of benefits contained many parallels to the categories of personal and social benefits found in the existing leisure and adult music research. Stebbins theorized that barbershop singing must have its own patterns of costs (negatives) and rewards (positives), and that understanding this relationship could help to explain participation in the activity. Stebbins presented his nine categories of benefits to selected barbershop singers, and he asked them to rank the benefits in order of importance. Stebbins determined that Personal Enrichment, Fun, and SelfActualization were the most important benefits for both men and women. Both genders ranked Financial Return as the least important benefit of their participation. 
Chiodo (1997) also used aspects of a benefits-based approach in a qualitative study of adult instrumental music participants. Using benefit categories similar to those of Stebbins, Chiodo had participants complete a card-sort activity to place benefits in order of importance. Chiodo found that Self-Expression, Fun, and Personal Enrichment were the most important benefits for the participants. As in the Stebbins study, Chiodo found that Financial Return was a benefit of minor importance.

In summary, there is much in common between the fields of leisure research and adult music research. Both fields outline broad categories of personal and social motivators or benefits, and there is additional agreement on benefits related to skill and skill development. The Chiodo and Stebbins studies reflected commonalities between the fields, and they demonstrated that a benefits-based approach to adult music research is viable.

\section{Purpose}

It has been demonstrated that piano is a frequently chosen area of study for adults, and the existing adult music literature has stated the need for further research on the question of why adults participate in music. Understanding the benefits that adult piano students receive from their study can help educators know more about what their adult students are seeking when they commit time, money, and effort to the study of piano. This line of investigation has proven to be successful in the field of leisure research, and its application to adult piano students could assist educators in understanding how the adult piano population is similar to and different from those who 
participate in other leisure and music activities. Both the leisure research and the adult music research demonstrated the existence of three broad categories of benefits:

Personal Benefits, Skill Benefits, and Social/Cultural Benefits.

The purpose of this study is to assess the benefits that selected adult piano students report receiving from their participation in piano study.

The following research questions will be asked:

1. To what extent do adult piano students report receiving personal benefits from piano study?

2. To what extent do adult piano students report receiving skill benefits from piano study?

3. To what extent do adult piano students report receiving social/cultural benefits from piano study?

Definitions

Adult

Writers in the field of adult education have acknowledged that this field has had trouble agreeing on a definition of the term "adult" (Merriam \& Brockett, 1997; Tuijnman, 1996; Wlodkowski, 1999). Wlodkowski noted that in the United States, one can be tried at court as an adult at the age of 14 , but cannot vote until the age of 18 or drink until the age of 21. He suggested that definitions of adults often have their limitations, as they do not always consider social and cultural relevance. 
Knowles (1990) noted that different definitions are often used to determine when a person reaches adulthood. A biological definition characterizes those able to reproduce as adults. A legal definition of adulthood determines a certain age of legal independence. A social definition of adulthood defines adulthood as the time when one assumes the social roles of an adult (e.g. becomes a full-time worker, spouse, citizen, or parent). Finally, a psychological definition of adulthood includes persons who determine that they are responsible for their own lives and become self-directed. Knowles suggested that "from the viewpoint of learning, it is this [psychological] definition that is the most crucial" (p. 57).

For the purposes of the present study, it was important that the adults involved be self-directed and exercise volition in choosing to participate in piano study. These criteria would also help to ensure that the subjects in this study viewed piano as a leisure activity and pursued piano study primarily for intrinsic rewards. In a study comparing adult class piano students with non-music major college class piano students, Johnson (1982) determined that adults have a different set of goals and priorities in studying piano than college students.

The present study will use the following definition of adult, as set forth by Belanger and Valdivielso (1997):

Adults are all persons aged more than 16, except those between 16 and 25 years of age who are still carrying on their formal initial education full-time and with no interruption at any point. This pragmatic definition refers to the distinction between, on the one hand, initial education that can vary in length from one individual to the other, and, on the other hand, further participation in learning activities throughout adult life (p. ix). 


\section{Benefit}

Driver, Brown, et al. (1991) reported that the term benefit was often used in connection with economic or monetary gain, but the use of the term benefit in leisure research usually has little to do with economics. For the purposes of this study, benefit will be defined as an "a change that is viewed to be advantageous - an improvement in condition, or a gain to an individual, a group, a society, or to another entity" (Driver, Brown, et al., 1991, p. 4).

Leisure

Iso-Ahola (1980) wrote that leisure is another term which writers and researchers have found challenging to define. His definition of leisure rests on the perception of perceived freedom and the intrinsic motivation inherent in a given activity. Other researchers have supported the notion that leisure involves free choice, and should be relatively free of extrinsic rewards and motivations (Cooper, 1999; Driver, Brown, et al., 1991; Goodale \& Cooper, 1991). For the purposes of this study, leisure will be defined as an activity chosen freely and desired for its own sake. 


\section{CHAPTER 2}

\section{REVIEW OF RELATED LITERATURE}

The purpose of this study was to assess the benefits that selected adult piano students reported receiving from their study. The following chapter will review related literature from the fields of leisure and adult music research. In addition, some brief supporting views from the field of adult education will also be reviewed. This chapter will highlight commonalities between adult music research and leisure benefits research, demonstrating that both fields share three broad categories of benefits: Personal Benefits, Skill Benefits, and Social/Cultural Benefits.

This review of related literature will be presented as follows: (a) research in the area of leisure benefits, including an overview of the development of instruments measuring leisure benefits and a review of leisure research that documents personal, skill-related, and social/cultural benefits of leisure participation, (b) research in the area of adult music participation, including reported demographic characteristics of adult music students, reported personal, skill, and social/cultural motivational factors influencing participation in adult music literature, and two existing research studies that examined specifically the benefits of adult music participation, and (c) a brief section of supporting research and writings from the field of adult education. 


\section{Leisure Research}

While relatively few studies have been conducted on the benefits of adult music participation, the field of leisure studies has been employing a benefits-based research approach to a wide variety of leisure activities for many years. Jackson and Burton (1999) wrote that the modern era in leisure studies may have begun about a hundred years ago, when Thorstein Veblen first subjected many of the commonly held ideas about leisure to empirical investigation in his work The Theory of Leisure Class (Veblen, 1899). The concept of leisure has been discussed by Western thinkers for centuries, dating back to Classical Greeks such as Socrates and Aristotle (Cooper, 1999). It seems that as long as humans have had free time, they have discussed and debated what to do with their free time.

While Veblen's 1899 work was an important event in the systematic investigation of different aspects of leisure, the real body of knowledge did not grow rapidly until the 1960's. This decade saw a monumental 28-volume work published by the United States Outdoor Recreation Resources Review Commission in an effort to document and explain various facets of recreational behavior. In 1969 the Journal of Leisure Research and Society and Leisure, two journals dedicated to the dissemination of research findings in leisure, published their first issues. In the following years two other journals,

Leisure Sciences (1977) and Leisure Studies (1982), were founded (Jackson \& Burton, 1999).

Leisure researchers have sought to describe and explain the use of free time using various means of investigation, studying areas including economics, the 
relationship of work and leisure, social and cultural factors, marketing, feminist perspectives, conservation implications, physiological outcomes, tourism, gender, ethnicity, life-span, leisure constraints, participation, and conflict in leisure (Jackson \& Burton, 1999). Branches of leisure inquiry have examined the philosophy of leisure, the history of leisure, the psychology of leisure, the social psychology of leisure, and the meaning of leisure. In recent years, there has been an increased emphasis by some researchers in the leisure field on the study of the benefits of leisure participation (Driver, Brown, \& Peterson, 1991; Driver \& Bruns, 1999).

Researching Leisure Benefits

Tinsley and Johnson (1984) noted that many leisure researchers have attempted to create a system of classification for leisure activities based on studies of frequency of participation. In discussing the limitations of this approach, they wrote "Frequency participation data tells us little about why the individual participates in the activity or about the psychological nature of the individual's experience when participating in the activity" (Tinsley \& Johnson, 1984, p. 234). Iso-Ahola (1999) stated that "to understand the essence or the true meaning of leisure is to understand why people participate (or fail to participate) and what they strive to get from their involvement" (p. 35). These ideas illustrate the basic concept behind a benefits approach to leisure study - an interest in determining the specifics of what people receive from their participation in leisure activities.

Driver, Brown, et al. (1991) suggested that to debate or question the existence of benefits in leisure participation is unnecessary. If people choose to spend their free time in a particular activity, it can be assumed that there is a benefit of some form that 
they are receiving from their participation. Driver, Brown, et al. wrote that the underlying issue behind the study of benefits is not whether beneficial consequences of leisure exist. Instead, the questions are: "Who benefits? What are the magnitudes of the beneficial consequences? What type of pursuits and environments produce which benefits? . . . What is the value - or relative worth - of the beneficial consequences?" (p. 7). Driver, Brown, et al. (1991) noted that in nearly every area of benefits research, more information and research is needed. The following sections of this review will outline the development of approaches to the measurement of benefits in leisure research and then review the personal, skill, and social/cultural categories of benefits documented in the reviewed literature.

Measuring Leisure Benefits

While many researchers have investigated the benefits of leisure activities, a review of the research literature showed that two researchers, Tinsley and Driver, have devoted considerable time and effort to this area of study over the last 25 years. Both Tinsley and Driver have worked to create instruments for the measurement of leisure activity benefits, and their efforts have resulted in instruments with documented reliability and validity for leisure activity participants. The instruments constructed by Tinsley and Driver have been used in multiple studies, establishing a larger body of knowledge and data than research studies that involved only one or two uses of a particular instrument. Therefore, this section will focus primarily on the research of Tinsley, Driver, and their associates.

Tinsley's Paragraphs about Leisure (PAL). In a 1977 study, Tinsley, Barrett, and Kass noted that despite the dramatic increase in leisure time available to individuals in 
recent history, relatively little systematic theory or research had been directed toward study of the relationship between leisure participation and life satisfaction. In an effort to measure the potential satisfaction that individuals might get out of leisure participation, Tinsley et al. sought to identify and measure needs that could potentially be satisfied by leisure participation.

After an extensive review of literature on psychological needs, 45 potential needs that could be satisfied by leisure participation were identified by Tinsley et al. (1977). Determining that this list was relatively exhaustive, the researchers borrowed items to measure each need from existing psychological instruments. This process resulted in the selection of 302 items representing the 45 potential needs.

To determine relevant and popular leisure activities for their study, Tinsley et al. asked undergraduate students representative of the population of undergraduate students who would ultimately participate in the final study to rank order 10 popular leisure activities. Based on these results, the five most popular leisure activities included for the study were: watching television; attending plays, concerts, and lectures; reading books and magazines; bicycling; and drinking and socializing.

Undergraduate college students $(N=378)$ were asked to complete surveys with respect to one of the five leisure activities. Some subjects were assigned leisure activities at random, while others were instructed to complete the survey with respect to the leisure activity about which they had the most knowledge.

The Tinsley et al. (1977) study established that their method of investigating the specific needs satisfied by leisure was feasible, reliable, and valid. The investigators reported reliability coefficients ranging from .82 to .92 for independently obtained 
samples of the five different leisure activities. Further, it was reported that 42 of the 45 specific needs had significant omega squared values, demonstrating significant variability of satisfaction for these needs across the five leisure activities studied. The purpose of this study was to explore the concept of measuring need satisfaction in leisure activities, and the results were promising enough to encourage the researchers to explore this concept further.

In 1978, Tinsley and Kass conducted a replication of the 1977 Tinsley et al. study. The purpose of the 1978 study was to determine if the findings of the 1977 study could be replicated with an extended sample of leisure activities. In addition, the researchers investigated the possibility of differences in need satisfaction between men and women. Six additional leisure activities (jogging, playing cards, playing tennis, watching basketball, scuba diving, and mountaineering) were selected for the 1978 study, which also involved undergraduate college students $(N=417)$.

The results of the 1978 study were similar to the 1977 study, although nine additional need dimensions were found to not differ significantly across various leisure activities. The findings suggested the possibility that some needs were "leisure activity general (i.e. needs which are satisfied to approximately the same degree by all leisure activities)" (Tinsley \& Kass, 1978, p. 201). The researchers also found there was nearly a complete absence of gender effect for the need dimensions, and they concluded that the future use of gender as an independent variable was not necessary.

In a 1979 study involving 414 undergraduate students, Tinsley and Kass replicated their prior research, using 10 categories of leisure activities from the 1977 and 1978 studies. Results again showed strong evidence for two categories of needs 
satisfied by participation in leisure: those needs that were leisure activity specific and varied from activity to activity, and those needs that were leisure activity general and were satisfied to some extent by participation in all leisure activities. The leisure activity specific and leisure activity general needs identified by the studies outlined above are presented in Table 1 (Driver, Tinsley, \& Manfredo, 1991; Tinsley et al., 1977; Tinsley \& Kass, 1978, 1979). 
Table 1.

Psychological Needs Identified by Tinsley et al.

Leisure Activity Specific Needs

$\begin{array}{lll}\text { Ability Utilization } & \text { Creativity } & \text { Security } \\ \text { Achievement } & \text { Dominance } & \text { Self-Esteem } \\ \text { Activity } & \text { Exhibition } & \text { Sentience } \\ \text { Advancement } & \text { Getting Along w/ Others } & \text { Sex } \\ \text { Affiliation } & \text { Independence } & \text { Social Service } \\ \text { Aggression } & \text { Nurturance } & \text { Social Status } \\ \text { Authority } & \text { Play } & \text { Supervision }{ }^{1} \\ \text { Catharsis } & \text { Responsibility } & \text { Understanding } \\ \text { Compensation } & \text { Reward } & \text { Variety }\end{array}$

Leisure Activity General Needs

$\begin{array}{lll}\text { Abasement } & \text { Infavoidance } & \text { Relaxation } \\ \text { Autonomy } & \text { Justice } & \text { Self-Control } \\ \text { Counteraction } & \text { Moral Values } & \text { Succorance } \\ \text { Defendence } & \text { Order } & \text { Task Generalization } \\ \text { Deference } & \text { Recognition } & \text { Tolerance } \\ \text { Harmavoidance } & \text { Rejection } & \end{array}$

\footnotetext{
${ }^{1}$ Supervision was originally split into two components - Supervision: Human Relations and Supervision: Technical (Tinsley et al., 1977). These components were later combined into Supervision, hence the presence of 44 needs on the table instead of 45 .
} 
The 1979 Tinsley and Kass study also included a factor analysis. In this analysis, the 45 needs were loaded onto an eight-factor solution which explained $77 \%$ of the variance. The split sample reliabilities of these factors ranged from .80 to .97 . The eight factors, as named by the researchers, were:

1. Self-Actualization

2. Companionship

3. Power

4. Compensation

5. Security

6. Social Service

7. Intellectual Aestheticism

8. Autonomy

Self-Actualization was the most dominant factor of the eight, accounting for $53.8 \%$ of the variance in one factor solution and $49.2 \%$ of the variance in a second factor rotation. Of the 27 leisure specific needs, 20 had loadings of .30 or higher on the Self-Actualization factor. The second factor, Companionship, accounted for $13.0 \%$ of the variance in one factor rotation and $8.6 \%$ of the variance in a second factor solution. The above factors, many of which reflect personal and social benefits of leisure, will be discussed in more detail later in this chapter.

In 1980, Tinsley and Kass published two articles (Tinsley \& Kass, 1980a, 1980b) documenting the construct validity and discriminant validity of the measurement instruments used in their previous studies. The first article illustrated a more efficient means of measuring the benefit constructs used in earlier studies, while the second 
article suggested that the eight-factor structure discussed above may represent the best way of classifying the constructs involved in these studies.

In the first study (Tinsley \& Kass, 1980a) the researchers administered two questionnaires to independent samples of subjects. The first questionnaire, the Leisure Activities Questionnaire (LAQ) contained 334 items that measured the 45 leisure needs identified in the previous studies (see Table 1). The researchers reported that the LAQ took subjects approximately 90 minutes to complete. The second questionnaire administered was the Paragraphs about Leisure (PAL), a 27-item questionnaire that measured only the 27 leisure activity specific need dimensions established by the 1979 study. The PAL contained only one item for each of the 27 needs, and the average time of completion for this instrument was less than 30 minutes. Despite the disparity in length between the two instruments, it was found that convergent validity between the two instruments was extremely high. The researchers illustrated this fact through a correlation matrix, an analysis of variance, and a factor analysis. All split group reliabilities for both instruments exceeded .90. From this study, the researchers concluded that measuring only the 27 leisure specific need dimensions with an abbreviated instrument was an effective, valid, and reliable way of investigating the needs satisfied by various leisure activities.

In the second article (Tinsley \& Kass, 1980b) the researchers administered the LAQ to a developmental sample of 418 undergraduate students as well as to a crossvalidation sample of 209 students. The PAL was given to a second cross-validation sample of 215 students. The purpose of this study was to determine the discriminant validity of these instruments when the initial 45 needs were reduced to just 27 leisure 
specific need dimensions, and then further reduced to the eight factors reported by Tinsley \& Kass (1979). The researchers were trying to determine if scores on an eightfactor solution could be accurately predicted by scores on the larger LAQ, thus determining the validity of an analysis using the eight-factor solution. It was found from a comparison of predicted and actual hit rates that the PAL and the eight-factor solution did have significant discriminant validity. In fact, the hit rates from the PAL crossvalidation sample were significantly higher than the hit rates from the LAQ crossvalidation sample when both were compared with the original LAQ developmental sample. The researchers concluded that the brevity of the 27-item PAL may have reduced some of the error variance that could be attributed to fatigue in the longer 334item LAQ. They also concluded that "the use of the PAL with results reported in terms of the eight factorial dimensions is the most valid and parsimonious approach to measuring the need satisfier dimensions of leisure activities" (Tinsley \& Kass, 1980b, p. 233).

This line of research conducted by Tinsley and his colleagues was extremely valuable to the study of leisure benefits, as it helped to both identify specific categories of benefits and determine a valid, reliable, and efficient means of measuring these benefits. It should be noted, however, that all of the Tinsley studies discussed to this point involved college undergraduate students, a population that does not fit the operational definition of adult (see Chapter 1) used for the present study.

In 1984, Tinsley and Johnson expanded the earlier line of research by including non-college aged adults and surveying a greater range of leisure activities. The purpose of the 1984 study was to propose a preliminary taxonomy of leisure activities based on 
data regarding the psychological benefits of participation in selected leisure activities. The PAL used in earlier studies was re-expanded to 44 items, including the 27 leisure activity specific need dimensions or benefits established in the 1979 study as well as 17 leisure activity general need dimensions. (This list of 44 items was identical to those items outlined in Table 1).

The sample for the study included 923 college student volunteers and 443 noncollege aged adults ranging in age from their early 20 's to retirement. The participants were each asked to describe a leisure activity about which they were knowledgeable, and questions were also asked about each subject's degree of participation and experience with their chosen activity. All of the respondents had participated in their activity for a year or more, had participated in their activity at least once in the last six months, and described themselves as knowledgeable about their activity. The researchers concluded that their data represented the "informed opinion of knowledgeable, experienced participants ... reasonably free of stereotypic biases and impressions" (Tinsley \& Johnson, 1984, p. 235).

In an effort to determine a preliminary taxonomy of leisure activities, Tinsley and Johnson conducted a factor analysis with respect to the 34 leisure activities represented in the study. After analyzing a number of different factor solutions, the researchers adopted 9 categories of leisure activities, which were reported as follows:

1. Intellectual Stimulation (e.g. crosswords, TV, movies, and reading).

2. Catharsis (e.g. bicycling, jogging, swimming, skating, and tennis).

3. Expressive Compensation (e.g. canoeing, camping, gardening and hiking). 
4. Hedonistic Companionship (e.g. attending popular music concerts and drinking/socializing).

5. Supportive Companionship (e.g. picnicking and visiting relatives).

6. Secure Solitude (e.g. collecting stamps and collecting autographs).

7. Routine, Temporary Indulgence (e.g. shooting pool and playing cards).

8. Moderate Security (e.g. playing guitar, golf, and bowling).

9. Expressive Aestheticism (e.g. playing chess, raising house plants, baking, cooking, woodworking, photography, ceramics, and painting).

In conducting this research, Tinsley and Johnson (1984) extended the scope of the PAL and collected further data that illustrated its reliability and validity with a large variety of leisure activity participants. In addition, their study demonstrated that the measurement of the benefits of leisure activities was practical for adults as well as college undergraduate students. The researchers also noted that because relatively little was known about the benefits of leisure, it would not be wise to view their taxonomy as a permanent solution, but rather as a starting point for future research. With respect to the present study of adult piano students, the Tinsley and Johnson study is particularly relevant, as it included the leisure activity of playing guitar - the first use of a musical participation activity (as opposed to a musical listening or spectator activity) in the reviewed leisure literature.

Tinsley and Bowman (1986) measured the discriminant validity of the PAL with respect to expert and naïve respondents. The purpose of the study was to measure the perceived benefits of a leisure activity as reported by both experts in the activity and those who were naïve about the activity. The researchers hypothesized that experts in 
an activity may be aware of psychological benefits that are not represented or considered by the stereotypical views of those who are not participants in the activity.

This study used 51 subjects involved in stamp collecting, an activity chosen by the researchers because of its status as a relatively uncommon and specialized leisure activity. In addition, the PAL was given to 31 non-stamp collectors, who were asked to complete the instrument with respect to the activity of stamp collecting. In the final results, it was found that the ratings of experts differed significantly $(p<.05)$ on 16 of the 44 benefits measured by the PAL. The researchers concluded that experts in an activity may have different views of the benefits of that activity than naïve respondents. The authors did caution against the generalizability of these findings, noting the small sample size, the lack of demographic information collected from the respondents, and the inclusion of only one leisure activity in the study.

Tinsely, Teaffs, Colbs, and Kaufman (1985) investigated the benefits of leisure as reported by 1,649 persons ranging in age from 55 to 75 . The purpose of this investigation was to identify the benefits that older persons received from their participation in leisure activities. This study also examined the relationship of reported leisure benefits to certain characteristics of older persons, including morale, physical health, socioeconomic status, gender, and age.

Respondents in the Tinsley et al. (1985) study completed a form of the PAL questionnaire that included the 27 leisure activity specific benefits established by earlier studies. Each respondent was allowed to choose the leisure activity described when completing the PAL. In addition, respondents were asked to complete a brief series of questions about their own personal characteristics. 
When the samples were randomly split into sub-samples and compared, obtained reliability coefficients ranged from .91 to .99 . In addition, the data on the specific benefits were similar to the data obtained in earlier PAL studies involving both college-age students and adults over age 25 . This led the researchers to conclude that "the psychological benefit dimensions that emerged from this analysis are consistent with previous research on this issue, supporting both the validity and the generalizability of these findings" (Tinsley et al., 1985, p. 61).

The eight-factor structure found in an earlier study using the PAL (Tinsley \& Kass, 1979) was also evident in the 1985 study, although it was found that older persons reported higher ratings for some of the social benefits of leisure related to the factors of Companionship and Power. This was particularly true for women over age 65 from a lower socio-economic status. The researchers also noted that this finding was consistent with research literature on loneliness. Further, a tendency of higher variation in benefit ratings among subgroups of elderly persons was reported, and the researchers recommended further investigation into these subgroups.

In summary, the research studies conducted by Tinsley and his colleagues have had an important influence on the study of leisure activity benefits. These studies have helped to identify and quantify both broad categories of leisure benefits and specific benefits that fall under the broader categories. Many of these benefits fall into the broad categories of personal and social/cultural benefits, and additional benefits are related to the development and use of skill and ability. (These categories will be discussed in further detail later in this review.) Tinsley and his associates have tested and demonstrated a method of measuring the benefits of leisure, and they have 
documented the reliability and validity of their instruments. Specifically, the Paragraphs about Leisure (PAL) instrument has demonstrated that benefits can be reliably and validly measured with a brief questionnaire. Through this line of research Tinsley and his colleagues have demonstrated the feasibility of measuring the benefits of leisure activities, and they have provided researchers with a framework to help guide and encourage future inquiries.

Driver's Recreation Experience Preference (REP) Scales. While Tinsley approached the study of leisure benefits from a psychological perspective of measuring need satisfaction, Driver's interest in the subject was based on his experience as a professional in the field of leisure and recreation (primarily outdoor activities), where he experienced frustration with the lack of a clear method for measuring the beneficial consequences of leisure and recreation (Driver, Tinsley, et al., 1991).

Driver began his research into benefits by first examining the motivational factors behind choices in leisure participation. This indirect look at potential benefits helped to lead his future research toward investigation of the specific benefits of leisure and recreational experiences. Since motivational factors were related to the benefits that participants received from an activity, the study of motivational factors helped to establish a framework for the investigation of the benefits of that activity. This line of reasoning is relevant to the present study, since much of the reviewed research literature in the field of adult music participation has examined motivational factors that influence participation.

As with Tinsley, Driver's initial studies were devoted to the identification of needs or benefits that could potentially be met by leisure activities. These benefit items were 
initially identified through literature reviews and focus groups comprised of participants in the leisure activities (primarily outdoor activities) in which Driver was specifically interested. After individual benefit items were identified, participants in various leisure activities were asked either to rate the importance of the potential benefit or to indicate if the benefit added to or detracted from a given leisure experience (Driver, Tinsley, et al., 1991). From these studies, Driver and his colleagues developed the Recreation Experience Preference Scales (REP), which have been in use in leisure research since 1982.

Driver sorted the individual benefits into categories he termed "recreation experience preference domains", and various forms of the REP were developed to measure each of these domains. The 19 domains of benefits established by Driver were: Enjoy Nature, Physical Fitness, Reduce Tension, Escape Physical Stressors, Outdoor Learning, Share Similar Values, Independence, Family Relations, Introspection, Social Security, Achievement/Stimulation, Physical Rest, Teach/Lead Others, Risk Taking, Risk Reduction, Meet New People, Creativity, Nostalgia, and Agreeable Temperatures (Driver, Tinsley, et al., 1991). Many of these domains included sub-domains, which detailed more specific components of the domain.

Driver, Tinsley, et al. (1991) noted that over 50 empirical studies have been conducted to test the reliability and validity of the REP scales. While all of these efforts have not been published, some examples from the published literature are cited below. Tinsley, Driver, and Kass (1982) computed Cronbach's alpha coefficients to document reliability for 32 of the REP scales, using two studies that employed large data sets. The obtained coefficients averaged .68 in one study, and .72 in the other, with a range 
of .46 to .86 across both studies. In addition, the split-group reliabilities of the REP were examined with both data sets. In one data set, the reliabilities ranged from .54 to .97 , with very few below .65 . The second data set had a range of .74 to .99 , with very few values below .80. Greafe, Ditton, Roggenbuck, and Schreyer (1981) documented the stability of the REP scales over time, noting that the stability was good for average scale scores when computed at different points in time across subjects.

The validity of the REP scales has also been tested, although Driver noted that many of the validity tests have gone unreported (Driver, Tinsley, et al., 1991). Driver, Tinsley et al. reported that the scales' content validity had been demonstrated by the scores of empirical studies using the scales, as well as the many efforts at refinement undertaken when the scales were developed. In addition, Graefe et al. (1981) stated that the scales' content validity had been upheld by the many scientists who have used the scales in their research.

Rosenthal, Driver, and Waldman (1982) examined the construct validity of eight of the REP scales using a multitrait-multimethod analysis, reporting that construct validity could be verified for seven of the eight REP scales. Driver, Tinsley, et al. (1991) noted that although it can be said that the REP scales have reasonable validity and reliability, further research should be conducted before more definitive statements are made about the validity and reliability of the scales.

The REP scales have been used to measure the experience preferences of outdoor recreationists in a variety of settings and locales. Summaries of these studies outlined in Driver, Brown, et al. (1991) indicated that some of the benefit domains were consistently rated higher than others. Domains with consistently high ratings included: 
Escape from Daily Routine, Reduce Tensions, Learning, Be With Other People, Tranquility/Privacy, and Physical Rest. Other domains often ranked highly included Relationships with Nature, Outdoor Learning, and Physical Exercise.

In summary, the research undertaken by Driver and his colleagues has helped to confirm the viability of measuring the benefits of leisure activities. While Driver's research with the REP has been used primarily for outdoor recreational and leisure activities, many of the reported benefits were identical or similar to those found by Tinsley. Evidence of benefits in the broad categories of personal, skill, and social/cultural benefits was consistent with both the Tinsley research and the existing research on adult music participation.

The research conducted with both Tinsley's PAL and Driver's REP has illustrated that there are a wide variety of psychological benefits to be found in leisure activities (Driver, Tinsley, et al., 1991). Driver, Tinsley, et al. (1991) suggested that "strong patterns of commonality exist in these psychologically measured dimensions of leisure choice which suggest there is predictability about these benefits" (p. 279). Some of the specific dimensions of these benefits of leisure will be discussed below. Benefit Categories in Leisure Research

While assembling a book dedicated to a synthesis of research on leisure benefits, Driver, Brown, et al. (1991) asked over 100 professionals in the field of leisure to recommend types or categories of benefits for inclusion. The authors reported that there was wide consensus leading to the 21 types of benefits included for review. In addition, this panel agreed that all of the 21categories considered for inclusion in the book were in fact actual benefits, and that no benefit categories had been omitted. In 
the review these 21 categories of benefits were divided into the following areas:

Physiological Measures, Psychological Measures, Sociological Measures, and Economic/Environmental Measures. The section on psychological measures focused specifically on the personal and individual benefits of leisure activities.

In another review of leisure benefits, Driver and Bruns (1999) listed the specific types and general categories of benefits that have been attributed to leisure by existing research. These benefits were listed in four broad categories: Personal Benefits, Social and Cultural Benefits, Economic Benefits, and Environmental Benefits. In the listing of the specific types of benefits included in the general categories, the personal and social/cultural categories contained considerably more individual benefit items and sub-components (90) than the economic and environmental categories (20).

In a summary of research on leisure benefits, Mannell and Stynes (1991) stated that the psychological benefits of leisure can be placed into three broad categories. The first category included self-actualization, identity affirmation, the development of interpersonal and leadership skills, and spiritual development. The second category included experiential learning, the acquisition of skills and knowledge, and environmental attitude. The third category consisted of short-term, transient outcomes such as flow experiences, changes in mood, and fun.

Levy (2000) reviewed literature on leisure education and quality of life, finding that two broad categories emerged. One category was personal in nature, including elements such as critical thinking, self-efficacy, control, positive mental attitude, joy in life, suspension of reality, cognitive problem solving, skills, and responsibility. (Note that many of these personal aspects are related to skill). The second broad category was 
social in nature, including parent/child attachment and interactions, effective parenting, roles, rules, responsibility, spouses, participation in community, and responsibilities to community outside the home.

It is evident from these reviews of leisure research that there is broad agreement concerning the personal and social/cultural categories of leisure benefits. Evidence of the skill benefits of leisure is also well documented, although many researchers include skill-related benefits under the broader heading of personal benefits (Driver \& Bruns, 1999; Driver, Tinsley, et al., 1991).

Because of their alignment with the categories of motivational factors and benefits reported by adult music researchers (to be reviewed later), the personal, skill, and social/cultural benefits of leisure will be reviewed in the following sections. This essay will not review the economic or environmental benefits of leisure for the following reasons: (a) most adult music students, particularly those non-professionals that will be involved in this study, are not seeking financial gain from their participation, (b) the research of Stebbins (1992) and Chiodo (1997) demonstrated that even professional adult musicians rank financial gain as the lowest benefit of their participation in music, (c) the economic and environmental benefits discussed in the reviewed leisure research were far less complex than the categories of personal and social/cultural benefits, and they were cited in the literature far less frequently than the categories of personal and social/cultural benefits, and (d) the environmental benefits discussed in leisure research were concerned with impact on the outside, natural world, and they were always discussed with respect to outdoor activities. Since piano study is not typically an 
outdoor or environmental activity, this category of benefits is not relevant to the present study.

Personal benefits of leisure. In a literature review compiled for the President's Commission on Americans Outdoors, Driver and Brown (1986) synthesized research from the field of recreation studies that dealt primarily with outdoor leisure activities such as hiking, camping, canoeing, and park usage. Their report stated that the authors had been associated with over 100 empirical studies, which collectively outlined the selfreports of over 100,000 recreationists. Driver and Brown noted that the validity and reliability of the instruments used in these studies had been well established.

Driver and Brown organized the benefits reported by these recreationists into broad categories that included Personal Development, Social Bonding, Improvement of Physical Health, Stimulation of Curiosity, and Benefits from Commodities. The most complex and detailed category reported in the review was the category of Personal Development. Driver and Brown outlined the nine areas of personal development most cited by these studies:

\section{Self-concept}

2. Self-actualization

3. Greater self-reliance

4. Value clarification

5. Humility

6. Improved leadership abilities

7. Spiritual growth and development

8. Enhanced creativity and aesthetic appreciation 


\section{Learning}

In another review by Driver and Bruns (1999) that divided the benefits of leisure into four broad categories, the category of personal benefits was by far the most complex and detailed category, including over 65 individual benefits. Some of these benefits included catharsis, stress management, positive mood changes, selfconfidence, self-reliance, self-competence, self-assurance, value clarification, independence, creativity enhancement, spiritual growth, self-actualization, flow, stimulation, spirituality, and physiological benefits. This category of personal benefits also included many individual benefits related to skills and abilities. These skill-related benefits will be discussed later in this review.

In Tinsley's research (Tinsley \& Johnson, 1984; Tinsley \& Kass, 1979), factor analysis was performed and leisure benefits were classified into eight factors. Five of those eight factors (Self-Actualization, Compensation, Solitude, Intellectual Aestheticism, and Security) included individual benefits that were personal in nature. Some of these specific personal benefits included catharsis, creativity, independence, play, responsibility, security, self-esteem, sentience, and variety.

Many of the research studies in the reviewed leisure literature cited selfactualization as an oft-reported benefit of leisure participation. When discussing selfactualization as a potential benefit of leisure, Csikszentmihalyi and Kleiber (1991) claimed that leisure offers unique conditions for self-actualization that other constrained contexts do not. They noted that leisure participation allows an individual to broaden his or her experiences. Self-actualization is defined by Abraham Maslow (1970) as "the full use and exploitation of talents, capacities, potentialities" ( $p$ 150), and it is characterized 
by peak experiences and moments of great personal fulfillment. Csikszentmihalyi's research, inspired by Maslow, examined interviews with hundreds of people involved with various leisure activities including rock-climbing, chess, dancing, basketball, and music composition.

Csikszentmihalyi found that whenever people enjoy what they are pursuing, they report similar dimensions of experience, no matter what the activity is. Chess players, musicians, and rock-climbers all reported similar states of experience when enjoying their activity, and these states were found to be present in persons of varying nationality, economic background, and age (Csikszentmihalyi, 1990; Csikszentmihalyi \& Csikszentmihalyi, 1988). Csikszentmihalyi organized these states and conditions into a concept he named the flow experience. His research documented specific facets of the flow experience that mirrored aspects of self-actualization, including personal growth, intense involvement, and a meeting of challenges and skills.

In the measuring of personal benefits, leisure researchers have found evidence that various components of self-actualization were reported by participants as concrete benefits of leisure. Driver and Bruns (1999) reported self-actualization as a specific benefit of leisure participation. As noted earlier, Tinsley reported Self-Actualization as one of the eight factors into which leisure benefits can be grouped. In Tinsley's published research on the subject, the Self-Actualization factor explained the highest percentage of the variance of the eight factors used to group leisure benefits (Tinsley \& Johnson, 1984; Tinsley \& Kass, 1979).

Another commonly cited personal benefit of leisure participation is self-identity. This is often included with similar self-related benefits such as self-esteem, self- 
reliance, and self-confidence. While these terms are not identical, they all convey a similar meaning. In a study designed to explore the self-affirmation process in leisure and recreation settings, Haggard and Williams investigated cognitive identity with respect to eight different leisure activities (Haggard \& Williams, 1991). This study involved 168 students enrolled in college leisure and recreation courses, and students of all levels of expertise (beginning to advanced) represented each of the eight leisure activities. This study is of particular relevance to the present study, as it is one of the few leisure studies to include participation in music as one of its activities. Folk guitar was one of the eight leisure activities represented in this study, along with weight training, kayaking, backpacking, volleyball, racquetball, chess, and outdoor cooking. All of the participants in this study selected the class in which they participated, and more than $99 \%$ of the subjects agreed with the statement "I am taking this class because I really want to" (p. 106).

Each participant was given an open-ended instrument on which they were to supply the attributes of participants in their leisure activity. Two weeks after these initial attributes were compiled, participants were then asked to quantify the attributes, rating how typical they felt the attributes were to their particular activity. This research was designed to illustrate the principle that leisure and recreation activities "may serve identity functions because they symbolize distinct identity images" (Haggard \& Williams, 1991, p. 107). The researchers noted that the results were preliminary, and that the sample size for each activity was relatively small, so further investigation was necessary. 
The attributes reported by the folk guitarists are of particular relevance to the present study, as they demonstrate the study of music as a leisure pursuit. The ten most salient attributes as reported by the folk guitarists in this study were: enjoy music, easy going, creative, patient, at peace with themselves, introspective, expressive, mellow, talented, and relaxed. After ranking and correlation, Haggard and Williams (1991) reported that the ten attributes that most uniquely defined the leisure activity of folk guitar were: patient, creative, introspective, intelligent, quiet, analytical, at peace with themselves, competent, determined, and conservationist. The majority of these attributes are personal in nature, and they reflect alignment with some of the personal benefits reported in leisure studies as well as the personal motivational factors reported in adult music research (to be reviewed later).

Studying sports participation, Csikszentmihalyi identified four major components for the evaluation of benefits. These components were: Personal Enjoyment, Personal Growth, Social Harmony, and Social Change (Wankel \& Berger, 1991). This model was presented with the idea of assessing the positive outcomes of sport and providing the conditions necessary for the maximization of these outcomes. Intrinsic motivation, enjoyment, and fun have been cited as consistent themes in leisure literature on sport activities. Other personal benefits, including stress reduction, depression and anxiety relief, and self-confidence have been attributed to participation in sports as a leisure activity (Wankel \& Berger, 1991).

Leisure researchers have also noted the presence of spiritual benefits in some leisure activities (Driver \& Bruns, 1999; McDonald \& Schreyer, 1991). McDonald and Schreyer (1991) reported that although very little is known about the spiritual aspect of 
leisure, it is a dimension that may be widespread in many leisure activities. Rossman and Ulehla (1977) conducted a study on University of Colorado students and found that one of the major perceived benefits of wilderness leisure activities was the opportunity for spiritual experiences. McDonald and Schreyer suggested that spiritual experiences in leisure activities may promote personal growth, mental wellness, social consciousness, sense of community, and creativity.

In summary, the personal benefits of leisure activities are varied and widespread. Leisure researchers have acknowledged that personal benefits comprise one of the broadest and most complex categories of leisure benefits. Specific personal benefits that appeared in the reviewed leisure research literature included accomplishment, achievement, creativity, aesthetic enhancement, enjoyment, escape from routine, fun, independence, self-actualization, self-confidence, self-esteem, self-expression, selfgrowth, self-identity, solitude, spirituality, and stress reduction.

Skill benefits of leisure. Reviews of leisure benefits (Driver, Brown, et. al, 1991; Driver \& Bruns 1999; Tinsley \& Johnson, 1984) often list personal and social/cultural benefits as two of the broader and more important categories of leisure benefits. While these reviews did not typically include skill-based benefits as a separate category, subcomponents of the cited categories, particularly the personal benefits category, often included many specific benefits relating to ability, skill acquisition, skill development, knowledge, learning, and understanding. Since the research on adult music participation demonstrated that skill was an important motivating factor and benefit (Conda, 1997; Patterson, 1985; Seago, 1993; Spell, 1989), the skill benefits of 
leisure will be reviewed here independently from the personal and social/cultural benefits of leisure.

In Tinsley's development of the PAL, he established 27 leisure activity specific needs or benefits. Many of these involved aspects of learning, skill, and ability development. Among the skill-based benefits cited by Tinsley et al. (1977) were ability utilization, achievement, advancement, and understanding. In addition to these specific components, skill and ability can be related to two of the eight factors used to classify the benefits of leisure (Tinsley \& Johnson, 1984). Self-Actualization was a factor that included many components related to the growth and development of skills and the opportunity to use one's talents and abilities to their fullest. Intellectual Aestheticism was a factor identified by Tinsley and Johnson that included intellectual stimulation, learning, and growth.

Among the skill-based and ability-based benefits listed in a comprehensive review of benefits attributable to leisure research by Driver and Bruns (1999) were improved academic and cognitive performance, cognitive efficiency, problem solving, awareness, learning, understanding, challenge, and stimulation. In another review of leisure benefits attributed to the REP scales, Driver and Brown (1986) noted that learning, skill development, competence testing, achievement, and the teaching/sharing of skills were commonly reported benefits of leisure activities.

Iso-Ahola (1980) suggested that perceived competence was an important factor underlying the pursuit of recreation. According to Iso-Ahola, "those activities which help to satisfy a person's need for competence are greatly preferred to those which are not congruent with individual competencies" (p. 197). Since Iso-Ahola's definition of leisure 
rested on the concept of perceived freedom, he believed that "competence-elevating activities enhance the sense of freedom" (p. 197). This concept of skills and competencies satisfying needs is similar to a tenant of Csikszentmihalyi's concept of "flow", which states that challenges and skills must be optimally matched for the achievement of flow - a state of optimal arousal (Csikszentmihalyi, 1990).

Easley (1991) reviewed the skill development benefits of various outdoor leisure activities designed to provide structure and promote growth. Some of these programs included Outward Bound, The National Outdoor Leadership School (NOLS), and Wilderness Vision Quest. All of these programs were designed to promote survival skills, leadership skills, and personal growth. Many of the benefits documented by Easley align with the personal and social benefits of leisure discussed above, including the improvement of self-esteem, self-confidence, interpersonal skills, and intrapersonal skills. In addition to these benefits, however, many respondents reported that an improvement in their skills was an important benefit of participation. An additional study sampled past students in the NOLS and found that there was a relatively high mean for the benefit of outdoor skills. Participants in the NOLS reported a change in their skills as a result of participation in the course (Easley, 1991).

In a review of the learning benefits of leisure activities, Roggenbuck, Loomis, and Dagostino (1991) cited many studies which had demonstrated that leisure activities increased specific skills and promoted skill learning, even when skill learning was not a primary intent of the leisure activity. Roggenbuck et al. reviewed a study by Gamble which demonstrated that students who participated in an outdoor leisure activity course learned significantly more outdoor skills than a control group that received a computer 
assisted course covering the same material. Factual learning and concept learning are other benefits that have been attributed to leisure participation by existing studies (Roggenbuck et. al, 1991).

In summary, it is evident that leisure researchers have acknowledged the presence of skill-based benefits. Consistent themes that emerged in the discussion of skill-related leisure benefits included ability utilization, achievement, challenge, cognitive development, conceptual learning, improved performance, learning, problem solving, and understanding.

Social and cultural benefits of leisure. Many leisure researchers have cited the social and cultural benefits of leisure participation. Iso-Ahola (1980) suggested that although a great deal of leisure research has focused on intrinsic motivation (which is usually placed in the "personal" category of leisure benefits), intrinsic motivation cannot exist in a social vacuum. Iso-Ahola noted that many leisure activities require the presence of others, even those leisure activities that do not appear to have an important social component. People learn how to participate in personal, individual leisure activities such as jogging and stamp collecting through a socialization process during which they learn from others, watch others, and compare their progress to others. Social interaction thus becomes both a motivation for and a benefit of leisure participation. Kelly (1999) stated that "leisure is always of the culture - it is ethnic" ( $p$. $61)$, noting that leisure is a social phenomenon, and that socialization into leisure is always culture specific.

In a review of leisure benefits, Driver and Bruns (1999) listed Social and Cultural Benefits as the second of four major categories of benefits. This category, like the 
category of Personal Benefits, included many individual benefits. Examples of these social/cultural benefits included community satisfaction, pride in community, cultural awareness, community involvement, ethnic identity, social support, conflict resolution, family bonding, social mobility, understanding, tolerance, socialization, acculturation, cultural identity, cultural continuity, and community integration.

In a synthesis of empirical studies measuring recreationists' preferences for experiences, Driver and Brown (1986) listed Social Bonding as an important benefit category of leisure. Social Bonding was defined by the authors as the increase of the cohesiveness of personal social relationships. Specific components of this broader category included increased family kinship, enhanced kinships with other significant people, and the formation of new friendships.

In research utilizing Driver's Recreation Experience Preference (REP) scale, social benefits were often rated as important outcomes of leisure participation. For example, in studies of fisherman, wilderness users, and Arkansas river recreationists, the benefits of being with similar people, being with friends, and sharing similar values were all rated as important outcomes of leisure participation (Driver, Tinsley, et al., 1991).

Tinsley's research on the benefits of leisure also outlined a broad category of social and cultural benefits. In an eight-factor structure designed to classify the benefits of leisure, three of the factors (Companionship, Power, and Service) related specifically to social benefits (Tinsley \& Johnson, 1984). In addition, some of the subcomponents of the other factors that Tinsley and Johnson listed included benefits or needs that were social in nature. A subcomponent of the Self-Actualization factor included the benefit of 
being able to enjoy recognition from others for one's efforts. Social and cultural leisure benefits that Tinsley investigated through the Paragraphs about Leisure (PAL) questionnaire included affiliation, aggression, authority, dominance, exhibition, getting along with others, sex, social service, social status, and supervision.

In a study by London, Crandall, and Fitzgibbons (1977), it was reported that positive interpersonal involvement was one of the three basic dimensions of leisure needs. This dimension included social aspects such as cooperation with others and the development of friendships. Iso-Ahola (1980) reported that when leisure participants were given a list of motives for leisure participation, social interaction emerged as one of the leading reasons for participation.

Wankel and Berger (1991) reported that while substantive empirical evidence on the socializing value of sports is lacking, many authors and researchers have noted that sports and athletic leisure activities can serve to transmit the values of a society or culture. Spreitzer and Snyder (1975) surveyed 500 subjects and found that $80 \%$ of the respondents agreed that sports fostered the development of fair play, while $70 \%$ agreed that sports developed good citizenship.

Allen (1991) suggested that leisure activities in a community can have an effect on the overall perception of life satisfaction in that community. In a regression study where leisure was rated in fifth in both importance and satisfaction out of seven major dimensions of community life, leisure was actually the strongest predictor of overall satisfaction within the community.

Orthner and Mancini (1991) found that leisure activities may have a positive impact on various facets of family life. They reported that leisure activities seemed to be 
associated with positive outcomes in family satisfaction, family interaction, and family stability. Studies by Palisi (1984) and Orthner (1975) indicated a significant positive relationship between joint leisure participation and marital happiness for subjects in Australia, England, and the United States. Family kinship and family bonding were two social benefits identified by Driver through research involving the REP scales (Driver \& Brown, 1986).

The reviewed leisure literature identified social and cultural benefits as another important and oft-cited category of leisure benefits. Together, social benefits and personal benefits constituted the broadest and most investigated areas of leisure research. Social benefits of leisure documented by empirical research included affiliation, belonging, bonding, community pride, community satisfaction, cooperation, cultural awareness, cultural identity, exhibition, friendships, social mobility, social recognition, social status, and social support.

In summary, the reviewed leisure research literature has demonstrated the existence of benefits which may be classified into three broad categories: personal benefits, skill benefits, and social/cultural benefits. The following sections will review the adult music research literature, with a focus on the personal, skill, and social/cultural motivations and benefits cited in this literature.

\section{Adult Music Research}

Descriptive research was the dominant mode of inquiry used in the reviewed adult music studies. As with any field of research that is relatively young, the majority of 
existing studies have sought to describe the adult music population. These studies typically included demographic data, and they often included information on musical background and motivations for adult music study. This section of the literature review will report the findings of selected studies investigating adult music participants, focusing first on demographic characteristics, then on motivations, and concluding with an examination of existing research on the benefits of adult music study.

Demographic Characteristics

A number of existing research studies have conducted surveys with large populations in an effort to obtain demographic data about adult music participants. These findings are presented below organized by setting - instrumental, choral, piano, and retired populations. In addition, a brief description of the demographic characteristics of the broader adult education population (not exclusive to music) will be presented.

Instrumental. Heintzelman (1989) conducted a study with the purpose of examining the membership and investigating the motivations of those who populate adult concert bands in the United States. Secondary research questions in this study sought to identify the factors that influenced participation and determined the structural characteristics of the bands themselves. The study used two survey instruments to collect the data, and the first questionnaire was administered to 347 subjects. This questionnaire provided descriptive data of the ensembles, and it provided the information necessary for the selection of a stratified sample for the second questionnaire. The second questionnaire was administered to 1,785 subjects, and it 
sought to measure demographic data and motivational factors which influenced participation.

Of the respondents to the Heintzelman study, $43 \%$ were between the ages of 31 49 , with $27 \%$ between the ages of 18 and 30 . Only $6 \%$ of the respondents reported employment in blue-collar professions, while a large majority of subjects reported working in white-collar or professional occupations. Approximately half of the respondents reported attaining a degree beyond secondary education. Heintzelman studied the town size and geographic location of these bands, and he reported that $29 \%$ of the bands came from towns with populations under 10,000 , and $71 \%$ came from towns with populations under 75,000 . The bands were heavily concentrated in the northeastern (35\%) and north-central (34\%) areas of the country, with relatively small percentages of bands coming from the northwestern, southern, south-central, and western regions of the country.

Patterson (1985) studied a smaller population of community band participants in the North Central Massachusetts area. The purpose of the study was to examine the motivations of the musicians that had joined community bands in the area. Nine managers, ten directors, and 185 band members completed surveys for this study.

Of the 185 band members responding, the average age was 38.6 years, with a fairly even distribution of members over all age groups. A majority of respondents $(53.5 \%)$ were employed in professional, technical, or managerial positions, with $28.5 \%$ of respondents identifying themselves as full-time students. Fourteen percent of the respondents were retired. Over $50 \%$ of the members reported some education beyond high school. 
The Patterson study found that prior music experience was reported by many of the respondents. Over $77 \%$ indicated that they had received private instruction on the instrument they played in their community band. A large majority of respondents reported previous participation in a school music ensemble. The most frequently mentioned school music ensemble was senior high school band, with $75 \%$ reporting participation in this activity. The experiences of family members were also noted in this study, as $57 \%$ of respondents indicated that members of their family had been or were currently active in community bands.

In 1996, Spencer completed a study which sought to ascertain factors that led adults to participate in community bands. The study utilized a questionnaire, and a randomly selected, stratified sample of 74 bands from the Association of Concert Bands participated in the study. The response rate was $65.9 \%$, with 1,725 questionnaires returned. Although the main purpose of the study was to examine factors that influenced participation, the study measured many demographic variables in an attempt to identify relationships between demographic data and participation.

In the Spencer study the largest age group was $36-50$, which included $33 \%$ of the study population. Members aged 51-65 made up $27.8 \%$ of the respondents. Over half $(57.5 \%)$ of the respondents were male, and $80 \%$ of the respondents were married. Seventy-five percent were college graduates, and more than $60 \%$ had performed in college music ensembles. More than half $(55 \%)$ of the respondents were employed in professional or white-collar occupations, and $10 \%$ of the respondents reported themselves to be professional musicians. 
Choral. Hinkle (1988) studied 133 choristers and directors from six choirs in the United Singers of Pennsylvania in an attempt to determine the meaning of the choral experience for singers in this organization, which was based on German singing traditions. Social, economic, and ethnic profiles of the singers were reported in this study.

Hinkle found that male participants comprised $52 \%$ of the singers. He noted that of the six choirs included in this study, one was a men's choir. Of the remaining choirs, females slightly outnumbered males. The respondents' marital status broke down as follows: $72 \%$ were married, with $22 \%$ single or divorced and $6 \%$ widowed. Participants' income was primarily lower and middle class, with $69 \%$ of the respondents reporting an annual income between $\$ 12,000$ and $\$ 40,000$. Two-thirds of the participants reported taking music lessons at some point in the past, with the most common areas of study being voice and piano. The average length of membership in a singing society was 12 years, with a range of one year to 58 years.

Seago (1993) examined the motivational factors that influenced adult participation in Southern Baptist church choirs in the Houston, Texas area. Members and directors $(N=956)$ representing 20 church choirs participated in the study. One of the research questions centered on the reported motivations of participants in various categories of gender, age, ethnicity, choral experience, and years of formal musical training. Surveys were distributed to directors of choirs who agreed to have their members participate. Seago did not report how many choirs declined to participate, if any, and he did not report any rates of return or response. 
Of the 956 respondents to this study, $72 \%$ were female, and $55 \%$ of the respondents were between the ages of 31 and 50 . The most common length of choir membership was $1-3$ years, with $25 \%$ of the respondents noting this length of experience. When asked how many years they had participated in other church choirs, however, $26 \%$ reported participating for 21 years or more, and more than $50 \%$ of the respondents reported participating in a church choir for 7 years or more. A large majority of subjects in this study were Caucasian (86\%), with smaller numbers of African-American (9\%) and Latino (1\%) reported. Over half of the respondents reported more than one year of formal musical training.

Spell (1989) studied motivational factors and socio-demographic characteristics of members and directors of community choruses in the state of Georgia. Three survey instruments were administered to singers and directors representing eight different community choruses. There were 208 usable surveys returned from an initial mailing of 573 surveys, making the response rate for this study $36 \%$. There was no discussion in the study of the poor response rate, nor was there any discussion regarding attempts to collect surveys from the non-respondents or account for the low response rate and its implications.

As in the Seago (1993) study, a majority of the respondents in the Spell study were female $(67 \%)$. Over $90 \%$ of the respondents reported some education beyond high school. The income range of the respondents was typically middle to upper class, with more than $50 \%$ of the subjects reporting an annual income of $\$ 30,000$ or more. Spell reported that $62 \%$ of the respondents were married, $24 \%$ were single, and $13 \%$ were either divorced or widowed. It was also noted that $84 \%$ of the participants were 
Caucasian, and $83 \%$ were employed. A majority (68\%) of the participants were employed in a technical or professional occupation. A majority $(75 \%)$ reported participation in a high school choir, while $82 \%$ reported prior experience in a church choir and $41 \%$ reported taking private voice instruction in the past.

One interesting aspect of the Spell (1989) study was the comparison of the demographic data with the profile of the typical adult education participant as defined by Boshier and Collins (1985). The Boshier and Collins profile had been constructed from over 60,000 responses to a 40 item adult education questionnaire. Spell reported that most of the characteristics of the respondents in her study closely matched the characteristics outlined in the Boshier and Collins profile. In the Boshier and Collins profile, the typical adult student was female, married, had more than one child, and was employed. The subjects in the Spell study were likely to be female, married, have children, and be employed in professional occupations. The largest difference between the demographic data was in level of education. Spell reported that $67 \%$ of the respondents in her study had earned a post-secondary degree, while only $22 \%$ of the subjects in the Boshier profile had earned a degree beyond high school.

A study of community choruses in the Kentucky region (Vincent, 1997) measured the demographic characteristics of singers in 21 different choral groups. The chorus members $(N=631)$ in the study represented $84 \%$ of the community choruses in Kentucky. Vincent reported that subjects tended to be White American, have a high degree of education, and have average to above average income levels. Two-thirds of the respondents reported coming from families where music was valued. Two-thirds of the respondents were female, and two-thirds of the respondents reported having 
attended an elementary school music program where singing was emphasized. A majority of the subjects reported involvement in music activities throughout various stages of their schooling.

Piano. Cooper (1996) studied adults' perception of piano study, gathering data on the demographics, achievements, experiences, and interests of 564 survey respondents. The survey was originally intended for a general adult population, not just adult piano students. Cooper reported, however, that three-quarters of the respondents had participated in piano lessons at some point in their lives. Since the overall response rate from the initial mailing (a card asking willingness to participate in the survey) was approximately $25 \%$, the large percentage of respondents with prior piano experience may be due to factors related to non-response error.

Nearly all of the respondents in the Cooper study (94\%) held professional or white-collar jobs, and $89 \%$ reported origins in lower middle, middle, or upper middle economic backgrounds. Three-quarters of the respondents were female, and a majority of those who had taken piano lessons in the past indicated that they did so as a child.

A case study of adult piano students was conducted by Conda (1997), in which twenty adults belonging to a piano performance club were studied intensively. The purpose of the study was to examine the club and discover why the club existed, what the relationships were within the club, and how the organization had developed. Secondary questions in the study examined the relationships among the club and its members, the role of socialization in the club's existence, the role of piano in the members' lives, and motivational and persistence factors related to participation in the club. 
Demographic information for the study was presented on a case-by-case basis. All of the occupations reported were professional or white-collar, and it appeared from the occupational descriptions that all of the subjects earned middle class or higher incomes (although this was not implicitly stated in the study). The subjects ranged in age from 35 to $85 ; 11$ of the 17 interviewees in the study were female.

Retired populations. The elderly population of the United States has been growing at a rapid pace over the past two decades. Improved medicine and nutrition has raised life expectancy, and a higher economic quality of life has increased the amount of disposable time and income that senior citizens possess. Many studies in the field of adult music education have focused specifically on this unique population of music students.

In 1990, Darrough examined over 400 singers in nine retirement community choruses in the Phoenix, Arizona metropolitan area. As with many of the previously mentioned studies, the Darrough study reported that a majority of respondents were female. The primary reported educational level was high school, with smaller proportions of the subject reporting some level of higher education. The study revealed a high degree of music participation throughout life among the subjects, including experiences in the home, church, school, and civic organizations.

In 1983, Larson investigated the lifelong musical interest and activity of twelve retired adults using a case study approach. Six of the subjects were either white-collar workers or came from white-collar families, and six subjects were either blue-collar workers or came from blue-collar families. Larson found that levels of musical interest and activity were not related to the subjects' working class or level of formal schooling. 
Larson also reported that music education and previous experience in music were the factors most related to musical interest and activity for these twelve retirees. Certain characteristics of childhood musical environments and childhood musical preferences were found to be related to later musical activity and interest for the twelve subjects. Larson concluded that musical participation did not decrease with retirement for the subjects involved in this study - in fact it frequently increased with retirement.

Coffman (1996) surveyed participants in a summer senior band camp, and found that past participation in music was a common trait among nearly all of the 35 respondents. Interestingly, the seniors did not always choose to study the same instrument in their elderly years that they chose earlier in life.

Adult education participants. One of the more well-researched areas in the broader field adult education (not exclusive to music) has been that of participation studies designed to describe the characteristics of adults that participate in educational pursuits. Studies have been conducted by individual researchers as well as government organizations. An excellent synopsis of the findings of these numerous studies can be found in Merriam and Caffarella (1999a). The general conclusion of this body of research is that adults who participate in education tend to be white, middle class, employed, younger, and better educated than adults who do not participate in education.

In summary, the demographic data reported in the reviewed adult music research literature demonstrated that the demographic characteristics of adults participating in music tended to match the profile of adults in the broader adult education population. More females than males were reported in the adult music studies reviewed above, and 
participants tended to be middle class, employed, and educated beyond high school. The one notable difference was found in the level of prior experience - the reviewed literature showed that adult music participants were very likely to report prior involvement or experience with music.

Motivations of Adult Musicians

Adult music students bring an aspect of volition to their music study. An adult music student chooses to invest time, money, and effort into an activity that is rarely, if ever, essential to their economic and survival needs. This aspect of choice in adult music study has led many researchers to examine the motivating factors which influence adults' participation in musical activities.

While the present study is concerned with investigating the benefits of adult piano study, the terms motivation and benefit are related. Both terms address the question of why someone chooses to act or participate. Motivations tend to describe the initial decision to participate, while benefits tend to describe the gains that are reaped while participating. In his investigations into the benefits of leisure, Driver first began by examining motivations (Driver, Tinsley, et al., 1991). While only two reviewed adult music studies have focused specifically on benefits, many adult music studies have examined motivations, and their findings are relevant to the present study.

Among the adult music studies that have investigated motivations, most of the data has been gathered through survey or interview research. It is important to note that most of the data concerning motivation were self-reported - the motivations were identified as the adult student saw them through his or her personal perceptions. Many of the studies found similar motivating factors reported by their subjects, so these 
findings will be organized below by motivating factor, not musical setting. The motivations reported in these studies tended to fall into three broad categories: personal, skill, and social/cultural motivations. This is of relevance to the present study, which will investigate the personal, skill, and social/cultural benefits of adult piano study.

Personal factors. Many subjects in the existing studies of adult music students have reported personal development or growth as an important motivator. In a qualitative examination of an adult piano group, Conda (1997) found that many of the members indicated they were participating primarily for themselves. Quotes reported in this study from different subjects included: "I'm not doing this for anyone else", "Playing makes me feel good", and "[I do this].... for my own self-esteem, I guess. It's an accomplishment. I like playing, but just for myself" (p. 120-121). In her final analysis of results, Conda reported that the most relevant theory of explanation for both motivation and persistence among adult piano students in this group was the Self-Actualization level of Maslow's Heirarchy of Needs, defined by Maslow (1970) as "the full use and exploitation of talents, capacities, potentialities" ( $p$ 150).

In a survey study of adults, Cooper (1996) examined the motivations of subjects who began or resumed piano study as an adult. Adults surveyed were asked questions regarding piano study in childhood and piano study in adulthood. Three-quarters (76\%) of the respondents who took piano as children reported that parental decision was their main motivation for starting lessons. The second most mentioned motivation for taking piano lessons as a child was Personal Pleasure and/or Self-Expression, indicated by $33 \%$ of the respondents. The study included three groups of piano students: (a) those who studied piano as a child, (b) those who studied piano as a child and resumed as an 
adult, and (c) those who did not study piano as a child but began piano study in adulthood. Of the adult respondents that took piano as children and resumed piano study as adults, Personal Pleasure and/or Self-Expression was cited as a motivating factor by $41 \%$ of the respondents, second only to the factor of Skill Development. Of particular interest to any teacher of adult beginners is the response given by those students who began piano study for the first time in their lives as adults. These students cited Personal Pleasure as the number one motivating factor (58\% of respondents).

Although the results of the Cooper study may be skewed due to a very low survey response rate (less than $25 \%$ ), they illustrated a clear distinction in motivation between those students who studied piano as a child, those who resumed lessons as an adult, and those who started lessons as an adult. According to the results, those who started piano lessons as children were directed by their parents, while those who started piano lessons as adults were motivated primarily by personal factors.

In a study of adult members of German singing societies in Pennsylvania, Hinkle (1988) examined factors which provided both motivation and meaning for the subjects' musical experience. Although this study identified a number of social and cultural factors that were important to the singers, there were also findings which indicated that self-directed learning and personal enrichment were important motivators for many of the participants. Some of the statements relating to personal motivation that received positive responses in the study included: "to gain a sense of accomplishment; to experience joy and happiness; to get a special feeling inside myself; to relax; and to brighten my day" (Hinkle, 1988, p. 82). 
In a study of amateur adult musicians in community bands, Spencer (1996) examined intrinsic motivational factors related to participation. A factor analysis identified Self-Growth as an important personal motivator. Spencer also wrote that selfesteem and stress relief were reported as intrinsic motivators by the subjects in the study.

In summary, researchers investigating adult music participation (Conda, 1997; Cooper, 1996; Hinkle, 1988; Spencer, 1996) have cited many personal motivating factors, including accomplishment, joy or happiness, personal enrichment, personal pleasure, self-actualization, self-esteem, self-expression, self-growth, and stress reduction. Many of these motivating factors are identical or similar to personal benefits cited in the reviewed leisure literature

Skill factors. Although many studies about adult music students have examined personal and social/cultural aspects of music study, there is always some degree of skill involved in singing or playing a musical instrument. The reviewed research literature has reported consistently that many adults cite reasons for taking music that relate to the development of skill or musical ability. For example, adults may say they are learning piano because they want to be better at playing the piano, and that improved ability on the piano is the main benefit they are seeking. In the discussion of other motivating factors and benefits, it is important that this basic function of music education - the development of musical skill and facility - not be overlooked.

In a study of Southern Baptist church choirs in Texas, Seago (1993) found that musical-artistic and achievement motivations were two of the important motivational factors reported by subjects. Some of the statements scored highly by the participants 
included: [l am motivated to participate.....] "to enrich my musical knowledge; to develop my musical talent; to train my ear; to learn how to control my voice; to learn to sing songs well; to learn to sing parts other than the melody; to present good concerts; and to try, succeed, and get better" (Seago, 1993, pp. 60).

Spell (1989) studied motivational factors reported by singers and directors of Georgia community choirs. Statements from the questionnaire loaded onto four different factors: Challenge, Skill, Enjoyment, and Performance. Three of these factors (challenge, skill, and performance) are related to the development of musical ability and skill, and some of the highly rated statements in the study included: [subjects were motivated....] "to be a part of a group which strives for musical challenge; to learn more about music; to improve my musical skills and sensitivity; to improve my singing skills" (Spell, 1989, p. 72).

Conda (1997) found that some members of an adult piano club were motivated to join by their desires to perform as well as their interest in overcoming performance anxiety. When asked about their motivations to study piano, many respondents in this qualitative study cited their desires to improve at the instrument and learn how to play the instrument. Cooper (1996) noted that Skill Development was the most important motivating factor for adult piano students who reported studying piano as a child.

Heintzelman (1989) asked community band participants to rate various statements relating to their motivation to participate in music. Seven of the eight highest scoring items were loaded onto a factor labeled as Music Participation (Heintzelman, 1989). This factor included statements that were related to the development of musical 
skills and abilities, as well as statements that reflected participants' motivation as being driven by the music performed.

In a study of motivational factors contributing to community band participation in the Massachusetts area, Patterson (1985) asked respondents to indicate the most important purpose of a community band. Over $72 \%$ of the respondents agreed that a purpose of a community band was to develop the skills of the performers.

Respondents in the study also indicated that an important aspect of community band participation was the opportunity to express one's self musically.

Spencer (1996) found that a main factor explaining the motivation of community band participants was Musical Growth. This factor was related to benefits gained from increased performance opportunities, the improvement of instrumental skill, and the professional opportunities that community bands afforded to music educators.

In summary, skill-related motivational factors have been cited in many of the reviewed studies on adult music participation (Conda, 1997; Cooper, 1996; Heintzelman, 1989; Patterson, 1985; Seago, 1993; Spell, 1989; Spencer, 1996). These skill-related factors were often reported as an important part of the participants' experience, and they included such dimensions as achievement, challenge, ear training, musical enrichment, musical knowledge, skill development, and skill improvement. Many of these motivational factors are similar to skill-related benefits reported in the reviewed leisure research literature.

Social and cultural factors. With the exception of private studio instruction, most adult music participation takes place in a social setting, where adults interact with other adults who are also involved in the musical process. Whether this takes place in group 
classes, performance ensembles, or supportive groups such as the Late Bloomer's Piano Club (Conda, 1997), the influence and impact of the social and cultural setting has been documented in many research studies concerning adult music participants.

In a qualitative study of 28 adult participants in music, Chiodo (1997) discussed the socialization and the culture inherent in amateur and professional orchestras and bands. Although some of this discussion centered on the limiting factors of these organizational structures, there was also a great deal of discussion about the sense of group accomplishment, shared values, and shared experiences which were valued by the participants.

Many of the subjects in the Chiodo study participated in chamber music or smallgroup settings, and these participants mentioned the enjoyment they felt when making music with others. In a portion of the study where subjects were asked to rank cards that listed various benefits, more than one third of the subjects indicated that Group Interaction was an important part of their musical experience. Many of these respondents indicated that making music was more fun when others were involved. Others mentioned the benefits of socializing within the group and working together to produce a group effort.

Hinkle (1988) studied participants in German singing societies with the expressed purpose of determining what aspects of the experience were the most meaningful. Since the study focused on a specific group with a cultural history, Hinkle sought to determine if the social or ethnic backgrounds of the participants influenced what they reported to be meaningful. 
In the results of his study, Hinkle organized the singers into one of three categories, based on their responses to his measurement instrument. The singers were distributed among the three categories equally - of the 133 respondents, 44 were identified as "Down to Business Singers", 45 were identified as "Praise God Singers", and 44 were identified as "Ethnic Heritage Singers" (Hinkle, 1988, p. 78).

Those singers that were identified as "Ethnic Heritage Singers" reported that the most meaningful aspects of the singing experience were those which helped to sustain traditions and cultural heritage. These singers tended to prefer folk music by native composers, were interested in preserving cultural heritage, and felt that ethnic music was special in meaning. Of the 44 Ethnic Heritage Singers, 34 were born in the United States, indicating that even though they may not personally come from Germany, their German heritage and culture was extremely important in their music participation.

In addition to the cultural factors noted by many of the subjects, all of the respondents in the Hinkle study indicated that social interaction was an important part of their musical experience. Hinkle scored the group responses to a number of statements concerning the musical experience. Statements receiving high overall scores included: "to have fun singing with others (the highest scoring item)"; "to share the warmth and fellowship with other singers in the group"; "to join with others in a common effort"; and "to sing so others feel like singing" (Hinkle, 1988, p. 82). Overall, this study found that the respondents placed a high value on the social and cultural benefits of music participation.

In her study of the Late Bloomer's Piano Club, an amateur adult piano group in Ohio, Conda (1997) found that socialization played an important role in attendance at 
the group functions. Many of the members indicated that they liked to meet other members, listen to the playing of others, and discuss aspects of piano playing with other members of the group. Two of the group members interviewed for the study reported that the club functioned like a support group.

In addition to the social factors that kept members participating in the Late Bloomer's Piano Club, Conda reported that many of the members were motivated to join the group or begin piano study by major changes in their social and cultural environments. A number of the subjects in the study reported being motivated by life changing events such as a divorce, the death of a family member, a change in career or economic status, or a change in the home environment. The majority of these changes were changes in the subjects' overall social environment, indicating that for these subjects, social aspects of their lives had an impact on their participation in music. In a study of over 1,700 community band participants in the United States, Heintzelman (1989) identified six factors as primary motivators for the respondents' participation in music. Three of these six factors were related to social concerns Social Convention, Social Improvement, and Social Relationships. Some of the statements that respondents agreed with included: [subjects were motivated to participate....] "to maintain or improve my social position; to make new friends; to improve my social relationships; to share an interest with my spouse or friend; and to fulfill an obligation to the community" (Heintzelman, 1989, p. 75).

Spencer (1996) studied the attitudes of adult community band participants, measuring motivational factors related to participation. In a factor analysis, Spencer labeled one of the factors explaining motivation "Community Pride" (p. 177), reporting 
that this factor was related to feelings of self-worth gained from participation with likeminded individuals and a desire to support an arts community.

Performance for others is a frequently cited motivating factor in the reviewed literature on adult music participation. Spell (1989) reported that subjects were motivated to participate in choir "to display my individual talent; and to give me the opportunity to perform publicly" (p. 172). Seago (1993) noted that an important motivating factor for choral participants was the opportunity to present good concerts.

Patterson (1985) noted that nearly all (98\%) of the respondents in his study agreed that one of the important purposes of a community band was to "provide a musical outlet for the performers" (p. 166). Spencer (1996) identified an important motivating factor as Musical Growth; this factor included benefits related to increased performance opportunities.

Kaltoft (1990) examined music as an agent for emancipatory learning in three community education programs. The purpose of the study was to "create an understanding of how music can be used as a valuable tool for fostering a transformative type of learning" (Kaltoft, 1990, p. 9). Qualitative data was gathered from three community education programs located in Tennessee, West Virginia, and Toronto, Canada. It should be noted that an underlying assumption throughout the data gathering process of this study was that music is a powerful force for change in the individual and social lives of people. The researcher indicated that part of her purpose was to illuminate areas where music education enhanced emancipatory learning.

Kaltoft reported that many participants agreed that music was unique among the arts in its capacity as a medium for both self and socio-political expression. Subjects in 
all three of the settings indicated that their participation in music was a liberating experience. Many subjects reported that through music they came to know "an external voice which had often been oppressed by social expectations and cultural norms" (Kaltoft, 1990, p. 380). Kaltoft also concluded that music can enhance group expression through movement towards an increased knowing of self in relationship to the outside world. Kaltoft suggested that music has the power to bring people together, break cultural barriers, and help people work towards social change.

The Kaltoft study was qualitative in nature, and much of the data collection was conducted in a phenomenological fashion. It was noted that the researcher herself was an important part of the process and communication with the subjects. When looking at the results, it should be noted that the researcher began with specific assumptions regarding the importance of music in bringing about emancipation, cultural identity, and social change. It should also be noted that there was no mention of triangulation of the results of the data in the methodology section of the study. Kaltoft did continue to "recheck" the findings with the subjects themselves, but the data were not verified by an outside observer. Nevertheless, the results of this study provided evidence of the social and cultural importance of music to the participants in these specific community education programs.

In summary, social and cultural motivating factors have been cited by many researchers examining adult music participation (Chiodo, 1997; Conda, 1997; Heintzelman, 1989; Hinkle, 1988; Kaltoft, 1990; Patterson, 1985; Seago, 1993; Spell, 1989; Spencer, 1996). These researchers identified social/cultural motivating factors such as common effort, community pride, cultural heritage, group accomplishment, 
group interaction, improvement of social position, meeting of others and/or new friends, performance for others, shared values and interests, socialization, and social interaction.

While the studies reviewed above have investigated motivational factors relating to music study, there have been two studies that have focused exclusively on the benefits of music. These studies, reviewed below, are of particular relevance to the present study, which will investigate the benefits of adult piano study.

Benefits of Adult Music

Stebbins (1992) investigated the costs and rewards of barbershop singing as reported by selected individuals. Stebbins, a sociologist with extensive experience in leisure research, noted that participation in any type of serious leisure activity results in costs and rewards for the participant. He was interested in determining both the costs and the "durable benefits" that barbershop singers reported encountering. This qualitative-exploratory study examined and observed the members of three different chapters of either the all-female Harmony International and the all-male Society for the Preservation and Encouragement of Barbershop Quartet Singing in America. In addition to participant observation of these groups at various functions, 32 of the singers were selected to participate in unstructured interviews with the researcher.

As part of the study, Stebbins compiled a list of nine potential rewards based on existing leisure research. The nine rewards were as follows: Enjoyment or Fun, Financial Return, Group Accomplishment, Personal Enrichment, Re-create Oneself, Self-Actualization, Self-Expression, Self-Image, and Social Attraction. These rewards were presented to each singer interviewed, and singers were asked to rank the rewards 
in order of importance. The singers were also asked if any rewards should be added to the list - no rewards were added by any of the singers. There was no significant difference in females' rankings of rewards versus males' rankings of rewards. Stebbins found that the most powerful reward as ranked by these singers was Personal Enrichment, followed by Enjoyment or Fun, and Self-Actualization. Group Accomplishment and Social Attraction were ranked as lower rewards, and SelfExpression, Self-Image, Re-creating Oneself and Financial Return were ranked as the least important rewards of barbershop singing.

Subjects of this study were also asked about "thrills" or "high points" of barbershop singing - moments that helped to motivate a participant to stick with the activity. Stebbins noted that prior research had shown that such thrills tended to be associated most often with the reward of Self-Enrichment, and to a lesser degree with the rewards of Self-Actualization and Self-Expression. The most frequently mentioned thrill for this study, by far, was associated with competing in or winning a barbershop singing contest. Other thrills cited included singing publicly and performing for an appreciative audience. Stebbins theorized that all three of these "thrills" could be interpreted as something similar to the "Flow experience" as defined by Csikszentmihalyi (1990). Csikszentmihalyi stated that Flow was a concept which expressed "the positive aspects of human experience - joy, creativity, the process of total involvement with life" (p. ix). Stebbins noted that the Flow experience was "one of the main generalized benefits discussed in the literature on the social psychology of leisure" (p. 128). 
Chiodo (1997) also studied the benefits of adult music participation. The purpose of the Chiodo study was to describe and analyze the participation of adults in music who exemplified a lifelong commitment to instrumental performance. One of the six research questions of this study asked "What are the benefits of adult instrumental music participation that support lifelong commitment?" (p. 8).

The qualitative study interviewed 28 informants, all of whom were individuals over the age of 21 actively participating in music, either as a vocation or an avocation. All of the adult informants were currently involved in some type of public musical performance. The informants were all from the Western New York area, and they had all established themselves in an occupation or profession, either inside or outside of music.

Chiodo used a nonscheduled standardized interview in the study, and the informants were encouraged to discuss the benefits of their continuation in music. One of the triangulation procedures employed by Chiodo involved the same ranking of benefits that Stebbins (1992) employed in his study of barbershop singers. As in the Stebbins study, the informants were given the opportunity to add any benefits to the list. No informant chose to add benefits to the existing list.

Chiodo reported that Self-Expression was found to be the most important benefit for the informants. In addition to Self-Expression, the benefits of Fun and Personal Enrichment were cited by the informants as the most important benefits of their music participation. When asked to elaborate on their concepts of Self-Expression, many of the informants linked Self-Expression to various aspects of performing, improving skills, and meeting musical challenges. It was also noted by many informants that Self- 
Expression in the form of musical performance provided them with an opportunity to demonstrate their skills and be recognized. In the minds of the informants, SelfExpression was a benefit that focused on individual accomplishment and the expression of one's skills and abilities (p. 209). It could be construed that the informants saw the category "Self-Expression" as representative of both personal and skill-based benefits.

The benefit of "Fun" was also highly ranked and frequently mentioned by the informants, and it received nearly as high a ranking as the benefit of Self-Expression. When asked to go into detail about the concept of "Fun", the informants tended to list skill- and technique-related concepts. "Fun" was related to the proficiency of execution, the choice of repertoire, the quality of the group interactions, the amount of playing, and the variety of performance opportunities. Having fun was also related to the ability to perform well on one's instrument and demonstrate skill and achievement. Informants agreed that performing with skill produced an enjoyable sense of accomplishment, and this was perceived as a fun aspect of participation in music.

The third highly ranked benefit in the Chiodo study was Personal Enrichment. The informants seemed to equate Personal Enrichment with the concept of "peak experience", as outlined by the psychologist Maslow (1968). These peak experiences were defined as moments of highest happiness and fulfillment, and they helped to keep the informants motivated and interested in their musical endeavors. Chiodo outlined aspects of the peak experience as it related to the informants' concept of Personal Enrichment. Some of the aspects of peak experience listed by Chiodo included an extraordinary occurrence, a vivid memory, the accompaniment of physical responses (e.g. weeping), the experience of a high degree of mastery, and total involvement and 
immersion in the musical event. As with the Stebbins (1992) study, some of these concepts were related to attributes of Csikszentmihalyi's "Flow".

Chiodo summarized her study by comparing her findings relating to benefits with those of Stebbins. In both studies the participants found the list of benefits to be adequate. In the Stebbins study, the top benefits were Self-Enrichment, Fun, and SelfActualization, while in the Chiodo study the top ranked benefits were Self-Expression, Fun, and Personal Enrichment. Chiodo noted in her study that:

Stebbins's list, developed inductively through qualitative interviews with individual participants from many fields, provided the common terminology that had been missing in previous attempts to discuss the benefits of music participation. These nine terms made it possible to discuss concepts that otherwise were difficult to verbalize (p. 245).

Summary of the Adult Music Research

Demographics. When taken collectively, the studies outlined in this review have many demographic consistencies. In most of the studies, there were more females participating in music than males. These studies indicated that those adults who were participating in music education tended to be employed in professional or white-collar occupations, and they tended to earn middle to upper class incomes. All of these characteristics were consistent with the characteristics of the broader adult education population as described by Merriam and Caffarella (1999a) in their review of adult education literature. The one consistent difference noted in the studies on adult music students, however, is that a large percentage of adult music students reported having some prior experience with music, either formal or informal. Participants in the broader field of adult education did not tend to report similar levels of prior experience with their particular subject. 
Personal, skill, and social/cultural categories. In addition to the demographic data outlined above, many of the reviewed studies reported other characteristics of adult music students and participants. The most common areas reported in these studies were motivational factors and benefits of adult music study, as perceived by the adult music students.

Among the studies reviewed, each of reported at least one common motivational or benefit factor among the subjects, and many studies reported multiple areas of motivation common to the subjects. Although none of these studies reported completely identical findings, many individual factors were reported in multiple adult music studies. When these studies are considered collectively, it is clear that three categories of motivational factors and/or benefits recur in the findings: personal, skill, and social/cultural.

Many of the studies outlined above mentioned personal motivating factors or personal benefits (Chiodo, 1997; Conda, 1997; Cooper, 1996; Hinkle, 1988; Spencer, 1996, Stebbins, 1992). A number of the studies also reported that skill-related factors were important (Chiodo, 1997; Conda, 1997; Heintzelman, 1989; Patterson, 1985; Seago, 1993; Spell, 1989; Spencer, 1996; Stebbins, 1992). Finally, many of the studies noted the importance of social and/or cultural factors reported by subjects (Chiodo, 1997; Conda, 1997; Heintzelman, 1989; Hinkle, 1988; Kaltoft, 1990; Seago, 1993; Spencer 1996). Four of the studies (Chiodo, 1997; Conda, 1997; Seago, 1993; Spencer, 1996) mentioned factors from of all three of these categories: personal, skill, and social/cultural. 
When these studies are taken collectively, it is evident that there is not one clear agreed upon factor which motivates adult music students, nor is there one clear benefit that adult music students report consistently. Instead, it appears that there is evidence for a combination of factors, and that when the broader picture is examined, it may be concluded that many adult music students are motivated to study by one or more of three categories of factors - personal, skill, and social/cultural. These three categories align with the personal, skill-related, and social/cultural benefits reported in the reviewed leisure research literature. One of the adult music studies examined the motivational factors behind Southern Baptist church choir members and found six motivating factors which covered all of these areas (Seago, 1993). The final postulate of this study read as follows: "Participant motivation is enhanced when directors organize and utilize opportunities for socialization, skill development, challenges associated with performance and operate within positive psychological environments" (p. 92).

The studies by Chiodo (1997) and Stebbins (1992) on the benefits of adult music participants also indicated that adults report personal, skill, and social/cultural benefits from their participation in music. Both of these studies were qualitative in nature, and the use of interviewing in the research design indicated that there was some degree of overlap among these categories when adults were asked to define specific terms. In the Chiodo study, the benefits of Self-Expression and Personal Enrichment were found to contain many skill and performance related concepts. In the field of leisure research, these benefits would likely be construed as personal benefits, but the Chiodo study illustrated that many adult music participants viewed these benefits as related to their own skills and abilities. 
The reviewed studies on adult music participation reflect the categories of benefits found in the leisure research: personal benefits, skill benefits, and social/cultural benefits. There is common ground between the two fields, and since adult music participation can be construed as a leisure activity, it is logical that many of the benefits found in leisure research were also found to be present in adult music activities. The following section of this chapter will briefly highlight some supporting writings from the field of adult education which are reflective of the personal, skill, and social/cultural benefit categories detailed above.

\section{Adult Education Research}

As discussed in Chapter 1 , the field of adult education is broad and far reaching. Merriam and Cafarella (1999a) reported that the enterprise of adult learning is a multibillion-dollar industry - one that spends more money than elementary, secondary, and post-secondary schools combined. There are many elements of leisure research that are relevant to adult music study, which is why in the present review the field of leisure has been reviewed extensively. There is also, however, relevant literature from the field of adult education. The following brief section will review some germane literature from the field of adult education that reflects the established categories of personal benefits, skill benefits, and social/cultural benefits.

Early learning theories in adult education tended to focus on one factor or area relevant to the adult learning process. More often than not, earlier writings addressed 
the personal or individual side of the learning transaction. In recent years, there has been more effort to account for the social and cultural contexts that affect adult learning.

Courtney (1994) examined the application of psychological models to the field of adult education and found that two broad types of psychological models have been applied to adult education. One area dealt with the linear progression of the individual, while another area which addressed life events by accounting for social and cultural contexts.

In an article outlining reasons for participation in adult learning, Henry and Basile (1994) tested some of the common reasons adults participate in learning. One identified reason for participation had social underpinnings, and this social construct included both the desire to meet new people and major life changes which initiated participation in the learning activity. Other reasons for participation reported by adults included the desires to become better informed, to satisfy curiosity, and to learn for the sake of learning. The social construct - particularly the desire to meet new people was found to be the most influential factor in the decision to participate, followed by a general interest in learning.

In a similar study that examined the state of adult education research, Merriam and Caffarella (1999b) noted that there were two major perspectives in adult education research - the individual perspective and the contextual perspective. Research from the individual perspective tended to focus on self-direction, while research from the contextual perspective addressed social and cultural contexts. Their conclusions urged future researchers to integrate these two perspectives, bringing psychological and 
sociological factors together in adult education research, thereby merging the individual and the social aspects of adult learning.

Although the trend toward a single, integrative approach to adult education may be fairly recent, one researcher found similar concepts in an examination of the historical purposes and philosophies of adult education. Beder (1989) surveyed a broad range of historical literature on adult education in an effort to synthesize the many purposes and philosophies which have been espoused in the field. In doing so, he reported four categories into which the historical purposes and philosophies could be placed (Beder, 1989):

"1. To facilitate change in a dynamic society.

2. To support and maintain the good social order.

3. To promote productivity.

4. To enhance personal growth." (p. 39).

These four categories align closely with the personal, skill, and social/cultural categories outlined earlier in the reviewed leisure and adult music research literature. Beder's four categories are almost an exact match, with one category related to personal growth (to enhance personal growth), one category related to skill development (to promote productivity), and two categories related to social/cultural contexts (to maintain the good social order and to facilitate change in a dynamic society).

This identified trend of personal, skill, and social/cultural benefits and motivating factors has been found in research literature on adult music education, in broad theories 
relating to adult education, in the historical purposes and philosophies pertaining to adult education, and in calls for future research in the field of adult education.

\section{Summary}

The review of related literature demonstrated that these fields of research (adult education, adult music participation, and leisure) have much in common. The existing research on adult music participants illustrated that many adults are motivated to participate for personal reasons. The field of leisure research has shown that personal benefits represent one of the broadest and most researched categories of benefits, while the field of adult education acknowledges that much of adult learning is directed towards personal growth. The research on adult music participants included stronger mentions of skill-based motivations than the leisure research, yet the literature in both leisure research and adult education also noted the importance of skill-based benefits. Finally, the literature on adult music participants reported that social and cultural motivations and benefits represented an important part of the decision to participate. Studies in the field of leisure research have shown that similar social and cultural benefits are attributable to leisure activities, and writers in adult education have noted the importance of addressing the social and cultural aspects of adult learning. All three areas of research provide support for the investigation of personal, skill, and social/cultural benefits in the present study. 


\section{CHAPTER 3}

\section{METHODOLOGY}

The purpose of this study was to assess the benefits that selected adult piano students reported receiving from their participation in piano study. Specifically, the study asked the following research questions:

1. To what extent do adult piano students report receiving personal benefits from piano study?

2. To what extent do adult piano students report receiving skill benefits from piano study?

3. To what extent do adult piano students report receiving social and cultural benefits from piano study?

The following chapter will detail the steps taken to answer the above research questions, including discussion of the development of a questionnaire, the pilot study, and the procedures for the main study.

\section{Questionnaire Development}

A questionnaire was used as the primary means of data collection for this study. Isaac and Michael (1997) noted that questionnaires were the most commonly used technique for gathering data in the fields of education and behavioral sciences. 
According to Veal (1997), while questionnaire research has limitations, it can provide an effective means for reaching a large number of people. In addition, questionnaires can provide a "transparent" research process where all aspects of the data collection and interpretation are evident. Questionnaires can also provide a means for assessing the multifaceted components of attitudes, meanings, and participation in leisure (Veal, 1997). While survey research has its weaknesses, it does represent an efficient and effective means of gathering numerical data from a large number of people spread over a wide geographic area.

Isaac and Michael (1997) suggested that four guiding principles should underlie any questionnaire or survey:

"1. The survey should be systematically planned and executed to insure appropriate content coverage and sound, efficient data collection.

2. The survey should be representative - closely reflecting the population of all possible cases or occurrences, either by including everyone or everything, or by using scientific sampling procedures.

3. The survey should be objective, insuring that the data are as observable and explicit as possible.

4. The survey should be quantifiable, yielding data that can be expressed in numerical terms." (p. 136-137).

Researchers have established that questionnaires can reliably and validly measure the perceived benefits of various leisure activities (Driver, Tinsley, \& Manfredo 1991; Tinsley \& Kass, $1977,1978,1979,1980 a, 1980 b)$. Since adult piano study fits the definition of a leisure activity as outlined in Chapter 1 (an activity freely chosen and 
pursued for its own sake), the research of Driver and Tinsley was used as a point of departure for the construction of the questionnaire used in the present study. The following section outlines the steps undertaken in the initial construction of the questionnaire for the present study.

Initial Questionnaire Construction

Among the reviewed leisure research dealing with benefits, the studies of Tinsley and his associates (Tinsley \& Johnson, 1984; Tinsley \& Kass, 1978, 1980a, 1980b) had the highest reported documentation of reliability and validity for leisure activity participants. In addition, Tinsley's questionnaires have been used with a variety of populations, settings, and leisure activities (Driver, Tinsley, et al., 1991). Leisure activities studied included sports, outdoor activities, social activities, hobbies, arts, and games. One of the studies (Tinsley \& Johnson, 1984) included playing guitar as a leisure activity. While none of the measurement instruments were published, the researcher was able to obtain a copy of the Paragraphs about Leisure (PAL) questionnaire from Tinsley for review and use related to the present study.

While the questionnaire for the present study was based loosely on the conceptual layout of the PAL, many changes to the format of the questionnaire were made. Isaac and Michael (1997) stated that when designing a survey, it is best to "avoid using an existing survey, if it was designed for a different purpose, population, or circumstance. Although they may serve as a point of departure, surveys usually have aims or situational factors that are specific to each application" (p. 137). Since the PAL was not designed specifically for adult piano students, it was used only as a point of departure for the construction of the questionnaire for the present study. The following 
sections explain changes made from Tinsley's format, including adjustments made to item length, the wording of questionnaire items, and the response format. A following section explains the process used to select individual benefit items for inclusion on the questionnaire.

Item length. In the development of the PAL questionnaire, Tinsley and Kass (1978) identified 27 leisure activity specific benefits and 17 leisure activity general benefits (see Table 1). Subsequent research (Tinsley \& Kass, 1979, 1980a, 1980b) determined that instruments measuring only the 27 leisure activity specific benefits yielded results that were approximately as reliable and valid as longer instruments measuring both leisure activity specific and leisure activity general benefits. In addition, it was found that short form instruments using one question for each benefit worked as well as longer form instruments which used over 330 items to measure the 44 categories of benefits. These studies demonstrated that longer form questionnaires were not necessary to maintain reliability and validity when measuring leisure benefits and that single items for each benefit may suffice. On each of these questionnaires, a paragraph described each potential benefit, and subjects indicated their level of agreement with the paragraph on a five-point Likert scale.

Gay (1992) noted that in constructing a questionnaire, each question should be brief, worded clearly, and should address only a single concept. In addition, Isaac and Michael (1997) suggested that questionnaires should be as brief, clear, and straightforward as possible, for respondents will often reject or resist complex questionnaires. Edwards (1957) noted that questionnaire statements should be short, and they should rarely exceed twenty words. Although the PAL used a paragraph to 
describe various facets of each leisure benefit, the present questionnaire used one brief statement for each potential benefit of adult music study.

Item wording. In the PAL questionnaire, subjects were asked to rate benefits by using the language "participants in this activity. . .", which suggested that responses were to be given with respect to all participants in a given activity. Based on suggestions made by music education professionals, including members of the content validity panel and educators asked to review the questionnaire for clarity, it was decided that this wording was not ideal for the present study. Since the present study was concerned with the self-reporting of adult piano students, the respondents were asked to consider their own personal beliefs when responding and not to assess whether other (or all) participants in adult piano perceived or valued a particular benefit. Therefore, the questions for the present study were restructured so that respondents were considering benefits with respect to themselves as individuals. All benefit statements in the present study were followed by the question: "Is this a benefit of piano study for you personally?", and the wording "participants in this activity" was not used.

Item response format. In the PAL Questionnaire, respondents were asked to read each paragraph, assess their level of agreement with that paragraph (with respect to their specific leisure activity), and respond on a five-point Likert scale indicating their level of agreement. Most of the paragraphs began with the words "participants in this activity..." and then detailed various components of a particular benefit. Based on suggestions made by music education professionals and experienced researchers in the field of music education, it was determined that for the present study two changes would be made in the response format: Respondents were first asked if a benefit 
existed for them personally. If respondents agreed that a benefit existed, they were then asked to rate the importance of the benefit.

Since the present study represented an initial inquiry into the benefits of adult piano study, it could not be assumed that all the benefits on the questionnaire actually existed. Tinsley's instrument was based on many previous studies which had established the presence of specific benefits for participants in a wide range of leisure activities. In the present study, each statement was followed by a simple yes or no question: "Is this a benefit of piano study for you personally?" Respondents were instructed to answer "yes" if they believed the item was a benefit, or "no" if they did not believe it was a benefit. Gay (1992) suggested that in questionnaire construction it is important "not to ask a question that assumes a fact not necessarily in evidence" ( $p$. 225). Allowing the respondents to indicate that they did not believe a given benefit existed avoided the assumption and bias that all benefits on the questionnaire existed for all adult piano students.

The questionnaire for the present study contained two levels of response. For each item, respondents indicated "yes" or "no" to the existence of a benefit as described above. For each item answered with a "yes", the respondent was then asked to rate the importance of that benefit on a scale of 1 to 10 . An answer of 10 indicated that the benefit was a most important benefit while an answer of 1 indicated that the benefit was a least important benefit. This scale was chosen for its ease of use, its familiarity, its range of interval level data, and its brevity. Subjects in both the field test and the pilot test did not report any problems understanding or responding to this format. Subjects in the pilot test also made use of the full range of numbers of 1-10 when responding to the 
pilot test items. When the pilot test was conducted with 31 adult piano students, over $75 \%$ of the items in the pilot test had more than seven different levels of response (i.e. respondents used at least seven different numbers between one and ten when responding) to the question of importance; over $95 \%$ of the items had six or more different levels of response.

Selection of questionnaire items. In determining the items for the questionnaire, the following steps were undertaken: (a) adult music research literature was reviewed for specific benefits and/or motivational factors, (b) leisure research literature was reviewed for specific benefits, (c) these items were compared and a list of benefits for the present study was drafted, (d) a list of relevant demographic data was drafted, (e) the items were reviewed by music education professionals for wording and clarity, (f) the benefit list was reviewed for content validity by a panel of adult music educators, and $(\mathrm{g})$ benefit and demographic items were field tested with adult piano students thought to be representative of the population that would be investigated by the main study. After all of the above steps were taken, the questionnaire was pilot tested with 31 adult piano students. The following section will discuss items a, b, c, and d from the above list. An additional section addressing the revision of the questionnaire will follow, discussing items $\mathrm{e}, \mathrm{f}$, and $\mathrm{g}$. A further section will then detail the pilot test procedures and results.

Literature review. The details of the relevant literature reviewed in the fields of adult music and leisure research may be found in Chapter 2. To summarize, the adult music research literature showed a great deal of agreement on the existence of motivational factors and benefits in three broad categories: personal, skill, and 
social/cultural (Conda, 1997; Cooper, 1997; Heintzelman, 1989; Hinkle, 1988;

Patterson, 1985; Seago, 1993; Spell, 1989; Spencer, 1996). The literature in the field of leisure research identified these same broad categories with two additional categories of benefits - Economic benefits and Environmental benefits (Driver \& Bruns, 1999; Driver, Tinsley, et al., 1991). Prior research by Stebbins (1992) and Chiodo (1997) demonstrated that financial benefits were ranked last in importance by adult musicians. In addition, since the target population for the study was adult piano students pursuing piano as a leisure pursuit, it could reasonably be assumed that the majority of adult piano students participating in the present study would not be studying piano for financial benefits. The primary focus of environmental benefits is on outdoor- and nature-related activities. Since neither of these categories had relevance to adult piano study, these two categories of benefits were excluded from the present study. Based on the review of literature, the three broad categories of benefits included for the present study were Personal Benefits, Skill Benefits, and Social/Cultural Benefits.

For the selection of specific items, the 27 leisure activity specific benefits from Tinsley's PAL instrument were selected as a point of departure (see Table 1). The research of Tinsley and his associates (Tinsley \& Johnson, 1984; Tinsley \& Kass, 1978, 1979, 1980a, 1980b) included a number of studies that established the existence, validity, and reliability of these 27 leisure activity specific benefits for participants in a wide range of leisure activities. Appropriate benefit items from Tinsley's list were included, and an additional 12 benefits documented in the research of Driver (Driver \& Brown, 1986; Driver, Tinsley, et al., 1991) using the Recreation Experience Preference (REP) scale were added to this list. These benefits were: reduce tension, solitude, 
privacy, be with friends, be with people having similar values, independence, spiritual, social recognition, skill development, meet new people, creativity, and nostalgia.

Driver's research has also been documented in a variety of recreational settings (Driver \& Brown, 1986; Driver \& Bruns, 1999; Driver, Tinsley, et al., 1991; Tinsley, Driver, \& Kass, 1982).

Selection of benefit items. This list of leisure benefits was then compared with specific benefits, motivational factors, words, or concepts mentioned in the adult music education literature, and a list of benefit items for use in the questionnaire was drafted. Table 2 lists the specific benefit items presented to the content validity review panel, field tested, and included on the pilot test of the questionnaire. Table 2 also notes the source of origin for each benefit in the existing research literature, whether leisure research, music research, or both. Benefits with two item numbers had alternate wordings in different research studies and both wordings were retained for the pilot test questionnaire. 
Table 2.

Benefit Items Included for Content Validity Review, Field Test, and Pilot Test

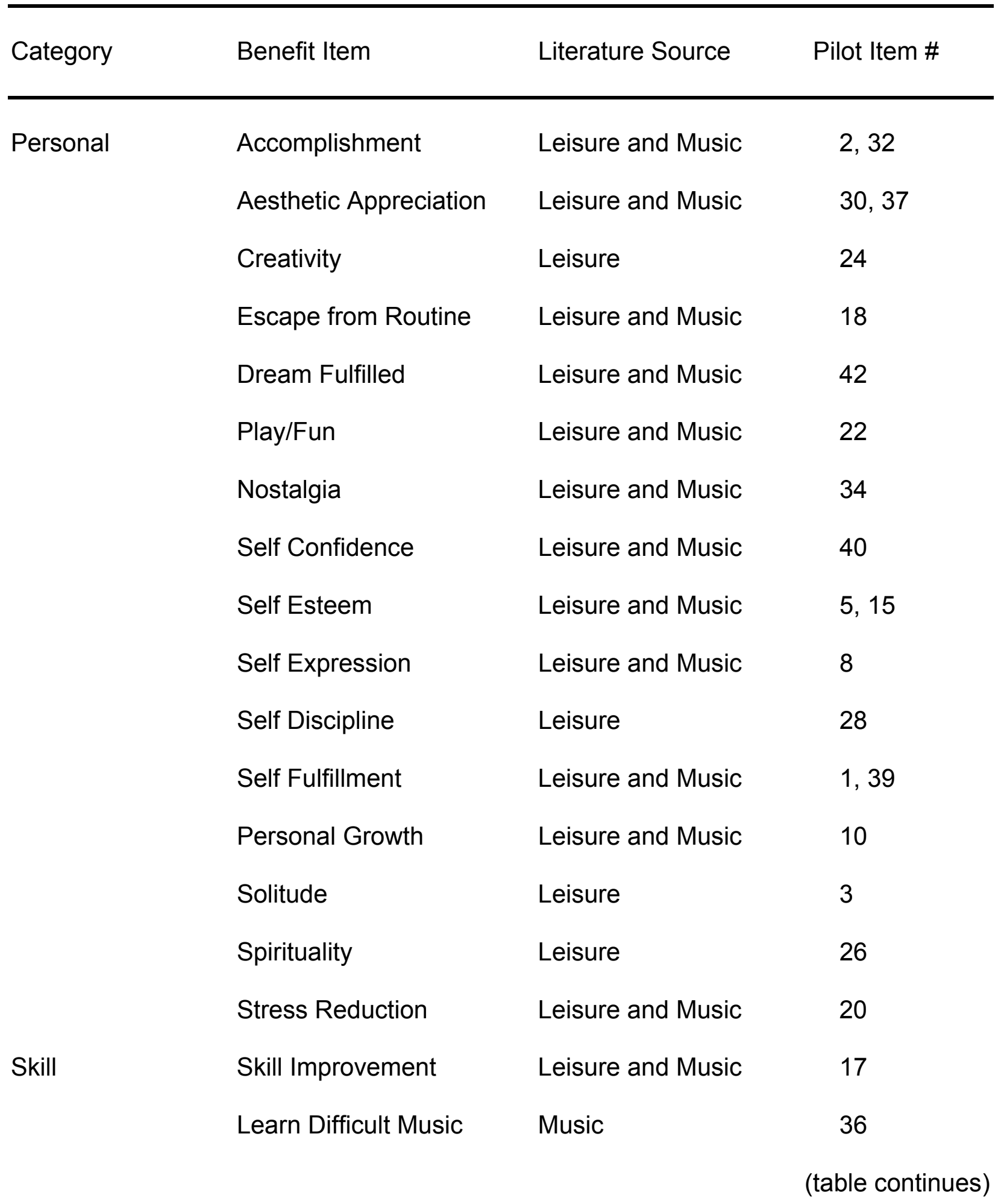


Table 2. (table continued)

\begin{tabular}{|c|c|c|c|}
\hline Category & Benefit Item & Literature Source & Pilot Item \# \\
\hline \multirow[t]{9}{*}{ Skill } & Music Theory & Music & 14 \\
\hline & Music Listening & Music & 21 \\
\hline & Musical Knowledge & Music & 25 \\
\hline & Musical Learning & Music & 29 \\
\hline & Motor Skills & Music & 41 \\
\hline & Musicianship & Music & 4 \\
\hline & Non-Musical Learning & Leisure and Music & 29 \\
\hline & Skill Refinement & Leisure and Music & 31 \\
\hline & Technique & Music & 11 \\
\hline \multirow[t]{10}{*}{ Social/Cultural } & Sense of Belonging & Leisure and Music & 19 \\
\hline & Common Purpose & Leisure and Music & 38 \\
\hline & Community & Leisure and Music & 12,33 \\
\hline & Cooperation & Leisure and Music & 27 \\
\hline & Cultural Heritage & Leisure and Music & 35 \\
\hline & Cultural Understanding & Leisure and Music & 7 \\
\hline & Meet New Friends & Leisure and Music & 3 \\
\hline & Performance for Others & Leisure and Music & 6 \\
\hline & Social Recognition & Leisure and Music & 23 \\
\hline & Social Status & Leisure and Music & 16 \\
\hline
\end{tabular}


$\underline{\text { Demographics. }}$ There was very little existing research on adult piano students, and no reviewed study had established a clear demographic profile of the typical adult piano student. Furthermore, there were no national databases, lists, or sampling frames of adult piano students available, making it extremely difficult for the present study to utilize random sampling procedures. For these reasons, it was important that this study included information on the basic demographic characteristics of the subjects. This could identify some of the basic qualities of the subjects involved in the study, providing more information on what the profile of a typical adult piano student may be. In addition, it could help identify any qualities that may be over- or under-represented as a result of a non-random sampling procedure. The final page of the questionnaire asked for general demographic information, as well as information about the specific nature of each subject's experience in piano study.

Based on existing research into the demographics of adult music students (Cooper, 1996; Spencer, 1996), the questionnaire included brief items which asked for each subject's age, gender, occupation, income range, and level of education. These data were not used for any comparative purpose; rather, they were collected to help construct a profile of the adult piano students who participated in this study. Main study questionnaires were completed anonymously, precluding any subject from being identified individually. Main study questionnaires were number-coded to aid in the identification of non-respondents, but each batch of numbered questionnaires could only be tracked to the teacher who distributed them, not to any one individual.

The general demographic data were reported as follows: (a) number and percentages of respondents for each category of gender, occupation, income level, and 
level of education; (b) mean age and age range of subjects; (c) median income range of subjects; and (d) number and percentage of non-respondents for each of the above items.

In order to understand more about the nature of the adult piano experiences of the subjects, the demographics portion of the questionnaire also included a few brief questions specific to piano study. Information collected included instructional setting (university, community music school, retail store, or independent teacher), type of instruction (group class or private lesson), length of study as an adult, length of study as a child (if any), self-described skill level, average time spent practicing each week, and type of repertoire studied. These data were reported as follows: (a) number and percentage of respondents for each category of instructional setting, type of instruction, self-described skill level, study as a child (yes or no), and type of repertoire studied; (b) means for length of study as an adult, length of study as a child, and average weekly practice time; and (c) number and percentage of non-respondents for each of the above categories.

Questionnaire Revision

After the questionnaire format was determined and benefit items were selected for inclusion, the instrument underwent additional steps of revision before being used in the pilot study. First, professionals in the field of music education were asked to review the benefit items and questionnaire format for wording and clarity. Second, a panel of experts in adult music education was asked to review the individual benefit items and judge content validity. The questionnaire was then field tested with six adult piano 
students thought to be representative of those who would participate in the final study. Following the field test, the questionnaire was pilot tested with 31 adult piano students.

Review for wording and clarity. Three music education professionals were asked to review the questionnaire items and comment on any errors of wording or clarity. All three educators were faculty members at a leading research university, and all three had experience with both adult music students and principles of questionnaire construction. Each educator was given a list of the benefit statements, as well as an outline of the response format, and they were asked to review the items for clarity, wording, and ease of use. They were also asked to provide specific suggestions for any items that needed revision. Based on their feedback, minor adjustments in wording were made and grammatical errors were corrected. Typographical errors were corrected, and all items were placed in the present tense for consistency. Panel members agreed that the present tense provided the clearest direction for the subjects, since subjects would be commenting on their current experience. All three educators agreed that the format of the questionnaire and the response format were clear.

Content validity. For the present study, a panel of five professionals in the field of adult music education was assembled to review the benefit items intended for inclusion on the questionnaire. One panel member was the author of a top-selling adult piano method and had given many presentations and workshops on the teaching of adult piano students. Another panel member was the head of the piano pedagogy department at a leading university and had co-authored and edited another top-selling adult piano method. One of the panel members was recognized as a national leader in the field of adult music education research, and had been active in the Music Educators 
National Conference (MENC) Special Research and Interest Group on Adult and Community Music Education. This panel member had also authored recent articles about adult musicians. One member of the panel was a local teacher of adult instrumental students, having taught in a national program for senior band participation. Another member of the panel was a local teacher of adult vocal students who taught adults exclusively and had taught group classes and private lessons to adults for over 15 years. For a list of the items submitted to the content validity panel, as well as specific instructions for the content validity panel, see Appendix A.

Each panel member was asked to review all of the benefit items on the questionnaire and assess their content validity for inclusion in the study. Panel members considered each item and determined if the item was appropriate for the questionnaire. Panel members also noted any errors in wording or items that seemed unclear. In addition, panel members were asked to consider their experience with adult students and determine if there were any benefits missing from the questionnaire. Each panel member provided written feedback to the researcher, and the researcher had an opportunity to discuss this feedback with each panel member individually.

Many panel members noted revisions in the wording of the items. Two typographical errors were spotted and corrected. Some panel members suggested that the wording of some benefit items was either too strong or too weak and needed to be tempered. For example, the statement "studying piano ... makes use of all my personal talents" was changed to "studying piano ... makes use of some of my personal talents" when one panel member noted that no activity can make use of all of one's talents. The panel made suggestions for the clarification of language so that 
certain concepts were presented clearly and directly to respondents. For example, the term "musicianship" was changed to "ability to understand, interpret, and make music". All suggestions made by the panel are noted in italics in Appendix A.

Each item had a majority of the panel agreeing that it should remain on the questionnaire, so all benefit items from the initial draft were included for the pilot study. One item was added to the list of benefits as a result of a suggestion made by two panel members. This item involved the benefit of improved coordination and motor skills, and it was placed in the Skill Benefit category.

Some panel members noted that certain items in the benefit list were highly similar and related. An example of this would be the benefit of self-esteem and the benefit of feeling good about one's self. Each time similar items were included on the initial benefit list, it was because different wordings of these items were present in the reviewed literature. A concept such as self-esteem is complex, and it is often defined in different ways. Alternate wordings for five of the 37 benefit items were retained for the pilot study, with the data from the pilot study determining which wording would be most effective for the main study questionnaire.

Field test. The revised benefit items were then formatted into a questionnaire which was field tested with adult piano students. An important step in the survey research process involves the field testing of any instrument, for it allows the researcher to "spot ambiguous or redundant items" and to determine a practical format for response and data analysis (Isaac \& Michael, 1997, p. 137). This process also allows the researcher to determine if respondents had any difficulties understanding the questionnaire and to assess the time needed for the completion of the questionnaire. 
The initial draft of the questionnaire was field tested with six adult piano students from the Dallas, Texas metropolitan area. All of these students were currently taking piano lessons with the researcher. Each field tester was given a questionnaire to review and complete anonymously. Field testers were asked for comments on the ease of use of the questionnaire, any problems they encountered, any changes they would suggest, and any additional items they would suggest for inclusion on the questionnaire. Field testers were also asked to identify any items that they thought were inappropriate for the questionnaire. After the questionnaires were completed and comments noted, the field testers were then interviewed briefly by the researcher to determine if there were any additional problems or suggestions. The cover sheet and instructions for the field testers is included in Appendix B.

All of the field testers were able to complete the questionnaires successfully, and there were no instances of response error. Two field testers noted that the directions for respondents needed clarification, and as a result of this suggestion the cover page and directions were revised and expanded to include three sample items with sample responses. These three samples were created to illustrate three different ways of responding to an item: (a) a response of "no" indicating disagreement that the item is a benefit, (b) a response of "yes" indicating agreement that the item is a benefit and a rating of " 10 " indicating that the benefit is a most important benefit, and (c) a response of "yes" indicating agreement that the item is a benefit and a rating of " 1 " indicating that the benefit is a least important benefit.

Two typographical errors were pointed out by the field testers and corrected by the researcher. None of the field testers reported any further problems or difficulties 
with the questionnaire. There were no comments from the field testers that any of the benefit items on the questionnaire were inappropriate. Three field testers commented that studying piano fulfilled a long held dream or desire of theirs, and that this might be included as an item on the questionnaire. Since the concept of fulfillment was found as a benefit in both the leisure and the adult music research literature, this item was added to the questionnaire and placed in the category of Personal Benefits.

Forty-two items were included in the pilot study questionnaire: 20 items represented Personal Benefits, 11 items represented Skill Benefits, and 11 items represented Social/Cultural Benefits. The complete pilot study questionnaire, including instructions, sample items, and sample responses, is contained in Appendix C. The following section details the procedures and results of the pilot study.

\section{Pilot Study}

The following section will outline the procedure and results from the pilot study of the questionnaire. The purposes of the pilot study were to: (a) identify any necessary revisions that should be made to the questionnaire, including the elimination of items that may not be representative of their benefit categories and/or may lower the reliability of the questionnaire, (b) collect data on the reliability of the questionnaire, and (c) identify any potential problems in the administration of the questionnaire or the calculating and reporting of results. The pilot study was conducted in January and February of 2002. 
Pilot Study Demographics

The pilot study included adult piano students $(N=31)$ from the Dallas, Texas metropolitan area. All of the pilot study subjects fit the definition of adult student outlined in Chapter 1: all pilot subjects were adults over the age of 16 who were not still involved in an uninterrupted track of formal education. At the time of the pilot study, all of the subjects were either currently taking or had recently taken a group piano class or private piano lessons with the researcher. The pilot test subjects were independent from the six subjects used to field test the questionnaire. The specific demographic characteristics of the pilot study subjects are reported below. All pilot study subjects were provided with a copy of the questionnaire and a postage paid return envelope. Pilot questionnaires were number-coded to track non-respondents.

Pilot questionnaires were distributed to 35 adult piano students from January $28^{\text {th }}, 2002$ through February $6^{\text {th }}, 2002$. After two weeks, 24 questionnaires had been returned. After a follow-up reminder was sent via e-mail, seven more questionnaires were returned. Three weeks after the last pilot questionnaire had been distributed, 31 of the original 35 had been returned, constituting a response rate of $89 \%$.

The pilot study questionnaire (see Appendix C) contained general demographic questions which inquired about age, gender, occupation, income, and level of education. In addition, subjects were asked specific questions about their piano study, including length of study as an adult, length of study in their present setting, nature of their present instructional setting (group or private), length of study as a child (if any), type of repertoire studied, average weekly practice time, and perceived skill level. 
General demographics. Of the 31 respondents, 21 (67.7\%) were female and 10 $(32.3 \%)$ were male. The mean age reported was 50.5 years $(S D=11.78)$, with a range of 29-79. Twenty percent of the respondents were aged 40 or below, sixty percent were aged between 40 and 60 years, and the remaining twenty percent were over age 60 . Almost all $(n=30,97 \%)$ of the respondents reported some education beyond high school. Ten percent reported earning an associate's degree, 35\% reported earning a bachelor's degree, $29 \%$ reported earning a master's degree, and $23 \%$ reported earning a doctoral degree.

The median annual income range reported was $\$ 65,000-\$ 100,000$, and respondents used the full range of income responses, from less than $\$ 25,000$ to over $\$ 100,000$. Roughly half $(52 \%)$ of the respondents reported an income below $\$ 100,000$, while $48 \%$ reported an income of $\$ 100,000$ or above. Due to the relative lack of variance in the responses reported for income, the income categories were revised for the main study questionnaire. The number of income range choices was expanded from five to seven, with narrower ranges for incomes between $\$ 25,000$ and $\$ 100,000$ and an additional range of income from $\$ 100,000$ to $\$ 150,000$.

The majority of pilot study respondents were employed in a professional occupation (67\%), while $22 \%$ were retired and $10 \%$ were homemakers. No respondents to this study reported being full-time students, which confirmed that all of the pilot study respondents fit the definition of adult as outlined in Chapter 1 .

Overall, the profile of the subjects in the pilot study seemed to be reflective of the profiles outlined in both the adult education research and the adult music research literature. Subjects in the pilot study tended to be female, employed in professional 
occupations, educated beyond high school, and earned middle to upper level incomes. These characteristics were also consistent with the characteristics of the main study population (reported later in this chapter).

Piano-related demographics. Slightly more than half of the respondents (54\%) reported studying piano primarily in a group setting, with the remainder listing private instruction as their primary setting for study. The mean length of study in their current setting was 1.72 years $(S D=1.22)$, with a range of one month to four years. The mean length of study as an adult student (including other settings) was 2.24 years ( $S D=$ $1.88)$, with a range of three months to ten years. Seven respondents $(23 \%)$ reported studying as an adult in a setting other than their current one.

Nearly two-thirds (65\%) of the pilot subjects reported studying piano as a child, with the mean length of child study being 4.32 years $(S D=3.99)$. Length of study as a child ranged from one year to 15 years. This statistic was reflective of the adult music research literature, which noted that adult musicians are likely to have studied as children (Cooper, 1996; Seago, 1993).

When asked about their skill level, $32 \%$ labeled themselves as beginners, and $64 \%$ labeled themselves as intermediate students. One student reported being at an advanced skill level. The mean length of reported weekly practice time was just over 4 hours ( 4.08 hours; $S D=3.55$ hours), with a range of 1.5 hours to 20 hours.

A large majority of respondents reported studying classical music (87\%), followed by beginning methods (32\%), pop music (26\%), Broadway (16\%), and jazz $(10 \%)$. (Subjects were asked to mark all categories of music studied.) Two subjects marked 
the "other" category for music studied, with one noting ragtime music and the other noting movie music.

Pilot Study Results

The following section will outline the results of the pilot study, beginning with revisions made to the questionnaire. This will be followed by information on the reliability of the revised questionnaire and the results of the benefit portion of the pilot study questionnaire.

Questionnaire revision. One of the purposes of the pilot study was to identify and eliminate items from the questionnaire that were not representative of their respective benefit categories and/or lowered the internal consistency of the measurement instrument. The following section describes the procedure used to eliminate items from the questionnaire.

A factor analysis was performed on the items in each of the three benefit categories to help identify items that may not have been representative of their benefit category. MacDonald (1985) wrote that factor analysis can "provide a very good way to construct homogenous tests" (p. 157). MacDonald (1985) and Rencher (1995) both noted that .3 is a common cutoff point for the elimination of items through factor analysis. In the present study those items that did not load strongly (.3 or lower) onto a factor with like items from the same category were interpreted to be less representative of their benefit category, and these items were eliminated from the questionnaire for the main study. Other items which had factor loadings between .3 and .5 were also examined individually with respect to the internal consistency of the instrument. Internal consistency coefficients were calculated for the category with and without each of these 
benefit items. Those items with a negative impact on the internal consistency of the questionnaire were eliminated from the questionnaire for the main study. In addition, for those five benefits which had two alternate wordings included on the pilot study, the item with the lower factor loading was eliminated from the questionnaire for the main study. Factor loadings for all of the pilot study questionnaire items can be found in Appendix D.

Based on the factor analysis and internal consistency calculations, the following items were eliminated from use for the main study questionnaire. In the category of Personal Benefits, items 34 (Nostalgia) and 13 (Solitude) were eliminated due to their low factor loadings and negative impact on internal consistency. Items 1, 15, 30, 32 were eliminated because their alternate wording items $(39,5,37$, and 2 , respectively) had stronger factor loadings with the other Personal Benefit items. Items 29 (Nonmusical Learning) and 41 (Motor Skills) were eliminated from the Skill Benefits category due to poor factor loadings. Items 9 (Musical Learning) and 36 (Learn Difficult Music) were also eliminated from Skill Benefits due to their negative impact on internal consistency. In the category of Social/Cultural benefits, item 12 was eliminated because its alternate wording item (33) had a higher factor loading. All remaining items were retained for use in the main study questionnaire (see Appendix E), as listed below in Table 3. Since items were eliminated from the pilot study questionnaire, the main study questionnaire items were renumbered. 
Table 3.

Benefit Items Included on Main Study Questionnaire

\begin{tabular}{|c|c|c|c|}
\hline Category & Benefit & Pilot Item \# & Main Study Item \# \\
\hline \multicolumn{4}{|l|}{ Personal } \\
\hline & Accomplishment & 2 & 1 \\
\hline & Self-Esteem & 5 & 4 \\
\hline & Self-Expression & 8 & 7 \\
\hline & Personal Growth & 10 & 11 \\
\hline & Escape from Routine & 18 & 10 \\
\hline & Stress Reduction & 20 & 14 \\
\hline & Play/Fun & 22 & 17 \\
\hline & Imagination/Creativity & 24 & 19 \\
\hline & Spirituality & 26 & 20 \\
\hline & Self-Discipline & 28 & 23 \\
\hline & Aesthetic Appreciation & 37 & 24 \\
\hline & Self-Fulfillment & 39 & 27 \\
\hline & Self-Confidence & 40 & 29 \\
\hline & Dream Fulfilled & 42 & 31 \\
\hline
\end{tabular}


Table 3. (table continued)

$\begin{array}{llll}\text { Category } & \text { Benefit } & \text { Pilot Item \# } \quad \text { Main Study Item \# }\end{array}$

Skill

$\begin{array}{lcr}\text { Musicianship } & 4 & 3 \\ \text { Technique } & 11 & 9 \\ \text { Music Theory } & 14 & 13 \\ \text { Skill Improvement } & 17 & 16 \\ \text { Music Listening } & 21 & 22 \\ \text { Musical Knowledge } & 25 & 26 \\ \text { Skill Refinement } & 31 & 30\end{array}$

Social/Cultural

Meet New Friends $\quad 3 \quad 2$

$\begin{array}{lll}\text { Performance for Others } & 6 & 6\end{array}$

Cultural Understanding $\quad 7 \quad 5$

$\begin{array}{lll}\text { Social Status } & 16 & 8\end{array}$

Sense of Belonging 19

Social Recognition $\quad 23 \quad 15$

$\begin{array}{lll}\text { Cooperation } & 27 & 18\end{array}$

$\begin{array}{lll}\text { Community } & 33 & 21\end{array}$

$\begin{array}{lll}\text { Cultural Heritage } & 35 & 25\end{array}$

$\begin{array}{lll}\text { Common Purpose } & 38 & 28\end{array}$ 
Reliability. Using the items retained for the main study questionnaire, Cronbach's alpha coefficient was calculated as a measure of internal consistency for each benefit category. Since there were two responses to each benefit item (yes/no to existence of benefit and rating of importance of benefit), this reliability coefficient was calculated separately for each response format.

Reliability coefficients for the level of importance ratings ranged from .77 for Skill Benefits to .88 for Social/Cultural benefits. Reliability coefficients for the dichotomous yes/no response to the existence of benefits ranged from a low of .61 for Skill Benefits to a high of .79 for Social/Cultural Benefits. After the item elimination process, only seven Skill Benefit items remained. In addition, these Skill Benefit items were widely agreed to exist by a large majority of the pilot study respondents. The lack of variance among the respondents and the low number of items in the category are possible causes for the lower reliability coefficient for the yes/no response in the category of Skill Benefits. Reliability results from the pilot study are reported in Table 4. 
Table 4.

Pilot Study Internal Consistency Coefficients

\begin{tabular}{llc}
\hline Benefit Category & Response Format & $\alpha$ Coefficient \\
\hline Personal & Yes/No (Benefit Exists) & .7767 \\
Personal & Importance (1-10) & .8773 \\
Skill & Yes/No & .6091 \\
Skill & Importance & .7773 \\
Social/Cultural & Yes/No & .7906 \\
Social/Cultural & Importance & .8597 \\
\hline
\end{tabular}

Benefit item ratings. For each benefit item, two statistics were reported: (a) the percentage of respondents who agreed that the item was a benefit for them personally, reported in Table 5, and (b) the mean level of importance of the benefit as rated by only those students agreeing that the benefit existed, reported in Table 6. 
Table 5.

Pilot Study Benefit Item Ratings - Percentage Agreeing the Benefit Exists

\begin{tabular}{|c|c|c|c|}
\hline Category & Item & Benefit & $\%$ Agreeing Benefit Exists \\
\hline \multicolumn{4}{|l|}{ Personal } \\
\hline & 2 & Accomplishment & 100 \\
\hline & 18 & Escape from Routine & 94 \\
\hline & 40 & Self-Confidence & 90 \\
\hline & 22 & Play/Fun & 87 \\
\hline & 42 & Dream Fulfilled & 84 \\
\hline & 10 & Personal Growth & 84 \\
\hline & 5 & Self-Esteem & 84 \\
\hline & 20 & Stress Reduction & 84 \\
\hline & 39 & Self-Fulfillment & 74 \\
\hline & 8 & Self-Expression & 71 \\
\hline & 28 & Self-Discipline & 68 \\
\hline & 24 & Imagination/Creativity & 64 \\
\hline & 37 & Aesthetic Appreciation & 58 \\
\hline & 26 & Spirituality & 52 \\
\hline \multicolumn{3}{|c|}{ Mean Percentage of Agreement for Personal Category } & gory \\
\hline
\end{tabular}


Table 5. (table continued)

Category Item Benefit \% Agreeing Benefit Exists

Skill

$\begin{array}{rlr}25 & \text { Musical Knowledge } & 97 \\ 17 & \text { Skill Improvement } & 97 \\ 31 & \text { Skill Refinement } & 97 \\ 11 & \text { Technique } & 97 \\ 14 & \text { Music Theory } & 94 \\ 4 & \text { Musicianship } & 90 \\ 21 & \text { Music Listening } & 90\end{array}$

Mean Percentage of Agreement for Skill Category 95

Social/Cultural

$\begin{array}{rll}6 & \text { Performance for Others } & 81 \\ 7 & \text { Cultural Understanding } & 77 \\ 38 & \text { Common Purpose } & 71 \\ 3 & \text { Meet New Friends } & 61 \\ 23 & \text { Social Recognition } & 61 \\ 19 & \text { Sense of Belonging } & 52 \\ 35 & \text { Cultural Heritage } & 32 \\ 16 & \text { Social Status } & 29 \\ 27 & \text { Cooperation } & 23 \\ 33 & \text { Community } & 12 \\ \text { Mean Percentage of Agreement for Social/Cultural Category } & 50\end{array}$


Table 6.

Pilot Study Benefit Item Ratings - Mean Importance of Benefits

\begin{tabular}{|c|c|c|c|c|c|}
\hline Category & Item & Benefit & $\mathrm{N}$ & Mean Importance * & $S D$ \\
\hline \multicolumn{6}{|l|}{ Personal } \\
\hline & 42 & Dream Fulfilled & 26 & 8.81 & 2.04 \\
\hline & 2 & Accomplishment & 31 & 8.23 & 1.76 \\
\hline & 26 & Spirituality & 15 & 7.60 & 2.53 \\
\hline & 10 & Personal Growth & 26 & 7.44 & 2.48 \\
\hline & 22 & Play/Fun & 27 & 7.41 & 1.78 \\
\hline & 18 & Escape from Routine & 29 & 7.31 & 2.98 \\
\hline & 39 & Self-Actualization & 23 & 7.13 & 2.01 \\
\hline & 37 & Aesthetic Appreciation & 18 & 6.94 & 2.10 \\
\hline & 20 & Stress Reduction & 26 & 6.85 & 2.72 \\
\hline & 8 & Self-Expression & 22 & 6.68 & 2.75 \\
\hline & 40 & Self-Confidence & 28 & 6.46 & 2.41 \\
\hline & 28 & Self-Discipline & 22 & 6.41 & 2.48 \\
\hline & 5 & Self-Esteem & 26 & 6.12 & 2.47 \\
\hline & 24 & Creativity & 21 & 5.76 & 2.09 \\
\hline
\end{tabular}

*A rating of 10 represents a most important benefit, while a rating of 1 represents a least important benefit 
Table 6. (table continued)

Category Item $\quad$ Benefit $\quad \mathrm{N} \quad$ Mean Importance * $S D$

Skill

$\begin{array}{rllll}11 & \text { Technique } & 30 & 8.23 & 1.99 \\ 4 & \text { Musicianship } & 27 & 8.00 & 1.86 \\ 31 & \text { Skill Refinement } & 30 & 7.87 & 1.55 \\ 17 & \text { Skill Improvement } & 30 & 7.75 & 1.78 \\ 25 & \text { Musical Knowledge } & 30 & 7.23 & 1.75 \\ 21 & \text { Music Listening } & 28 & 6.25 & 2.10 \\ 14 & \text { Music Theory } & 29 & 6.24 & 2.36\end{array}$

Social/Cultural

$\begin{array}{rlrll}33 & \text { Community } & 4 & 7.50 & 1.73 \\ 7 & \text { Cultural Understanding } & 24 & 6.75 & 2.13 \\ 6 & \text { Performance for Others } & 24 & 5.75 & 2.83 \\ 27 & \text { Cooperation } & 8 & 5.50 & 3.07 \\ 35 & \text { Cultural Heritage } & 10 & 5.30 & 2.26 \\ 19 & \text { Sense of Belonging } & 16 & 5.06 & 2.72 \\ 16 & \text { Social Status } & 9 & 4.67 & 3.08 \\ 23 & \text { Social Recognition } & 19 & 4.63 & 3.47 \\ 38 & \text { Shared Purpose } & 22 & 4.50 & 2.67 \\ 3 & \text { Meet New Friends } & 20 & 4.05 & 2.42\end{array}$

\footnotetext{
*A rating of 10 represents a most important benefit, while a rating of 1 represents a least important benefit.
} 
Benefit category ratings. When the items in each benefit category (Personal, Skill, and Social/Cultural) were taken collectively, Skill Benefits was the most agreed upon category of benefits by the respondents in the pilot study. The mean percentage of agreement for all Skill Benefits was $95 \%$, compared with $78 \%$ for Personal Benefits and $50 \%$ for Social/Cultural Benefits.

To compare the mean level of importance of each category of benefits, the responses in each category were summed for each individual, and then a mean rating of importance was calculated for each individual in each of the three categories of benefits. These individual category means were then averaged to compute an overall or summed mean level of importance for each category of benefits. The summed mean level of importance for Skill Benefits was 7.05 (on a scale of 1-10, with 10 representing a most important benefit), with a standard deviation of 1.58. By comparison, the summed mean level of importance for Personal Benefits was $6.79(S D=1.57)$ and the summed mean level of importance for Social/Cultural Benefits was $4.89(S D=2.17)$.

Summary of the pilot study. The pilot study resulted in revision of the questionnaire, reducing the number of items from 42 to 31 . Factor analysis and internal consistency measures identified items from the pilot questionnaire that were not representative of their category of benefits, and these items were eliminated from the questionnaire for the main study. With the exception of the reliability coefficient of the skill-based yes/no responses in the category of Skill Benefits $(\alpha=.61)$, the internal consistency of each category in the pilot study ranged from .78 to .88. Gay (1992) noted that for instruments that do not measure achievement or aptitude, reliabilities ranging in the "seventies and eighties" (.70-.89) are acceptable (p. 168). 
The demographic profile of pilot study respondents appeared to resemble the demographic characteristics reported in both the adult music research literature and the adult education research literature. The pilot study also demonstrated that the questionnaire was functional, as there was no item non-response error. Isaac and Michael (1997) noted the importance of keeping questionnaires as brief as possible. Subjects in the pilot study reported completing the questionnaire in an average time of 15.11 minutes (standard deviation of 6.32 minutes). Since the main study questionnaire contained 11 fewer items than the pilot study questionnaire, main study participants may have completed the questionnaire in even less time. The revised questionnaire used in the main study is found in Appendix E.

\section{Main Study Procedure}

The following section will detail the procedures used in the main study, including a description of the location of the main study subjects, the demographic characteristics of the main study subjects, the reliability of the main study questionnaire, and procedures for data collection and analysis.

Location of Main Study Subjects

While it is advisable for most survey studies to utilize random sampling procedures (Casey, 1992), this presented a difficulty for the present study. Because there was no national list, frame, or database of adult piano students or teachers of adult piano students from which to sample, it was extremely difficult for the present study to utilize any type of probability or random sampling procedure. While the use of 
a non-probability sampling procedure can lessen the chance that the subjects in the study are truly representative of the greater population, it was the most feasible and practical method available for the present study. Although this reduced the generalizability of the results, this study still represented an initial step in the effort to understand the adult piano student and to contribute to the body of knowledge on adult music participation.

The present study made efforts to ensure that the subjects: (a) were representative of a variety of geographic locations, (b) were representative of a range of ages and levels of experience, and (c) were representative of adult piano students in a variety of instructional settings, including both group and private instruction. While these efforts still did not allow generalization of the results to the broader population, it was hoped that these steps would help to increase the likelihood that the subjects in the present study could be construed as similar in nature to other adult piano students.

To locate subjects, the researcher began by asking 12 leading piano teachers and pedagogues around the country to identify teachers in their area who taught adult piano students. In an effort to locate teachers who specialized in teaching adult piano students, the initial persons contacted by the researcher included: the author of a column on adult piano study found in a leading piano pedagogy periodical, the dean of a university school of music, four authors of best selling adult piano methods, the author of a recent book marketed to adult piano students, the chair of a national committee on the teaching of adult piano students, and four committee chairpersons and members from recent national piano pedagogy conferences and conventions. These initial contacts were from various locations around the country, including: Austin, TX; Boston, 
MA; Chicago, IL; Cincinnati, OH; Dallas, TX (2 contacts); Elizabethtown, PA; Los Angeles, CA; Miami, FL, Norman, OK; Princeton, NJ; and Wayne, NE.

These 12 initial contacts were asked to identify teachers of adult piano students in their area, and 9 of the 11 responded with 34 suggestions of teachers to contact, representing states including $A R, C A, D C, F L, I L, M A, M D, M I, N J, N Y, P A, O H, T N$, and TX. Two of the eleven initial contacts indicated that they did not know any teachers of adult students in their immediate area. The locations of the teachers referred by the initial contacts are detailed in Table 7. 
Table 7.

Location of Main Study Subjects

Initial Contact Location \# $\quad$ \# of Referrals $\quad$ Referral Locations

Austin, TX

0

Boston, MA

2

MA

Chicago, IL

2

IL

Cincinnati, $\mathrm{OH}$

7

$\mathrm{OH}, \mathrm{AR}$

Elizabethtown, PA

2

PA, FL

Dallas, TX

4

IL, TX

Dallas, TX

7

CA, DC, FL, MD,

PA, TN, Australia

Los Angeles, CA

2

MI, OK

Miami, FL

0

Norman, OK

2

OK

Princeton, NJ

2

NJ

Wayne, NE

4

$A R, K S, M O, W V$

The 34 teachers suggested by the initial contacts were then contacted by the researcher and asked to participate in the study. In addition, these teachers were asked if they knew of any teachers of adult students in their own area who might be willing to participate. Twenty-six of these 34 teachers responded and agreed to 
participate in the study. Three responded and indicated that they had retired from teaching; these retired teachers were located in PA and FL (2). Two teachers did not respond at all; these teachers were located in IL and OK. One teacher from DC responded with an offer to solicit participation in the study through a newsletter mailed to members of an adult piano association. Given the time involved to solicit such responses, this offer was declined by the researcher. The teacher from Australia was not included in the study, as it was determined by the researcher that the study would only include adult piano students from the United States. Finally, one response from the list of 34 came from a person in NY who turned out to be an adult piano student, not a teacher. This person agreed to participate in the research study. The researcher was also contacted directly by three other adult piano students, all in the state of $\mathrm{OH}$, who had heard about the study through their teachers. Each of these students offered to participate in the main study, and each was mailed an individual questionnaire.

Among the 26 teachers who responded, one was the head of a community music school in Dallas, TX that was active in a national association of community schools. Through their directory, this administrator referred the researcher to 14 additional community music schools that taught adult piano students. These community music schools were located in AL (2), CO, CT, DC, GA, IN, IL, MD, MN, NY, OH, OR, and WI. All of these schools were contacted, and all agreed to participate in the study. In addition, one of the initial contacts from Dallas, TX referred the researcher to an administrator involved with adult education in the Yamaha music corporation. This contact referred the researcher to eight retail stores offering adult piano study. These stores were located in AK, CA, FL, KS, NE, NY, and TX (2). All of these locations were 
contacted; representatives from six of the stores agreed to participate in the study. Representatives from the retail stores in AK and NE declined to participate in the study, citing low current enrollment of adult piano students.

At the commencement of the main study, 52 individuals had agreed to participate or have their students participate in the study. Forty-eight of the individuals were either teachers of adult piano students or administrators of programs that taught adult piano students. Each of these individuals agreed to distribute questionnaires to their adult piano students and collect and return the completed questionnaires. In addition, four individual adult piano students agreed to participate and were mailed individual questionnaires. Collectively, these students represented 24 different states from all geographic regions of the continental United States. The following section details the demographic characteristics of the main study participants.

Main Study Demographics

Demographic characteristics of the main study participants will be presented in two categories. General demographics will outline the gender, age, income, geographic distribution, education level, and occupation of the subjects, while piano-related demographics will include the instructional setting, type of lesson (group or private) skill level, length of study as an adult and as a child (if applicable), practice time, and repertoire genres studied as reported by the main study participants.

\section{General Demographics}

Gender. The ratio of female respondents to male respondents in the main study was nearly three to one (see Table 8 ). Slightly less than three-quarters $(n=513,72 \%)$ of 
the respondents were female, while $183(26 \%)$ respondents were male. Two percent of the respondents $(n=15)$ did not respond to the gender item on the questionnaire.

Table 8.

Distribution of Subjects by Gender ( $N=711)$

\begin{tabular}{lcc} 
Gender & $n$ & $\%$ \\
\hline Female & 513 & 72 \\
Male & 183 & 26 \\
No Response & 15 & 2 \\
\hline
\end{tabular}

Age. The average age of the respondents in this survey was $51(S D=14)$, with a minimum reported age of 24 and a maximum reported age of 94 . There were 55 respondents $(8 \%)$ who did not report their age. Nearly three-quarters $(72 \%)$ of the respondents were age 40 or older. The largest number of students in the present study was found in the $40-49$ age range (25\%). The distribution of subjects by age is reported in Table 9. 
Table 9.

Distribution of Subjects by Age ( $N=711)$

\begin{tabular}{lcc} 
Age & $n$ & $\%$ \\
\hline $20-29$ & 43 & 6 \\
$30-39$ & 101 & 14 \\
$40-49$ & 178 & 25 \\
$50-59$ & 149 & 21 \\
$60-69$ & 114 & 16 \\
$70-79$ & 60 & 8 \\
$80+$ & 11 & 2 \\
No response & 55 & 8 \\
\hline
\end{tabular}

Income level. Nearly one-fourth (24\%) of the respondents did not respond to the income question. Of the 539 respondents who did answer this question, the median level of annual individual income was in the $\$ 50,000$ - $\$ 74,999$ range. All levels of reported annual income from the present study are reported in Table 10. 
Table 10.

Distribution of Subjects by Reported Annual Income Level ( $N=711)$

\begin{tabular}{lcc} 
Reported Annual Income & $n$ & $\%$ \\
\hline Less than $\$ 25,000$ & 124 & 17 \\
$\$ 25,000-\$ 34,999$ & 75 & 11 \\
$\$ 35,000-\$ 49,999$ & 66 & 9 \\
$\$ 50,000-\$ 74,999$ & 102 & 14 \\
$\$ 75,000-\$ 99,999$ & 78 & 11 \\
$\$ 100,000-\$ 149,999$ & 37 & 5 \\
$\$ 150,000$ or more & 57 & 8 \\
No Response & 172 & 24 \\
\hline
\end{tabular}

Geographic distribution. While it was impractical for this study to obtain a sample of students that precisely matched the geographic population of the United States, every effort was made to include students from a variety of geographic regions and individual states.

Reports from the 2000 U.S. Census divided the country into four geographic regions and nine geographic sub-regions (U.S. Census Bureau, 2001). All of these regions were represented in the present study. In each of the nine geographic subregions the percentage of students in the present study did not differ from the corresponding percentage of the U.S. population (as reported in the 2000 census) by more than eight percentage points. 
The most represented region was the Midwest, followed by the South, the West, and the Northeast. The most represented geographic sub-region in the study was the Pacific (West), followed by the East North Central (Midwest) and the West North Central (Midwest). Complete results are reported in Table 11.

Table 11.

Distribution of Subjects by Region (Boldface) and Sub-Region ( $N=711)$

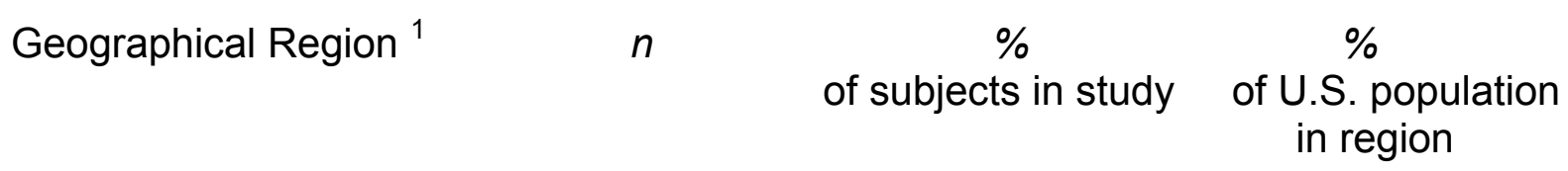

Midwest

\section{7}

116

101

191

84

12

95

177

3

174

126

37

89
30

23

16

14

27

12

2

13

25

$<1$

24

18

5

13

16

7

36

19

6

11

22

6

16
New England

Middle Atlantic

89

19

5

14

\footnotetext{
${ }^{1}$ Regions identical to those reported in the 2000 Census Report (U.S. Census Bureau, 2001).
} 
The 711 adult piano students who participated in the current study resided in 24 different states, as listed in Table 12. The five most represented states in the study were California, Minnesota, New York, Texas, and Oregon. The five most populous states in the U.S. (California, Texas, New York, Florida, and Illinois) were all represented in the present study.

Table 12.

Distribution of Subjects by State $(N=711)$

\begin{tabular}{lll}
\hline State & $n$ & $\%$ \\
\hline California & 118 & 17 \\
Minnesota & 76 & 10 \\
New York & 71 & 10 \\
Texas & 65 & 9 \\
Oregon & 56 & 8 \\
Maryland & 53 & 8 \\
Ohio & 50 & 7 \\
Illinois & 44 & 6 \\
Connecticut & 26 & 4 \\
Oklahoma & 23 & 3 \\
& & (table continues)
\end{tabular}


Table 12. (table continued)

\begin{tabular}{lcc}
\hline State & $n$ & $\%$ \\
\hline Kansas & 19 & 3 \\
New Jersey & 18 & 3 \\
Florida & 17 & 2 \\
Michigan & 15 & 2 \\
Massachusetts & 11 & 2 \\
Alabama & 8 & 1 \\
District of Columbia & 8 & 1 \\
Arkansas & 7 & 1 \\
Wisconsin & 7 & 1 \\
Missouri & 6 & $<1$ \\
Georgia & 5 & $<1$ \\
Tennessee & 4 & $<1$ \\
Colorado & 3 & $<1$ \\
West Virginia & 1 & 1 \\
\hline
\end{tabular}

Education level. All of the students who responded to this question reported education at the level of an earned high school degree or above. Seventy-seven percent of the subjects reported attending college, with $32 \%$ earning a Bachelor's degree, $30 \%$ earning a Master's degree, and $11 \%$ earning a Doctoral degree. There 
were 46 non-responses $(7 \%)$ to this question. Complete results are reported in Table 13.

Table 13.

Distribution of Subjects by Education Level $(N=711)$

\begin{tabular}{lrc} 
Education Level & $n$ & $\%$ \\
\hline Earned High School Degree & 116 & 16 \\
College Beyond High School & 30 & 4 \\
Earned Bachelor's Degree & 230 & 32 \\
Earned Master's Degree & 214 & 30 \\
Earned Doctoral Degree & 75 & 11 \\
No Response & 46 & 7 \\
\hline
\end{tabular}

Occupation. The occupation question on the study questionnaire was deliberately open-ended, due to the vast number of professions in today's society. The most common response to this category was Retired, with 178 subjects (25\%) indicating that they were retired. Other categories receiving more than 20 responses were: Homemaker ( $n=94,13 \%)$, Teacher/Educator $(n=54,8 \%)$, No Response $(n=49,7 \%)$, Manager ( $n=28,4 \%)$, Systems/Information Technology $(n=25,4 \%)$, and Registered Nurse $(n=24,3 \%)$. Those professions receiving at least six responses are listed in Table 14. Excluding those who were retired and those with no response, there were 63 different occupations represented in this study (see Table 14). 
Table 14.

Occupations of Subjects $(N=711)$

\begin{tabular}{|c|c|c|}
\hline Occupation & $n$ & $\%$ \\
\hline Retired & 178 & 25 \\
\hline Homemaker & 94 & 13 \\
\hline Teacher/Educator & 54 & 8 \\
\hline No Response & 49 & 7 \\
\hline Manager/Management & 28 & 4 \\
\hline Systems/Information Technology & 25 & 4 \\
\hline Registered Nurse & 24 & 3 \\
\hline Engineer & 19 & 3 \\
\hline Office/Clerical & 19 & 3 \\
\hline Executive & 19 & 3 \\
\hline Student & 18 & 3 \\
\hline Administration & 17 & 3 \\
\hline Attorney & 13 & 2 \\
\hline Physician & 13 & 2 \\
\hline Accounting & 9 & 1 \\
\hline Consultant & 8 & 1 \\
\hline Artist & 7 & $<1$ \\
\hline Researcher & 6 & $<1$ \\
\hline
\end{tabular}


Occupations receiving five responses each were: Banking, Human Resources, Marketing, Musician, Self-Employed/Owner, and Social Worker. Occupations receiving four responses each were: Nutritionist/Dietician, Pharmacist, Realtor, and Therapist. Occupations receiving three responses each were: Architect, Financial Planner, Funeral Director, Lab Technician, and Media/Broadcasting. There were two responses for each of the following occupations: Bus Driver, Court Reporter, Designer, Factory Worker, Hair Stylist, Health Care Professional, Law Enforcement, Librarian, Translator, and Writer.

Each of the following occupations was listed by one subject: Actor, Actuary, Art Director, Caterer, Chemist, Contractor, Customer Service Representative, Dentist, Flight Attendant, Fundraiser, Government Employee, Grower, Home Builder, Inspector, Insurance Agent, Pilot, Public Speaker, Truck Driver, Veterinarian, and Waitress.

Piano-related demographics. In addition to the general demographic data, the present study also collected descriptive data that described the nature of the subjects' piano experiences. Responses to these items are reported below.

Instructional setting. The subjects in the present study each received piano instruction in one of four settings: University or College, Community Music School, Retail Music Store, or Independent Teacher/Studio. The distribution of subjects by instructional setting is reported in Table 15. 
Table 15.

Distribution of Subjects by Instructional Setting $(N=711)$

Instructional Setting

$n$

$\%$

University

238

33

Community School

204

29

Retail Music Store

158

22

Independent Teacher

111

16

Group vs. private lessons. Subjects were asked whether their primary mode of receiving instruction was in the form of group classes or private lessons. Over half of the respondents $(n=388,55 \%)$, reported group classes as their primary mode of instruction, while 323 subjects $(45 \%)$ indicated that they received their primary piano instruction in the form of private lessons.

Self-reported skill level. Respondents were asked to indicate their perceived skill level as a pianist. The most common skill level reported was beginning, with 327 subjects $(46 \%)$ responding in this category. Intermediate was reported by 305 subjects (43\%), while 62 respondents (9\%) selected advanced. There were 17 subjects (2\%) who did not respond to this question.

Length of adult piano study. Subjects were asked to report how long they had been taking piano both in their current setting and as an adult student. The average length of study as an adult student among those who responded to this question was 3.5 years $(S D=5.19)$, with a range of responses from one month to 75 years. There 
were fourteen $(2 \%)$ non-responses to this question. The mean length of study reported for a subject's current instructional setting was 3 years $(S D=4.01)$, with a range of one month to 36 years.

Just over one third ( $n=264,38 \%)$ of the subjects reported studying piano as an adult for one year or less. Slightly more than half of the subjects $(n=385,55 \%)$ reported studying piano as an adult for two years or less. Less than six percent $(n=37)$ of the subjects in this study reported taking piano as an adult for 10 years or more.

Piano study as a child. Subjects were asked if they had studied piano as a child. Less than half of the respondents $(n=304,43 \%)$ reported taking piano lessons as a child. Nine subjects (1\%) did not respond to this question. Of the subjects that did study piano as a child, the mean length of study (as a child) was 4.5 years ( $S D=3.72$ ), with a range of one month to 17 years.

Practice time. Subjects in the study were asked to approximate the amount of time they spend practicing in an average week. The mean weekly practice time reported by respondents was 5 hours $(S D=3.64)$, with a range from 30 minutes a week to 28 hours a week. There were 33 subjects (5\%) who did not respond to the practice time question.

$\underline{\text { Repertoire. }}$ Respondents were asked to indicate the genres of repertoire they primarily study. Subjects were instructed to mark all categories that were applicable, and space was provided to write in any categories other than the five choices provided (Classical, Jazz, Pop, Beginning Methods, and Broadway). The most prevalent response was Classical ( $n=432,61.5 \%)$, with over half of the respondents indicating they studied Classical music. Nearly half of the subjects ( $n=322,46 \%)$ studied 
beginning piano methods. Sacred music (including hymns and gospel) was the most popular write-in category, with $19(2 \%)$ responses. There were eight (1\%) nonresponses to the repertoire question. All of the repertoire categories are detailed in Table 16. 
Table 16.

Repertoire Genres Studied (N=703)

\begin{tabular}{|c|c|c|}
\hline Genre & $n$ & $\%$ \\
\hline Classical & 432 & 62 \\
\hline Beginning Methods & 322 & 46 \\
\hline Jazz & 128 & 18 \\
\hline Pop & 125 & 17 \\
\hline Broadway & 100 & 14 \\
\hline \multicolumn{3}{|l|}{ Write-in Categories } \\
\hline Sacred/Hymns/Gospel & 19 & 2 \\
\hline Folk & 7 & 1 \\
\hline Blues/ R\&B & 6 & $<1$ \\
\hline New Age & 3 & $<1$ \\
\hline Ragtime & 3 & $<1$ \\
\hline Rock & 2 & $<1$ \\
\hline Alternative & 1 & $<1$ \\
\hline Children's & 1 & $<1$ \\
\hline Country & 1 & $<1$ \\
\hline Movie & 1 & $<1$ \\
\hline
\end{tabular}


Reliability

To measure reliability for the main study questionnaire, Cronbach's alpha coefficients were calculated for each response level for each of the three benefit categories. The reliability coefficients calculated for the main study were similar to those calculated for the pilot study, with four of the six categories in the main study having reliability coefficients slightly higher than the pilot study. Reliability coefficients for the main study questionnaire (see Table 17) ranged from a low of .58 for the yes/no response in the category of Skill Benefits to a high of .93 for the importance rating in the category of Social/Cultural Benefits. With the exception of the yes/no response for Skill Benefits, all other coefficients were .77 or higher. Fraenkel and Wallen (1993) noted that "For research purposes, a useful rule of thumb is that reliability should be at least .70 and preferably higher." (p.149). Gay (1992) noted that for instruments that do not measure achievement or aptitude, reliabilities ranging in the "seventies and eighties" (.70-.89) are acceptable (p. 168).

As in the pilot study, the yes/no response to the benefits in the Skill category had the lowest reliability figure $(\alpha=.58)$. A large majority of main study subjects ( $90 \%$ or more) agreed that each of the seven Skill Benefits existed. Given the small number of items in this category, the lack of variance among the respondents, and the dichotomous response format, it was not surprising that the reliability figure for this category was low. Boyle and Radocy (1987) noted that "a restricted range of scores will lower the reliability [of a test]" (p. 67). The reliability for the importance ranking facet of the Skill category was much higher $(\alpha=.85)$. Main study reliability coefficients are reported in Table 17. 
Table 17.

Main Study Internal Consistency Coefficients

Benefit Category

Response Format

$\alpha$ Coefficient

\begin{tabular}{lll}
\hline & & \\
Personal & Yes/No (Benefit Exists) & .7722 \\
Personal & Importance (1-10) & .9255 \\
Skill & Yes/No & .5819 \\
Skill & Importance & .8452 \\
Social/Cultural & Yes/No & .8112 \\
Social/Cultural & Importance & .9286 \\
& & \\
\hline
\end{tabular}

Data Collection

Response rate. A typical problem with mailed questionnaires is a low response rate (Gay, 1992; Veal, 1997). In an effort to circumvent this problem, teachers involved in this study presented the questionnaires to their adult students directly and then collected the completed questionnaires from their students. While this procedure could not guarantee a perfect response rate, it was hoped that the response rate from an administered questionnaire would be higher than that of a mailed questionnaire. Teachers were also asked to track the number of questionnaires that they distributed and collected, so that a response rate could be reported. 
Teachers of adult piano students were mailed packets of questionnaires based on estimates they provided for the number of students that might participate. The researcher included the required number of copies of the questionnaire, a small number of additional copies of the questionnaire, and return postage for the teacher. Completion times for the pilot study averaged 15 minutes; the questionnaire for the main study was considerably shorter. Teachers were provided with instructions for the administration of the questionnaire, even though it was designed to be self-explanatory. In addition, the researcher was available via phone or e-mail for any questions or problems that teachers may have encountered. Teachers were asked to allow their students sufficient time to complete the questionnaire, and although teachers were asked to administer and collect the questionnaires during classes or lessons, it was ultimately left to the teacher's discretion whether or not to allow students to complete the questionnaires outside of instructional time. While this may have lowered the response rate, the researcher recognized that many teachers may not have been willing to devote instructional time to the questionnaire. Teachers were asked to collect the completed questionnaires and return them to the researcher in a timely manner.

Questionnaires were number-coded to track non-responding teachers or administrators. For those questionnaires that were not returned after the initial threeweek period, a follow-up letter was sent to the teacher. After another three weeks, nonresponding teachers were contacted directly by the researcher. The cover letter, instructions, teacher response sheet, and follow-up letter mailed to teachers are included in Appendix F. 
For the main study, 52 individuals were mailed survey packets for distribution, completion, and collection. These individuals included 32 teachers of adult piano students, 16 administrators of programs that taught adult piano students, and 4 individual adult piano students who expressed an interest in participating in the study.

Of the 52 individuals who were mailed survey packets, all $52(100 \%)$ responded to the researcher concerning the study. Completed surveys or survey packets were returned by 49 of the individuals (94\%). Three individuals (6\%) responded to the researcher to say that they were unable to participate in the study. One of the individuals who elected not to participate cited a high incidence of dropout among adult students in the time between agreeing to participate in the study and receiving the survey packets. The remaining two individuals who did not participate both chose not to participate after failing to distribute the packets to their students before the end of the spring semester.

Teachers and administrators who distributed surveys to students were asked to track the response rates of the students surveyed. Teachers were provided with a response sheet (see Appendix F) on which to note the number of surveys distributed to students and the number of surveys collected. Two individuals who together returned 84 completed surveys failed to track the response rate for their portion of the survey. Upon follow up, both of these individuals responded that they distributed the surveys to a number of different teachers and failed to have the teachers properly track responses. Both individuals were administrators of large programs, and both were unable to reconstruct any potential response rate. 
The remaining 47 individuals ( $96 \%$ of those returning completed surveys) either reported a response rate or were able to reconstruct the response rate upon follow up by the researcher. Collectively, these individuals distributed 848 surveys to adult piano students and returned 698 completed surveys to the researcher, representing a tracked response rate of $82 \%$, an acceptable response level for questionnaire or survey research (Fowler, 1988; Gay, 1992; Rainbow \& Froehlich, 1987).

Response error. Administration of the questionnaire proceeded with minimal problems. All questionnaires were distributed, administered, and collected by teachers of adult piano students who agreed to participate in the study. Of the 45 administrators and teachers who administered or distributed the questionnaire, only one contacted the researcher with a question about the completion of the questionnaire. The question posed by this individual concerned the completion of the demographic portion of the questionnaire, and whether it was absolutely necessary. None of the four individual adult piano students participating contacted the researcher with any questions or problems. None of the participating teachers or administrators asked any questions or reported any problems relating to the benefit portion of the questionnaire.

A total of 782 questionnaires were returned to the researcher, including 698 questionnaires returned by participants who tracked response rates and 84 questionnaires returned by the two participants who did not track or report a response rate. Of these 782 surveys, $71(9 \%)$ were deemed to be unusable by the researcher. Sixty-two of these surveys were excluded after it was determined that they were completed by individuals who did not meet the definition of adult for this investigation as defined in Chapter 1. The determination for exclusion of these individuals was based 
on responses to the age, occupation, and highest degree earned questions on the survey. Anyone reporting an age under 16 was excluded per the definition of adult as outlined in Chapter 1. Respondents reporting "student" as a full time occupation with ages in their twenties and a highest earned degree of high school were also excluded, since it could reasonably be assumed that these were individuals who were still in their primary track of education, per the definition outlined in Chapter 1. A majority of these 62 excluded surveys (45) were returned by one individual, who apparently distributed these surveys to full-time college students. The remaining 17 questionnaires filled out by non-adult students came from 10 different teachers, none of whom accounted for more than three non-adult responses.

Eight questionnaires were excluded from the study because they contained incomplete pages. For each of these questionnaires, it appeared that the respondent had inadvertently omitted a page of questions, often skipping the back side of a twosided page. These eight incomplete questionnaires were returned by six different teachers, with no teacher returning more than two incomplete questionnaires. One additional questionnaire was excluded due to a copying error - the back side of each page never printed, omitting half of the questionnaire questions. After excluding the questionnaires detailed above, 711 questionnaires remained for data compilation and analysis.

Subjects in the main study were willing to utilize the full range of responses available to them on the questionnaire. For each of the 31 benefit items, there were both yes and no responses to the existence of the benefit. For those who answered yes to the existence of the benefit and proceeded to rate its importance on a scale of one to 
ten, respondents utilized the full range of responses for all of the 31 benefit items, with responses present for each number (1-10) for each of the 31 items.

In response to the existence of the various benefits on the questionnaire, there was a wide range of responses. Nearly all of the respondents $(99 \%)$ agreed that the benefit of Skill Improvement existed, while less than one-quarter (22\%) of the respondents agreed that Social Status was a viable benefit of adult piano study. Given the respondents' evident willingness to answer yes or no to the existence of different benefits, it appeared that they understood the principle of this level of response on the questionnaire.

When asked to rate the importance of those benefits they agreed existed, the students in this study also provided a wide range of responses. Respondents made use of all levels of response (1-10) for each of the 31 benefit items, and mean importance ratings ranged from a high of 8.77 for Dream Fulfilled to a low of 4.35 for Social Status. Data Analysis

Data analysis and reporting for this study was primarily descriptive in nature. The demographic data collected were used to describe the characteristics of the study participants. In response to the research questions, each benefit item had two levels of response on the main study questionnaire - one question to indicate if the benefit existed, and one question to assess the level of importance of the benefit for those who answered "yes" to the first question. For each benefit item, the percentage of respondents agreeing and disagreeing to the existence of that benefit was reported. For each benefit item a mean level of importance was also calculated from the ratings assigned by those subjects who agreed to the existence of the benefit. 
In addition to the percentages of agreement and mean importance ratings of the individual benefit items, a mean percentage of agreement and summed mean importance rating was reported for each of the three broad categories of benefits: Personal Benefits, Skill Benefits, and Social/Cultural Benefits. For the Personal Benefits category, the percentages of agreement for the existence of each of the 14 items were summed, and then a mean percentage for that category was reported. In addition, the mean levels of importance for each of the 14 Personal Benefit items were summed for each individual, giving that individual a summed score for the category. These individual category scores were then averaged, resulting in a summed mean of importance rating for the entire category. These processes were repeated for the 7 Skill Benefits and the 10 Social/Cultural benefits on the main study questionnaire.

All data in this study were analyzed using version 10.0 .5 of the Statistical Package for the Social Sciences (SPSS) for Windows, released January, 2000. 


\section{CHAPTER 4}

\section{RESULTS}

The purpose of this study was to assess the benefits that selected adult piano students reported receiving from their participation in piano study. The following research questions were asked:

1. To what extent do adult piano students report receiving personal benefits from piano study?

2. To what extent do adult piano students report receiving skill benefits from piano study?

3. To what extent do adult piano students report receiving social/cultural benefits from piano study?

The following chapter will present the results from the main study. Data on the existence of benefits as well as the rating of importance of benefits will be presented with respect to both the individual benefit items and the broader categories of Personal, Skill, and Social/Cultural Benefits. A summary section will then discuss the results of the main study with respect to the three research questions listed above. 


\section{Benefit Data}

There were 31 benefit items on the main study questionnaire (see Appendix E). A detail of these benefit items and the three categories of benefits (Personal, Skill, and Social/Cultural) may be found in Table 3. For each benefit item, a sentence describing the benefit was presented, and subjects were given the opportunity to respond to two questions: (a) "Is this a benefit of piano study for you personally?", and (b) "If you answered yes, please rate the importance of this benefit on a scale of 1-10." Students were reminded on each page of the questionnaire that 10 represented a most important benefit and 1 represented a least important benefit. The two levels of response were designed to allow subjects to first indicate whether they agreed that a benefit existed and then, if they responded positively, to rate the importance of that benefit. The following sections of this chapter will report the results of these responses, beginning with the percentage of agreement that a benefit existed (reported for both individual items and the broad categories of Personal, Skill, and Social/Cultural Benefits), and followed by the mean importance ratings of the benefits (also reported for individual items as well as the three categories).

Existence of Benefits

Data for the existence of benefits were reported in terms of percentages of respondents answering "yes" to the question, "Is this a benefit of piano study for you personally?" Data for individual benefit items will be presented first, followed by the data for the broader categories of Personal, Skill, and Social/Cultural Benefits. 
Benefit items. For the 711 subjects participating, the range of positive responses on the existence of benefits spanned from a high of $99.0 \%$ for Skill Improvement to a low of $22.4 \%$ for Social Status. Eleven of the benefit items (Skill Improvement, Musical Knowledge, Musicianship, Accomplishment, Skill Refinement, Technique, Play/Fun, Escape from Routine, Music Theory, Music Listening, and Personal Growth) received a $90 \%$ or higher positive response. Four of the benefit items (Cooperation, Cultural Heritage, Community, and Social Status) received a positive response from less than $50 \%$ of the subjects. The complete results of this question are organized by benefit item in Table 18. 
Table 18.

Benefit Item Ratings - Percentage Agreeing the Item Exists, Grouped By Item

\begin{tabular}{rlll}
\hline Item & Benefit & Category & \% Agreeing Benefit Exists \\
\hline 16 & Skill Improvement & Skill & 99.0 \\
26 & Musical Knowledge & Skill & 98.2 \\
3 & Musicianship & Skill & 98.0 \\
1 & Accomplishment & Personal & 97.3 \\
30 & Skill Refinement & Skill & 97.3 \\
9 & Technique & Skill & 96.8 \\
17 & Play/Fun & Personal & 92.7 \\
10 & Escape from Routine & Personal & 92.1 \\
13 & Music Theory & Skill & 92.1 \\
22 & Music Listening & Skill & 90.9 \\
11 & Personal Growth & Personal & 90.2 \\
31 & Dream Fulfilled & Personal & 84.4 \\
5 & Cultural Understanding & Social/Cultural & 82.1 \\
4 & Self-Esteem & Personal & 81.3 \\
14 & Stress Reduction & Personal & 80.7 \\
\hline & & & 9 \\
\hline 1
\end{tabular}

(table continues) 
Table 18. (table continued)

\begin{tabular}{llll} 
Item & Benefit & Category & \% Agreeing Benefit Exists \\
\hline 6 & Performance for Others & Social/Cultural & 75.1 \\
27 & Self-Fulfillment & Personal & 74.3 \\
29 & Self-Confidence & Personal & 72.9 \\
23 & Self-Discipline & Personal & 72.0 \\
2 & Meet New Friends & Social/Cultural & 70.8 \\
7 & Self-Expression & Personal & 70.8 \\
19 & Imagination/Creativity & Personal & 69.5 \\
28 & Common Purpose & Social/Cultural & 66.8 \\
24 & Aesthetic Appreciation & Personal & 66.0 \\
12 & Sense of Belonging & Social/Cultural & 62.5 \\
15 & Social Recognition & Social/Cultural & 57.5 \\
20 & Spirituality & Personal & 55.7 \\
18 & Cooperation & Social/Cultural & 39.8 \\
25 & Cultural Heritage & Social/Cultural & 33.9 \\
21 & Community & Social/Cultural & 28.7 \\
\hline 8 & Social Status & Social/Cultural & 22.4 \\
\hline
\end{tabular}

Benefit categories. Results for percentages of agreement organized by benefit category are presented in Table 19. Subjects in the study agreed strongly on the existence of all of the benefit items in the Skill category. Each of the seven Skill 
Benefits received a $90 \%$ or higher "yes" response to the question, "Is this a benefit of piano playing for you personally?" All seven Skill Benefits were among the top 10 of all items in terms of percentage of agreement, and four of the five highest agreed upon benefits were Skill Benefits. The percentages of agreement on the existence of Skill Benefits ranged from a high of $99.0 \%$ for Skill Improvement to a low of $90.9 \%$ for Music Listening.

The category of Personal Benefits also tended to have high percentages of agreement. Of the 14 Personal Benefits on the questionnaire, all but one received a "yes" response from two-thirds or more of the study population, with seven Personal Benefits (Accomplishment, Play/Fun, Escape from Routine, Personal Growth, Dream Fulfilled, Self-Esteem, and Stress Reduction) receiving a "yes" response from $80 \%$ or more of the subjects. The percentages of agreement on the existence of Personal Benefits ranged from a high of $97.3 \%$ for Accomplishment to a low of $55.7 \%$ for Spirituality.

The category of Social/Cultural Benefits was rated lower than the Skill and Personal categories. The highest rated Social/Cultural Benefit, Cultural Understanding, was only the $13^{\text {th }}$ highest rated overall benefit. The 10 lowest agreed upon benefits included 7 items from the Social/Cultural category (Common Purpose, Belonging, Social Recognition, Cooperation, Cultural Heritage, Community, and Social Status). The range of agreement on Social/Cultural Benefits spanned from a high of $82.1 \%$ for Cultural Understanding to a low of $22.4 \%$ for Social Status. 
Table 19.

Benefit Item Ratings - Percentage Agreeing the Item Exists, Grouped By Category

Benefit Catsonal

Item Benefit

$\%$ Agreeing Benefit Exists

$\begin{array}{rlr}1 & \text { Accomplishment } & 97.3 \\ 17 & \text { Play/Fun } & 92.7\end{array}$

10 Escape from Routine

92.1

11 Personal Growth

90.2

31 Dream Fulfilled

84.4

4 Self-Esteem

81.3

14 Stress Reduction

80.7

27 Self-Fulfillment

74.3

29 Self-Confidence

72.9

23 Self-Discipline

72.0

7 Self-Expression

70.8

19 Imagination/Creativity

69.5

24 Aesthetic Appreciation

66.0

20 Spirituality

55.7

Mean percentage of agreement for Personal Benefits

78.56

(table continues) 
Table 19. (table continued)

Benefit Category Item Benefit

\% Agreeing Benefit Exists

Skill

$\begin{array}{rlr}16 & \text { Skill Improvement } & 99.0 \\ 26 & \text { Musical Knowledge } & 98.2 \\ 3 & \text { Musicianship } & 98.0 \\ 30 & \text { Skill Refinement } & 97.3 \\ 9 & \text { Technique } & 96.8 \\ 13 & \text { Music Theory } & 92.1 \\ 22 & \text { Music Listening } & 90.9\end{array}$

Mean percentage of agreement for Skill Benefits

96.04

Social/Cultural

$\begin{array}{rlr}5 & \text { Cultural Understanding } & 82.1 \\ 6 & \text { Performance for Others } & 75.1 \\ 2 & \text { Meet New Friends } & 70.8 \\ 28 & \text { Common Purpose } & 66.8 \\ 12 & \text { Sense of Belonging } & 62.5 \\ 15 & \text { Social Recognition } & 57.5\end{array}$

(table continues) 
Table 19. (table continued)

Benefit Category Item Benefit \% Agreeing Benefit Exists

Social/Cultural

18 Cooperation $\quad 39.8$

25 Cultural Heritage $\quad 33.9$

21 Community 28.7

8 Social Status $\quad 22.4$

Mean percentage of agreement for Social/Cultural Benefits $\quad \mathbf{5 3 . 9 6}$

When the three categories of benefits are examined collectively, it is evident that the subjects in this study responded most strongly to the category of Skill Benefits, followed by the categories of Personal Benefits and Social/Cultural Benefits. The average percentage of agreement for the Skill Benefit category was $96.04 \%$, followed by $78.56 \%$ for Personal Benefits and $53.96 \%$ for Social/Cultural Benefits (see Table 20.) 
Table 20.

Mean Percentages of Agreement, by Category

\begin{tabular}{lllc}
\hline Benefit Category & Range of \% & Mean \% & $S D$ \\
\hline Skill Based Benefits & $90.9-99.0$ & 96.04 & 3.20 \\
Personal Benefits & $55.7-97.3$ & 78.56 & 11.87 \\
Social/Cultural Benefits & $22.4-82.1$ & 53.96 & 21.11 \\
\hline
\end{tabular}

Importance of Benefits

After responding to the question of the existence of a benefit, subjects who agreed a benefit existed were then asked to rate the importance of that benefit on a scale of 1-10. On this scale 10 represented a most important benefit, and 1 represented a least important benefit. The following section reports the mean importance ratings for each benefit item as well as summed means for the broader categories of Personal, Skill, and Social/Cultural Benefits.

Benefit items. The highest rated benefit among the 31 benefits on the main study questionnaire was Dream Fulfilled, which received a mean importance rating of $8.77(S D=2.02)$ from the 600 respondents who agreed that this benefit existed. This was followed by Technique ( $n=688, M=8.30, S D=2.16)$, Accomplishment $(n=692$, $M=8.27, S D=1.94)$, Escape from Routine $(n=655, M=8.16, S D=2.34)$, and Skill Improvement $(n=704, M=8.11, S D=2.11)$. The lowest rated benefit item was Social Status, with a mean rating of $4.35(n=159, S D=2.23)$. The complete results organized by benefit item are listed in Table 21 . 
Table 21.

Benefit Item Ratings - Mean Rating of Importance, Grouped by Item

\begin{tabular}{|c|c|c|c|c|c|}
\hline Item & Benefit & Category & $n$ & Mean Rating ${ }^{*}$ & $S D$ \\
\hline 31 & Dream Fulfilled & Personal & 600 & 8.77 & 2.02 \\
\hline 9 & Technique & Skill & 688 & 8.30 & 2.16 \\
\hline 1 & Accomplishment & Personal & 692 & 8.27 & 1.94 \\
\hline 10 & Escape from Routine & Personal & 655 & 8.16 & 2.34 \\
\hline 16 & Skill Improvement & Skill & 704 & 8.11 & 2.11 \\
\hline 3 & Musicianship & Skill & 697 & 7.91 & 2.32 \\
\hline 26 & Musical Knowledge & Skill & 698 & 7.85 & 2.23 \\
\hline 17 & Play/Fun & Personal & 659 & 7.74 & 2.26 \\
\hline 30 & Skill Refinement & Skill & 692 & 7.72 & 2.26 \\
\hline 11 & Personal Growth & Personal & 641 & 7.61 & 2.36 \\
\hline 14 & Stress Reduction & Personal & 574 & 7.47 & 2.56 \\
\hline 27 & Self-Fulfillment & Personal & 528 & 7.16 & 2.61 \\
\hline 20 & Spirituality & Personal & 396 & 6.79 & 2.75 \\
\hline 22 & Music Listening & Skill & 646 & 6.71 & 3.17 \\
\hline 4 & Self-Esteem & Personal & 578 & 6.69 & 2.54 \\
\hline
\end{tabular}

(table continues)

\footnotetext{
${ }^{*}$ A rating of 10 represents a most important benefit, while a rating of 1 represent a least important benefit.
} 
Table 21. (table continued)

\begin{tabular}{|c|c|c|c|c|c|}
\hline Item & Benefit & Category & $n$ & Mean Rating ${ }^{*}$ & $S D$ \\
\hline 13 & Music Theory & Skill & 655 & 6.64 & 2.73 \\
\hline 24 & Aesthetic Appreciation & Personal & 469 & 6.55 & 2.68 \\
\hline 29 & Self-Confidence & Personal & 518 & 6.55 & 2.61 \\
\hline 23 & Self-Discipline & Personal & 512 & 6.52 & 2.61 \\
\hline 7 & Self-Expression & Personal & 503 & 6.42 & 2.71 \\
\hline 19 & Imagination/Creativity & Personal & 494 & 6.41 & 2.70 \\
\hline 5 & Cultural Understanding & Soc./Cult. & 584 & 6.36 & 2.63 \\
\hline 6 & Performance for Others & Soc./Cult. & 534 & 5.98 & 2.85 \\
\hline 25 & Cultural Heritage & Soc./Cult. & 241 & 5.95 & 2.84 \\
\hline 18 & Cooperation & Soc./Cult. & 283 & 5.83 & 2.83 \\
\hline 28 & Common Purpose & Soc./Cult. & 475 & 5.74 & 2.76 \\
\hline 12 & Sense of Belonging & Soc./Cult. & 444 & 5.59 & 2.77 \\
\hline 21 & Community & Soc./Cult. & 204 & 5.48 & 2.93 \\
\hline 2 & Meet New Friends & Soc./Cult. & 503 & 5.32 & 2.87 \\
\hline 15 & Social Recognition & Soc./Cult. & 409 & 4.63 & 2.74 \\
\hline 8 & Social Status & Soc./Cult. & 159 & 4.35 & 2.23 \\
\hline
\end{tabular}

\footnotetext{
A rating of 10 represents a most important benefit, while a rating of 1 represents a least important benefit.
} 
Benefit categories. Personal and Skill Benefits were the highest rated benefits in this study, as each category had five benefits among the top ten rated benefits in the study. The range of mean ratings on Skill Benefits spanned from a high of 8.30 on Technique $(n=688 ; S D=2.16)$ to a low of 6.64 on Music Theory $(n=655 ; S D=2.73)$, and the mean ratings of importance for Personal Benefits ranged from a high of 8.77 for Dream Fulfilled $(n=600 ; S D=2.02)$ to a low of $6.41(n=494 ; S D=2.70)$ for Imagination/Creativity.

Social/Cultural benefits were rated the lowest by the respondents, as the highest rated Social/Cultural benefit (Cultural Understanding: $n=584 ; M=6.36 ; S D=2.63$ ) was still rated lower than all Personal and Skill Benefits. The range of ratings on Social/Cultural benefits spanned from a high of 6.36 for Cultural Understanding to a low of 4.35 for Social Status $(n=159 ; S D=2.74)$. A complete list of the benefit ratings organized by category is reported in Table 22 . 
Table 22.

Benefit Item Ratings - Mean Rating of Importance, Grouped by Category

\begin{tabular}{|c|c|c|c|c|c|}
\hline $\begin{array}{l}\text { Benefit } \\
\text { Category }\end{array}$ & Item & Benefit & $n$ & Mean Rating ${ }^{*}$ & $S D$ \\
\hline \multicolumn{6}{|l|}{ Personal } \\
\hline & 31 & Dream Fulfilled & 600 & 8.77 & 2.02 \\
\hline & 1 & Accomplishment & 692 & 8.27 & 1.94 \\
\hline & 10 & Escape from Routine & 655 & 8.16 & 2.34 \\
\hline & 17 & Play/Fun & 659 & 7.74 & 2.26 \\
\hline & 11 & Personal Growth & 641 & 7.61 & 2.36 \\
\hline & 14 & Stress Reduction & 574 & 7.47 & 2.56 \\
\hline & 27 & Self-Fulfillment & 528 & 7.16 & 2.61 \\
\hline & 20 & Spirituality & 396 & 6.79 & 2.75 \\
\hline & 4 & Self-Esteem & 578 & 6.69 & 2.54 \\
\hline & 24 & Aesthetic Appreciation & 469 & 6.55 & 2.68 \\
\hline & 29 & Self-Confidence & 518 & 6.55 & 2.61 \\
\hline & 23 & Self-Discipline & 512 & 6.52 & 2.61 \\
\hline & 7 & Self-Expression & 503 & 6.42 & 2.71 \\
\hline & 19 & Imagination/Creativity & 494 & 6.41 & 2.70 \\
\hline
\end{tabular}

*A rating of 10 represents a most important benefit, while a rating of 1 represents a least important benefit. 
Table 22. (table continued)

$\begin{array}{lllll}\text { Benefit } & \text { Item Benefit } & n & \text { Mean Rating } & \\ \text { Category } & & \end{array}$

Skill

$\begin{array}{rlccc}9 & \text { Technique } & 688 & 8.30 & 2.16 \\ 16 & \text { Skill Improvement } & 704 & 8.11 & 2.11 \\ 3 & \text { Musicianship } & 697 & 7.91 & 2.32 \\ 26 & \text { Musical Knowledge } & 698 & 7.85 & 2.23 \\ 30 & \text { Skill Refinement } & 692 & 7.72 & 2.26 \\ 22 & \text { Music Listening } & 646 & 6.71 & 2.61 \\ 13 & \text { Music Theory } & 655 & 6.64 & 2.73\end{array}$

Social/Cultural

\begin{tabular}{rlccl}
5 & Cultural Understanding & 584 & 6.36 & 2.63 \\
6 & Performance for Others & 534 & 5.98 & 2.85 \\
25 & Cultural Heritage & 241 & 5.95 & 2.84 \\
18 & Cooperation & 283 & 5.83 & 2.83 \\
28 & Common Purpose & 475 & 5.74 & 2.76 \\
12 & Sense of Belonging & 444 & 5.59 & 2.77 \\
21 & Community & 204 & 5.48 & 2.93 \\
2 & Meet New Friends & 503 & 5.32 & 2.87 \\
15 & Social Recognition & 409 & 4.63 & 2.74 \\
8 & Social Status & 159 & 4.35 & 2.74 \\
\hline
\end{tabular}

*A rating of 10 represents a most important benefit, while a rating of 1 represents a least important benefit. 
To compare mean ratings of importance across benefit categories, summed mean ratings of importance were calculated for each of the three benefit categories. This was accomplished by summing each individual's ratings for each of the items in a benefit category, giving each individual a summed score for the entire category. It is important to note that these summed categorical scores are reflective of all responses to the benefits in a category, including those individuals who did not agree that certain benefits existed. While Tables 21 and 22 included mean importance ratings reflective of only those individuals who agreed that a benefit existed, obtaining individuals' scores for an entire of category of benefits required that responses of no to the existence of a benefit be included. For example, if an individual rated 4 benefits in a category with a 10 and did not agree that six other benefits existed, that individual's summed score for the category would be 40 , giving the individual a summed category mean of 4 (40 divided by 10 benefits in the category). Therefore, the summed mean statistics for each benefit category reported in Table 23 are lower than the individual benefit ratings, which only reflected those individuals who agreed that a given individual benefit existed.

These summed ratings were then averaged for all subjects in each of the three benefit categories. The category of Skill Benefits received a summed mean rating of $6.96(S D=1.90)$, while the summed mean rating for Personal Benefits was $5.73(S D=$ 2.10) and the summed mean rating for Social/Cultural Benefits was $2.88(S D=2.22)$, as reported in Table 23. 
Table 23.

Summed Mean Ratings of Importance

Benefit Category

No. of Items

Summed Mean

$S D$

Rating $^{1}$

Skill Benefits

Personal Benefits

Social/Cultural Benefits
7

14

10
6.96

5.73

2.88
1.90

2.10

\subsection{2}

\footnotetext{
${ }^{1}$ Note that these summed ratings are reflective of all respondents, including those who may have responded "no" to the existence of some benefits in a category. Therefore, these summed mean ratings of importance are lower than the individual benefit item ratings of importance (Tables 21 and 22), which included only those individuals who agreed that the individual benefit existed.
}

\section{Summary of Results}

In response to the three research questions, the results of the study will be summarized below for the categories of Personal, Skill, and Social/Cultural Benefits. Personal Benefits

Research question one asked, "To what extent do adult piano students report receiving personal benefits from their piano study?" The mean percentage of agreement on the existence of Personal Benefits was $79 \%$, compared with $96 \%$ and $54 \%$ for the categories of Skill and Social/Cultural Benefits, respectively. The percentages of agreement for individual Personal Benefits ranged from a low of $55.7 \%$ for Spirituality to a high of $97.3 \%$ for Accomplishment. 
The range of importance ratings in the category of Personal Benefits spanned from a high of 8.77 for Dream Fulfilled to a low of 6.41 for Imagination/Creativity. The summed mean rating of importance for the entire category of Personal Benefits was 5.73, compared with summed means of 6.96 for Skill Benefits and 2.88 for Social/Cultural Benefits.

Skill Benefits

Research question two asked, "To what extent do adult piano students report receiving skill benefits from their piano study?" The mean percentage of agreement for all seven of the Skill Benefits in the present study was $96 \%$, compared with $79 \%$ for all of the Personal Benefits and $54 \%$ for all of the Social/Cultural Benefits. The range of agreement on the existence of each of the Skill Benefits extended from a low of $91 \%$ for Music Listening to a high of $99 \%$ for Skill Improvement.

The range of importance ratings for Skill Benefits spanned from a high of 8.30 for Technique to a low of 6.64 for Music Theory. The summed mean rating for the importance of Skill Benefits was 6.96, compared with summed means of 5.73 and 2.88 for the categories of Personal and Social/Cultural Benefits, respectively. Social/Cultural Benefits

Research question three asked, "To what extent do adult piano students report receiving social/cultural benefits from their piano study?" The mean percentage of agreement that Social/Cultural Benefits existed was $54 \%$, considerably lower than the $79 \%$ and $96 \%$ agreement found for Personal and Skill Benefits, respectively. The percentages of agreement in the Social/Cultural Benefits category ranged from a high of $82.1 \%$ for Cultural Understanding to a low of $22.4 \%$ for Social Status. The category of 
Social/Cultural Benefits was the only category that contained individual benefit items for which less than half of the subjects agreed that the benefit existed.

The mean levels of importance assigned to Social/Cultural Benefits ranged from a high of 6.36 for Cultural Understanding to a low of 4.35 for Social Status. In terms of importance, the ten Social/Cultural benefits listed on the questionnaire were the ten lowest ranked benefits in the entire study. The summed mean importance rating for Social/Cultural Benefits was much lower (summed mean of 2.88 for the category) than the respective summed means for Personal Benefits (5.73) and Skill Benefits (6.96).

In summary, the category of Skill Benefits was the most widely agreed upon and highest rated category of benefits in the study. Many Personal Benefits were also rated highly by respondents, while the category of Social/Cultural Benefits was the least agreed upon and lowest rated category of benefits in the study. The following chapter will present conclusions and recommendations based on these findings. 


\section{CHAPTER 5 \\ CONCLUSIONS AND RECOMMENDATIONS}

The purpose of this study was to assess the benefits that selected adult piano students reported receiving from their participation in piano study. The following research questions were asked:

1. To what extent do adult piano students report receiving personal benefits from piano study?

2. To what extent do adult piano students report receiving skill benefits from piano study?

3. To what extent do adult piano students report receiving social/cultural benefits from piano study?

The following chapter will present conclusions based on the findings of this study. This section will begin with a brief discussion of the study population, to be followed by conclusions based on the findings for each of the three benefit categories (Personal, Skill, and Social/Cultural). A concluding section will present recommendations for future research.

The procedure used for selecting this study's population functioned as expected, considering the lack of a national database or sampling frame. While random sampling was not attempted, a large number of adult piano students from various instructional 
settings and geographic areas participated. Although the characteristics of adult piano students were not documented in the reviewed literature, the characteristics of the adult students in the present study were similar in nature to the characteristics reported by other researchers in the field of adult music participation.

The gender distribution of the main study population ( $72 \%$ female, $24 \%$ male, $2 \%$ no response) was similar to that of the pilot study population, in which $68 \%$ of the subjects were female. While some researchers in the broader field of adult education (not specific to music) have noted that the participation rates of females and males is essentially equal (Merriam and Caffarella, 1999a; Valentine, 1997), Boshier and Collins (1985) noted in their research that the typical adult student was female. In the narrower field of adult music research, there are many existing studies with female to male ratios that are similar to the ratio found in the present study (Conda, 1997; Cooper, 1996; Hinkle, 1988; Seago, 1993; Spell, 1989; Vincent, 1997). A 1997 survey of adult participation in the arts found that females were more likely than males to take music lessons by an approximate ratio of 5 to 4 (National Endowment for the Arts, 1997).

The average age of the respondents in this study was $51(S D=14)$. This finding was consistent with the findings of researchers who have studied adult music participants (Heintzelman, 1989; Seago, 1993; Spencer, 1996; Vincent, 1997). The students in the present study were slightly older than the respondents in a National Endowment for the Arts (NEA) survey on public participation in the arts, which reported that the largest percentage of adults taking music lessons (24\%) was in the $35-44$ age group (National Endowment for the Arts, 1997). 
The median income level reported by respondents in the present study was $\$ 50,000$ - $\$ 74,999$. This finding was consistent with the findings of an NEA survey, which stated that of adults taking music lessons, the most common reported income range was $\$ 50,001-\$ 75,000$ (National Endowment for the Arts, 1997). This range was well above the per capita income of $\$ 26,987$ (U.S. Department of Commerce, 2003) reported for the month of April 2002, the month in which the majority of the surveys in the present study were completed and returned. While many of the reviewed research studies on adult music participants did not report on participant income, Cooper (1996), Spell (1989), and Vincent (1997) reported middle to upper middle class or above average incomes for study participants.

The levels of education reported in the present study $(77 \%$ reported attending college) were consistent with the findings of other research studies on adult music participants (Heintzelman, 1989; Patterson, 1985; Spell, 1989; Spencer, 1996). The NEA reported that of adults taking music classes or lessons, $62 \%$ reported at least some college education (National Endowment for the Arts, 1997). In the field of adult education, both Valentine (1997) and Merriam and Caffarella (1999a) have noted that adult students tended to be better educated than those adults who did not participate in adult education activities.

Excluding responses of Retired and Homemaker, the professions listed by respondents in the present study (see Table 14) were predominately white-collar in nature. Other researchers in the field of adult music have noted a predominance of white-collar occupations reported by subjects (Heintzelman, 1989; Patterson, 1985; Spell, 1989; Spencer, 1996). 
Slightly less than half $(43 \%)$ of the respondents in the main study reported studying piano as a child. Study as a child and prior musical experience are characteristics that have been documented by other researchers examining adult music participation (Cooper, 1996; Hinkle, 1988; Patterson, 1985; Seago, 1993; Spell, 1989; Vincent, 1997).

In summary, the characteristics of the main study population were similar to characteristics reported by adult music and adult education researchers. This was evident in the tendency of the population of the present study to be female, educated beyond high school, and employed in a professional or white collar occupation. It is ultimately unknown whether the population of the present study is reflective of the entire population of adult piano students. The findings of the present study cannot and should not be generalized to the broader population of adult piano students.

\section{Conclusions}

The following section presents conclusions based on the findings of the present study, including comparisons to the reviewed leisure and adult music research literature. Conclusions will be organized by benefit category, beginning with Personal Benefits, followed by Skill Benefits and Social/Cultural Benefits. Individual benefit items will be discussed within their respective categories.

Personal Benefits

In the field of leisure research, personal benefits were among the most cited, documented, and researched benefits of leisure activities (Driver, Brown, \& Peterson, 
1991; Driver \& Bruns, 1999). Personal benefits have also been well documented in the reviewed literature on adult music participation (Chiodo, 1997; Conda, 1997; Cooper, 1996; Hinkle, 1988; Spencer, 1996; Stebbins, 1992). The findings of the present study concerning personal benefits are in accordance with the findings in the reviewed literature: the adult piano students in this study, like other adult musicians and adult leisure participants, reported the existence of many personal benefits and rated them as important benefits.

One of the more frequently cited personal benefits in leisure research was selfactualization (Driver \& Brown, 1986; Driver, Brown, et al., 1991; Driver \& Bruns, 1999; Driver, Tinsley, \& Manfredo, 1991; Tinsley \& Johnson, 1984; Tinsley \& Kass, 1979). Self-actualization was also reported as a personal benefit and motivating factor by researchers investigating adult music participation (Chiodo, 1997; Conda, 1997; Stebbins, 1992). Self-actualization was defined by Abraham Maslow (1970) as "the full use and exploitation of talents, capacities, potentialities" (p. 150), and it is characterized by peak experiences and moments of personal fulfillment.

Four individual Personal Benefit items in the present study were related to the concept of self-actualization: Dream Fulfilled, Accomplishment, Personal Growth, and Self-Fulfillment. All four of these individual benefit items were agreed to exist by a large majority of respondents; these benefits were also rated as important by respondents. With a mean importance rating of 8.77 , Dream Fulfilled was the highest rated individual benefit (from all categories) in the study, and the other three benefits all had mean importance ratings above 7 . It appears that these self-actualization-related benefits were very important to the adult piano students surveyed. This finding is consistent with 
the findings of self-actualization as a benefit and motivating factor in the reviewed leisure and adult music research literature.

Teachers may wish to consider the significance of these benefits for their adult piano students when planning instruction. Understanding students' goals and dreams can help teachers plan subject material, repertoire, and activities that are designed to meet students' personal needs, thereby improving teacher effectiveness. Since these benefits are personal in nature, it is likely that individual dreams and goals will vary considerably from student to student. Therefore, teachers should consider spending time identifying their students' individual goals, perhaps through informal interviewing or brief questionnaires. The findings of the present study suggest that instructional programs which do not address students' goals and the means to accomplish them may be omitting what many students feel is a very important benefit of piano study.

Another highly rated Personal Benefit was Play/Fun. A large majority (93\%) of respondents who did agree that this benefit existed gave it a mean importance rating of 7.74. This finding is consistent with the findings of other leisure researchers (Csikszentmihalyi, 1990; Csikszentmihalyi \& Csikszentmihalyi, 1988; Tinsley \& Kass, 1979; Wankel \& Berger, 1991) as well as researchers in the field of adult music participation (Chiodo, 1997; Cooper, 1996; Stebbins, 1992).

Stebbins (1992) found that Enjoyment and Fun was the second highest ranked reward among barbershop singers participating in a qualitative study measuring the perceived costs and rewards of this activity. In another qualitative study using terminology similar to that of Stebbins, Chiodo (1997) also found that Fun was the second highest ranked benefit among adult musicians. Cooper (1996) reported that 
Personal Pleasure as a motivating factor was second in importance only to Skill Development among adult piano students who studied as children. Of those students who began piano study as adults, Cooper found that Personal Pleasure was cited as the most important motivating factor. This distinction is of note to the present study, in which $46 \%$ of the respondents described themselves as beginners.

Individual benefits such as Accomplishment, Personal Growth, Skill Improvement, and Technique were rated very highly in the present study, indicating that the respondents valued progress and improvement. The high rating of Play/Fun, however, may remind teachers that many adult piano students have an expressed interest in enjoying their piano study as well. Teachers may wish to consider individual students' repertoire preferences, goals, and desired activities when planning instruction in an effort to maximize students' enjoyment as they progress and improve in their piano study. For example, activities such as improvisation or ensemble playing (if they match students' goals) could enhance the benefit of Play/Fun. Repertoire which is not enjoyable or fun for students may actually counteract an important benefit of their piano study.

In the present study, Escape from Routine was the third highest rated Personal Benefit on both levels of response, with $92 \%$ of the subjects confirming its existence and assigning it a mean importance rating of 8.16. Stress Reduction was also cited as an existing and important benefit by respondents (81\% percentage of agreement; 6.00 mean rating of importance). These concepts have been cited as leisure benefits (Driver \& Brown, 1986; Driver \& Bruns, 1999; Driver, Tinsley et. al, 1991; Tinsley \& Johnson, 
1984; Tinsley \& Kass, 1979), but they have not appeared frequently in the reviewed literature on adult music participation.

The high ratings accorded to Escape from Routine and Stress Reduction may indicate that a large percentage of the students valued the ability of piano study to provide them with escape from the challenges of everyday life. Despite the emphasis placed on improvement and progress by the students in this study, the results also indicated that studying piano provided students with an important outlet for relaxation and release from their daily routine.

Other Personal Benefits receiving high ratings included Self-Confidence, SelfDiscipline, Self-Esteem, and Self-Expression. Seventy percent or more of the respondents agreed that each of these benefits existed, with mean importance ratings ranging from a low of 6.42 for Self-Expression to a high of 7.47 for Stress Reduction. Each of these benefits has been documented in existing leisure research (Driver \& Bruns, 1999; Driver, Tinsley, et al., 1991; Tinsley \& Kass, 1977), and with the exception of Self-Discipline, each has also been documented in existing research concerning adult music participants (Chiodo, 1997; Conda, 1997; Cooper, 1996; Stebbins, 1992).

In a qualitative study investigating the benefits of adult music participation, Chiodo (1997) found Self-Expression to be the most important benefit cited by subjects. Stebbins (1992), however, found Self-Expression to be a lower ranked reward among barbershop singers. Cooper (1996) found Self-Expression to be a frequently cited motivator among adult pianists who had studied piano as a child. The findings of the present study place Self-Expression among the lower ranked Personal Benefits, 
although overall it was still ranked as an important and agreed upon benefit $(71 \%$ agreement, mean importance rating of 6.42).

The ratings given to this group of Personal Benefits (Self-Confidence, SelfDiscipline, Self-Esteem, and Self-Expression) indicate that the respondents valued the impact that piano study had on their overall sense of self, and they viewed piano study as a personal endeavor. This is supported by the research of Conda (1997), who reported that many adult subjects indicated that they were studying piano purely for themselves. Quotes reported in the Conda study included: "I'm not doing this for anyone else" and "[I do this] ...for my own self-esteem, I guess... I like playing, but just for myself' (p.120-121).

Teachers should consider the importance of these self-related benefits when planning repertoire and activities for students. Helping students structure and organize practice activities and learning goals may help promote the benefit of Self-Discipline, which was valued by the respondents. Repertoire, instructional material, and activities designed to bolster and improve Self-Confidence may be more appreciated and valued than repertoire and activities which may have a negative impact on a student's sense of self. For example, presenting difficult material too soon may be frustrating and discouraging, and it may negate the potential positive benefits of Self-Confidence, SelfEsteem and Self-Expression.

The least agreed upon Personal Benefits (in terms of percentage agreeing the benefit exists) in the present study were Imagination/Creativity (70\%), Aesthetic Appreciation (66\%), and Spirituality (56\%). Creativity was mentioned as a benefit in leisure research studies (Driver \& Bruns, 1999; Driver, Tinsley, et al., 1991; Tinsley \& 
Johnson, 1984; Tinsley \& Kass, 1979), but it was cited rarely in the literature on adult music participation. Stebbins (1992) found that the reward "Re-Create One's Self" was one of the lowest ranked rewards among barbershop singers. Spirituality was another benefit cited in the field of leisure research (Driver \& Bruns, 1999; McDonald \& Schreyer, 1991; Rossman \& Ulehla, 1977), although it was not mentioned in the reviewed adult music research literature. Although Spirituality was the least agreed upon Personal Benefit in the present study, those who did agree that it existed valued the benefit. Spirituality had a mean importance rating of 6.79 , higher than six other Personal Benefits.

The lowest rated Personal Benefits in this study (Imagination/Creativity, Aesthetic Appreciation, and Spirituality) were among the more introverted in nature of the Personal Benefits. While respondents obviously valued Personal Benefits, these three benefits may be so personal in nature that students did not expect to receive them from their piano study.

In summary, although the consensus of agreement and the strength of importance ratings for Personal Benefits were not as high as those for Skill Benefits, the category of Personal Benefits was still rated highly by the adult piano students surveyed. In response to research question one: "To what extent do adult piano students report receiving personal benefits from their piano study?" the findings of this study suggest that many Personal Benefits both existed and were important to the respondents. Many of the highest rated Personal Benefits were related to the broader construct of Self-Actualization, a benefit well-documented in existing research literature on leisure benefits and adult music participation. Accomplishment, Play/Fun, Escape 
from Routine, Personal Growth, and Dream Fulfilled were particularly important to the adult piano students in the present study, and each of these benefits was found to be as important as many of the Skill Benefits investigated.

Skill Benefits

Skill benefits were often cited and documented in the reviewed leisure research, but unlike personal and social/cultural benefits they were not typically placed in a separate category. Broad reviews of leisure benefits as well as specific research studies on the benefits of leisure have listed personal and social/cultural benefits as two of the most prominent and cited categories of leisure benefits (Driver \& Bruns, 1999; Driver, Tinsley, et al., 1991; Tinsley \& Johnson, 1984). While these reviews did not include a separate category for skill benefits, the personal benefits category reported by leisure researchers often included many skill-related benefits such as ability development, challenge to improve, learning, knowledge acquisition, skill refinement, and understanding (Driver \& Brown, 1986; Driver \& Bruns, 1999; Driver, Tinsley, et al., 1991).

Tinsley, Barrett, and Kass (1977) identified 27 leisure activity specific needs or benefits. This list included ability utilization, achievement, advancement, and understanding. Self-Actualization and Intellectual Aestheticism were identified as two factors in a later study which classified the benefits of leisure (Tinsley \& Johnson, 1984). These factors included components related to skill and ability development. Driver and Bruns (1999) identified improved cognitive performance, problem solving, learning, understanding, and challenge as benefits in a comprehensive review of leisure research. Other leisure researchers who have noted the presence of skill-related 
benefits include Driver and Brown (1986), Easley (1991), Iso-Ahola (1980), and Roggenbuck, Loomis, and Dagostino (1991). While all of these leisure researchers had mentioned the existence of skill-related benefits, they were generally not accorded the degree of importance found in the present study. Skill-related benefits and motivations were cited frequently in the reviewed adult music research literature (Chiodo, 1997; Conda, 1997; Cooper, 1996; Heintzelman, 1989; Patterson, 1985; Seago, 1993; Spell, 1989; Spencer, 1996).

One potential explanation for the difference in the presence and importance of skill benefits in the reviewed adult music literature (including the present study) and the reviewed leisure research could be the level of technical skill required for music participation. Playing a musical instrument or singing requires not only specific technique, but the ability to understand and organize rhythms and tones. Music students also need to have the ability to listen critically to their own music making and the music making of others around them. For most students, playing a musical instrument or singing involves some skill and ability in reading music - a specific system of symbols and notations that must be learned and deciphered. For those students who may choose not to read music, aural skills are required to learn and play by ear. Music has a specific harmonic language and structure, and understanding this structure is often a part of learning to play a musical instrument.

It could be argued that many of the activities investigated in the reviewed leisure research are not as technically intensive as piano study. Leisure activities studied by Tinsley and his associates in the development of the PAL questionnaire included, among others, reading, watching television, attending lectures, jogging, playing cards, 
and watching basketball (Tinsley et al., 1977; Tinsley \& Kass, 1978, 1979). The research of Driver and his associates (Driver \& Brown, 1986; Driver, Tinsley, et al., 1991) focused primarily on outdoor recreational activities such as camping, hiking, and canoeing. Although many of these activities involve some degree of technical skill, it could be argued that less technical knowledge is required for most adults to begin reading, watching television, or jogging than is required to play the piano.

Another explanation for the high ranking and importance accorded to Skill Benefits by subjects in the present study may lie in the contrast between a student and a participant. All of the subjects in the present study were students who were actively pursuing formal lessons at the piano. It can reasonably be assumed that most or all of the subjects were paying for their instructional experience. Many of the leisure activities investigated in the reviewed literature did not require the participant to be a formal student, and many of these activities could be pursued with little economic investment. One's perception as a student, particularly a paying student, may be more likely to center on the acquisition of skill and knowledge than the perception of one who is pursuing an activity as a non-student. Because our educational systems are based predominantly on demonstrated achievement, we may tend to view any pursuit as a student as one centering on the acquisition and development of skills and knowledge. The adult piano students in this study appeared to place a higher emphasis on skillrelated benefits than the participants in other leisure activities.

Stebbins (2001) outlined differences between serious leisure pursuits and other more causal forms of leisure participation, noting that certain leisure participants were more oriented toward technical concepts and the application of skills, while other leisure 
pursuers were more focused on the acquisition of broad knowledge. Based on their ratings of Skill Benefits, the adult students in the present study may consider themselves to be more serious than casual in their piano study.

The majority of documented research on benefits comes from the field of leisure research, in which benefits tend to be placed into personal and social/cultural categories. The results of this study suggest that these categories are appropriate for adult piano students as well. The present study, however, demonstrates the importance of a third category of Skill Benefits for adult piano students, as Skill Benefits comprised the most agreed upon and highest rated category of benefits in the study. All of the Skill Benefits were agreed to exist by more than $90 \%$ of the respondents, and all of the Skill Benefits received high ratings of importance. While the reviewed leisure research often included individual skill-related benefits within the broader category of personal benefits, the results of this study demonstrate that for adult piano students, it is appropriate to place Skill Benefits in a separate and distinct category.

The highest rated Skill Benefit (in terms of importance) in the present study was Technique. The large majority of subjects $(97 \%)$ who agreed that this benefit existed gave it a mean importance rating of 8.30 . Skill Improvement (99\% agreement, 8.11 mean importance rating) and Skill Refinement (97\% agreement, 7.72 mean importance rating) were also rated very highly by the respondents.

Cooper (1996) noted that Skill Development was the most cited motivating factor among adult piano students who studied as children. Conda (1997) reported that many adult piano students were motivated by their desire to improve at the instrument. Patterson (1985), Heintzelman (1989), and Spencer (1996) all noted the importance of 
skill development and improvement to community band participants, while Seago (1993) and Spell (1989) each reported that community choir members found the desire to improve and refine skills and abilities to be a very important and highly rated motivating factor.

Chiodo (1997) found that Self-Expression was the most important benefit to a group of adult musicians participating in a qualitative study. In her analysis of SelfExpression, Chiodo noted that this concept included various aspects of performing, improving musical skills, and meeting musical challenges. When informants in the study were asked to describe in more detail the concept of "Fun" (another highly rated benefit in the Chiodo study), many of the descriptors given by the informants were related to skill, technique, and proficiency of execution on a given musical instrument. It appeared that possessing some measure of skill and technique on an instrument helped to make it more "fun".

The findings of the present study indicate that of all the benefits investigated, those relating to Skill Improvement, Skill Refinement, and Technique are among the most agreed upon and most important. As discussed above, this may reflect the fact that all of the subjects in the present study were students pursuing formal piano instruction, which by its nature promotes the improvement of skills and abilities. While students did place emphasis on having fun and enjoying their piano study, they appeared to be most interested in technical progress. Teachers planning instructional curricula for adult piano students may consider this finding and make efforts to provide educational activities which further promote and satisfy students' expressed desire for improvement in technique and ability. 
Musicianship, Musical Knowledge, and Musical Theory were also Skill Benefits that were widely agreed to exist and rated as important by respondents. Each of these benefits relates to the intellectual learning and understanding of music, as well as the knowledge needed to interpret and analyze music. From the field of choral music, Seago (1993) reported that "enrichment of musical knowledge" (p. 60) was a chief motivating factor, and Spell (1989) reported that many choir participants were motivated by a desire to both learn more about music and improve musical sensitivity. Conda (1997) noted in her study that many adult piano participants cited their desire to learn more about playing the piano as a motivation for study. The importance of Musicianship, Musical Knowledge, and Music Theory to the participants in the present study illustrated the students' desire not just to improve technical skill, but also to improve their understanding of concepts relating to musical structure and interpretation.

Music Listening was agreed to exist as a benefit by $91 \%$ of the students, and it was assigned a mean importance rating of 6.71. Although Music Listening was cited rarely in the reviewed literature on adult music participation, Seago (1993) did report that one motivating factor among choir participants was a desire to train the ear. The high levels of agreement and importance accorded this benefit in the present study illustrate that Music Listening was a valued benefit. Therefore, teachers planning instruction may wish to consider the inclusion of activities focused on developing aural and listening skills. Merriam and Caffarella (1999a) noted that self-directed learning was an important topic and theory in the field of adult education. If instructional time is limited, teachers wishing to help adult students develop listening skills may consider 
recommending recordings, concerts, or even aural skills software for students to pursue outside of formal instructional time.

In summary, the adult piano students in the present study valued the category of Skill Benefits more than any other category. In response to research question number two: "To what extent do adult piano students report receiving skill benefits from piano study?", the results indicate that more respondents reported receiving Skill Benefits from their piano study than Personal or Social/Cultural Benefits. Additionally, respondents rated Skill Benefits as among the most important benefits of their piano study. This is consistent with many of the findings of the reviewed literature in the field of adult music participation, yet it is not as consistent with the reviewed leisure research. While leisure researchers have often cited skill-related benefits, the students in the present study placed more importance on Skill Benefits than participants in other nonmusical leisure activities.

Social/Cultural Benefits

Social and cultural benefits have been cited frequently in the existing research literature on both leisure participation and adult music participation. In a summary of leisure benefits research, Driver and Bruns (1999) listed Social and Cultural Benefits as a major category for classifying individual benefits of leisure participation. Other researchers documenting the social and cultural benefits of leisure included Allen (1991); Driver and Brown (1986); Driver, Tinsley, et al. (1991); Orthner and Mancini (1991); Tinsley and Johnson, 1984; and Wankel and Berger (1991). The reviewed adult music research literature reported various aspects of social interaction, community, shared values, group accomplishment, and cultural heritage to be either benefits of 
music participation or motivations for adult musicians (Conda, 1997; Chiodo, 1997; Heintzelman, 1989; Hinkle, 1988; Kaltoft, 1990; Spencer, 1996).

One potential explanation for the relative lack of importance assigned to Social/Cultural Benefits in the present study could lie in the nature of piano study. Piano is one of the more solitary of the musical instruments, with the large majority of piano repertoire consisting of solo works. Typical piano students at any skill level spend the majority of their time practicing, playing, and even performing alone. Even if a student studied piano in a group setting, it is still likely that a large percentage of that student's time at the piano would be spent alone. By contrast, much of the existing research on adult music participation dealt with organizations such as community bands (Heintzelman, 1989; Patterson, 1985; Spencer, 1996) or choral groups (Hinkle, 1988; Seago, 1993; Spell, 1989; Stebbins, 1992; Vincent, 1997). In groups such as these, the performance of music is a social event, requiring many musicians to interact and play together. Group interaction is not typical of most piano study experiences, and this fact may help to explain the relative lack of enthusiasm from the students in the present study with respect to social and cultural benefits.

The highest rated Social/Cultural Benefit was Cultural Understanding. Eighty-two percent of the students agreed that this benefit existed, and it had a mean importance rating of 6.36. Driver and Bruns (1999) listed cultural awareness and appreciation as a benefit of leisure activities in a review of leisure benefit research. Hinkle (1988) identified a large group of choral participants as "Ethnic Heritage Singers" (p. 78). These singers reported that the most meaningful aspects of their musical experience related to cultural heritage and traditions. 
The Social/Cultural Benefit that was ranked second highest in both existence (75\%) and mean level of importance (5.98) in the present study was Performance for Others. Performance, exhibition, and recognition have been documented as benefits in existing leisure research (Driver \& Bruns, 1999; Driver, Tinsley, et al., 1991; Tinsley \& Johnson, 1984; Tinsley \& Kass, 1979). Researchers in the field of adult music participation have also documented the importance of performance as a benefit or motivator (Heintzelman, 1989; Patterson, 1985; Seago, 1993; Spell, 1989; Spencer, 1996).

It may be of interest that the two highest rated Social/Cultural Benefits, Cultural Understanding and Performance for Others, are two of the least socially interactive of the ten Social/Cultural Benefits included in the present study. Cultural Understanding involves learning and knowledge, while Performance for Others involves the application of technique and skill. These two benefits, which share similar characteristics with Skill Benefits, were rated much higher than other Social/Cultural Benefits that involved more social interaction.

The research literature reviewed for the present study made frequent mention of social interaction, community, friendship, cooperation and social bonding as benefits of leisure activities (Driver \& Brown, 1986; Driver \& Bruns, 1999; London, Crandall, \& Fitzgibbons, 1977; Tinsley et al., 1977; Tinsley \& Kass, 1978, 1979). In the field of adult music research, many writers have noted the presence of similar social motivators and benefits (Chiodo, 1997; Conda, 1997; Heintzelman, 1989; Hinkle, 1988).

In the present study, however, these concepts were rated and ranked among the lowest of all the individual benefit items. This is not to say that these benefits did not 
exist - over half of the students agreed that the benefits of Meeting New Friends, Common Purpose, Sense of Belonging, and Social Recognition existed. When compared with the Skill and Personal Benefits, however, these Social/Cultural Benefits were rated considerably lower. This finding is consistent with the findings of the Stebbins (1992) study on the rewards of barbershop singing, in which the subjects ranked Group Accomplishment and Social Attraction as lower rewards than Personal Enrichment, Enjoyment or Fun, and Self-Actualization. In a similar study of adult music participants, Chiodo (1997) also found that the personal benefits of Self-Expression, Fun, and Personal Enrichment were ranked higher than social benefits.

As mentioned above, the benefits which involved more social interaction and contact were rated lower than the benefits of Cultural Understanding and Performance for Others. This indicates that the average respondent in this study placed the least value and importance on those benefits that involved social interaction with other students. It did not appear that many adult students in the present study were valuing their piano study as an important source of social interaction.

The lowest ranked Social/Cultural Benefits in the present study were Cooperation, Cultural Heritage, Community, and Social Status. Less than half of the students agreed that these benefits existed, and each benefit received low ratings of importance compared to the other benefit items investigated. Each of these benefits was cited frequently in the existing literature on leisure research (Allen, 1991; Driver \& Bruns, 1999; Driver, Tinsley, et al., 1991; London et al., 1977; Tinsley \& Johnson, 1984; Tinsley \& Kass, 1979), and there was also frequent mention of these benefits in the 
literature on adult music participation (Chiodo, 1997; Heintzelman, 1989; Hinkle, 1988; Spencer, 1996).

Although Cultural Understanding was the highest rated of all the Social/Cultural Benefits, Cultural Heritage was among the lowest rated of all the benefits in the study. This may indicate that while the respondents were interested in learning and understanding culture, they did not necessarily view piano study as a means for preserving their cultural heritage and traditions. Given the low likelihood that students were studying piano for career or professional advancement, it is not surprising that the benefit of Social Status was the least agreed upon and lowest rated benefit in the entire study.

In response to research question three: "To what extent do adult piano students report receiving social/cultural benefits from their study?", the results indicate that the respondents reported receiving Social/Cultural Benefits to a much lesser extent than they reported receiving Skill and Personal Benefits. In addition to lower percentages of agreement on the existence of Social/Cultural Benefits, these benefits were ranked as less important than Skill and Personal Benefits. Despite frequent mentions of social and cultural benefits in both the existing leisure research and the existing research on adult music participation, the students in the present study did not view Social/Cultural Benefits as among the most prevalent or the most important benefits of their adult piano experience.

Another conclusion relates to the three categories collectively. There appears to be some measure of interrelatedness between the categories. Personal Benefits such as Accomplishment and Self-Fulfillment depend to some degree on the development 
and improvement of skill and ability. A benefit such as Performance may actually have personal, skill, and social components. It is possible that individual students interpret benefits differently - for one student Performance may be highly related to praise and recognition from others, while another student may view Performance as very personal in nature and a third student may focus exclusively on the skills necessary to perform. This interrelatedness is evident in the reviewed leisure literature, where skill-related benefits were often included within a broader category of personal benefits. Further inquiry into the nature of individual benefits and how individual students perceive certain benefits could provide more information.

The researcher recognizes that the findings of the present study suggest a number of instructional areas which are valued by students. Instructional time, however, is often limited, making it challenging for teachers to offer all of these activities. This fact underscores the importance of individual teachers taking the time to know their students, assess their needs, and understand the benefits which individual students value. The benefits valued in the present study may not be valued by the entire adult piano population, and simple informal investigation could help educators identify the interests of individual students or the shared interests of small groups of students. Adult students are consumers, choosing to spend their time, money, and effort in the endeavor of piano study. Understanding more about what these students seek and value can help educators offer instructional experiences that meet students' needs and optimize the rewards for all involved. 


\section{Recommendations}

The descriptive findings of the present study represent a first step toward understanding the benefits of adult piano study. Future studies could report more data, further describe the adult piano population, and begin to explore relationships among various characteristics of adult piano students and benefit ratings. Recommendations for future research are presented below.

1. Identifying adult piano students and teachers of adult piano students is challenging, and this challenge impairs the ability of researchers to locate subjects for further studies and employ random sampling techniques. The establishment of a professional organization, society, or database that includes teachers and institutions offering adult piano instruction would help to facilitate future research, discussion, and professional exchange in the field. This could be accomplished within the framework of existing professional organizations by establishing networks and resources devoted exclusively to the instruction of adults. There are established committees on adult piano study, but until more nationwide information is collected and disseminated, future research will remain challenging.

2. Very little is known about the basic demographic characteristics of adult piano students. While the absence of sampling frames makes random sampling techniques and generalizations extremely difficult, future studies examining other selected groups of adult piano students could help to increase our knowledge of the basic characteristics of adult piano students. In addition, such research could help to determine the extent to 
which the adult piano students in the present study were reflective of the entire population of adult piano students.

3. Although the questionnaire used in this study served as an effective measurement instrument, it should undergo further testing, revision, and use with other populations of adult piano students. More data on its reliability should be collected, and efforts should be made to improve the reliability rating for the yes/no response in the Skill Benefits category. The addition of more benefits items to the Skill category, specifically items which elicit a greater variance of yes/no responses, could improve the reliability of this category, thus improving the effectiveness of the questionnaire. In addition, the demographic portion of the questionnaire could be improved and revised in an effort to collect more information about the characteristics of adult piano students.

4. Future research could examine the benefits of non-piano forms of adult music study. Examining potential differences in benefit ratings between adult instrumentalists, singers, and pianists could yield information about the nature of these activities and the benefits that adults report receiving from them. These studies could include participants in adult concert bands, chamber groups, musical theaters, orchestras, and choirs. The collection of this information could also help identify potential differences in benefit ratings between these groups of students and yield more information about both the nature of benefits and the nature of these varying adult music experiences.

5. Future research could compare the benefits reported by adult piano students actively participating in formal instruction (such as those in the present study) with those benefits reported by adults who actively play the piano but do not pursue formal piano instruction. Differences in benefits ratings may clarify the goals and needs of those 
students who choose to study formally, helping to assist the educators who dispense formal instruction in the understanding of their students.

6. Comparisons in benefit ratings among various groups of adult piano students could be made in an effort to clarify the nature of these benefits. For example, beginning students may have a different sense of benefits than more advanced students. Some students may be more serious or more casual than other students in their approach to piano study, and this may have an impact on what benefits are reported and perceived to be important. Those who receive private piano instruction may have a different view of social benefits than those who study piano in a group setting. Students who study primarily one type of repertoire may have a different view of benefits than students who focus on a different genre. Studies comparing benefit ratings among different groups could help to identify differences and provide insight into the nature of various benefits.

7. Potential differences between adult piano students and younger students could be explored through future research. College, high school, and middle school students may report the existence of benefits differently than adult students. Exploring differences in benefit ratings among these groups could provide insight into different teaching approaches or styles that may be more appropriate for adult piano students.

8. Future research could examine attrition in adult piano study with respect to benefits. Understanding the benefits perceived and valued by those adult piano students who stop taking formal instruction may help to identify potential explanations for the discontinuation of study. Perhaps adult students who stop taking lessons or classes are not receiving benefits that they expect or value. 
9. Future research could compare differences in benefit ratings for students who have not yet begun piano study and those who have studied for a given length of time. Beginners who have not yet started their study may expect and value certain benefits that more experienced students do not. Longitudinal studies of beginners could identify potential changes in their perceptions of benefits as they begin their study and gain experience.

10. Adult students taking piano instruction may be involved with other leisure pursuits as well. Comparing the benefit ratings of adult piano study and other non-piano leisure activities for the same individuals could help researchers identify benefits that students associate specifically (or more strongly) with piano as opposed to other leisure activities. Potential differences could be of use in the marketing and promotion of adult piano instruction.

11. Future research into the benefits of adult piano study and adult music study could explore additional benefit items and categories. While participants in the field test and content validity review did not suggest adding any additional benefits to the questionnaire in the present study, there may be other unexplored benefits that students value. Qualitative research may also assist in the identification of any such benefits. Future studies could employ factor analysis and other techniques to identify constructs or categories that may not have been explained fully by the three categories of benefits used in the present study.

12. The present study was an initial investigation, and it was designed to be descriptive in nature. Future comparative studies could include more statistical analysis, including testing to determine levels of significance among benefit items and 
benefit categories. In addition, future studies could examine potential interactions between benefits and various characteristics (e.g. group lessons vs. private lessons, beginners vs. advanced, type of repertoire studied) of adult piano students and adult musicians.

13. Once more is known about both the characteristics of the adult piano population, and their overall tendencies in benefit item ratings, experimental studies could examine potential factors that may influence the benefits that students value. For example, instructional methods focusing exclusively on Skill Benefits could be compared with instructional methods that focus more on Personal or Social/Cultural Benefits in an effort to see if instructional method has an impact on perceived benefits and their value to students. Other instructional variables such as teaching style, genre of repertoire studied, and emphasis on certain activities (e.g. ensemble or chamber playing, improvisation, public performance) could also be explored to see if they impact the perception and value of benefits.

14. The collection of more information on both the characteristics and benefit ratings of adult piano students could lead to the development of a typology of adult piano students. Some students may tend to be more skill-oriented while others may be inclined to seek and value personal or social/cultural benefits. Relationships between personality types (i.e. existing psychological measures) and benefit ratings could be explored. Understanding these potential differences and learning to identify different types of adult piano students could help educators offer instruction that meets their students' needs and desires. 
15. Qualitative research on the benefits of adult piano study could help to provide a more detailed description of the nature, scope, and origins of the benefits adult piano students report receiving. It is the nature of a questionnaire study to present concise statements with limited answer possibilities such as yes/no. While all of the benefits included in the present study were documented in existing research literature, qualitative research could help to provide more detail about these benefits and how selected students describe, react to, and explain these benefits. Open-ended interviews, structured interviews, observations, and other qualitative techniques could help add to the information provided by the present study.

In conclusion, the present study yielded initial information regarding the benefits of adult piano study as reported by the population involved. Skill Benefits were favored over the category of Personal Benefits, and Social/Cultural Benefits were found to be the least important. This study represents a first step in what the researcher hopes will be a continuing process of investigation into both the benefits of adult piano study and the overall nature of the adult piano experience.

Adult students represent an important portion of the music education landscape, which is increasingly less confined to the traditional boundaries of K-12 instruction. Understanding more about adult piano students and what they value in their study can help educators offer instruction and experiences designed to meet students' needs and optimize their musical experiences. 
APPENDIX A

CONTENT VALIDITY ITEMS 


\section{Content Validity for the}

\section{Benefits of Adult Piano Study Questionnaire}

\section{Background:}

For my dissertation, I will be studying the self-reported benefits of adult piano students. Subjects in the study will fill out a brief questionnaire, rating a series of potential benefits. Subjects will be asked if they feel each statement actually represents a benefit for them personally. If they respond "yes", they will then be asked to rate the importance of that benefit on a scale of 1-10.

\section{Items:}

Each of the items (or statements) represents one potential benefit of adult piano study. Each of the items is well-documented in prior research. These benefits were taken from two sources - research on adult music students and research on adult leisure activities. Each item you will review has been found in numerous existing studies.

The items fall into three broad categories: Personal Benefits, Social/Cultural Benefits, and Skill-Based benefits. These three categories are also well documented in existing research literature.

\section{Your Job:}

As a content validity reviewer, your job will be to read each item and determine if you think it is appropriate (or content valid). You were chosen for this review because you have experience working with adult students. I will take your feedback on these items and make any necessary revisions before conducting the pilot study. Please look at each item and decide:

- If you think the item is appropriate

- If the wording of the item is clear

Also, consider your experience with adult students and see if you feel there are any benefits that are missing from this questionnaire.

\section{Sample Item:}

Each item on the questionnaire will look like this. Aside from this sample, I have only included the actual statements for you to review.

\section{A. Eating broccoli improves my social life.}

Is this a benefit (of broccoli eating) for you personally? $\quad$ YES NO

If you answered yes, please rate the importance of this benefit on a scale of 1-10:

$(10=$ a most important benefit to me; $1=$ a least important benefit to me $)$

Subjects will be asked to think about each statement in relation to their own personal experience (group or private), and they will be encouraged to use the full range of numbers from 1-10. 
The following is the original list of items presented to the content validity panel

for review. Suggestions made by the panel appear in italics after each item.

\section{Questionnaire Items}

1. Studying piano gives me the opportunity to use all of my personal talents and abilities to their fullest.

3 reviewers were uncomfortable with "all of". Changed to: "Studying piano gives me the opportunity to use my personal talents and abilities to their fullest."

2. Studying piano gives me a satisfying sense of accomplishment.

3. Studying piano has led to many new friendships in my life.

4. Studying piano improves my overall musicianship.

2 reviewers were uncomfortable with the term musicianship - too vague. Changed to: "Studying piano improves my ability to understand, interpret, and make music."

5. Studying piano increases my self-esteem.

1 reviewer was uncomfortable with the causeleffect relationship implied by this item and preferred the wording of item \# 15.

6. Studying piano improves my ability to perform music in front of others.

7. Studying piano improves my understanding of culture and the arts.

8. Studying piano allows me to express my inner thoughts and feelings.

9. Studying piano leads me to the discovery of different musical ideas and concepts.

1 reviewer was uncomfortable with the term "different". Changed to: "Studying piano leads me to the discovery of new and different musical ideas and concepts".

10. Studying piano helps me to improve and grow as a person.

1 reviewer was uncomfortable with "as a person". Changed to "Studying piano helps me to improve and grow personally." 
11. Studying piano improves my technique and facility (at the piano).

1 reviewer suggested deleting "at the piano". Another suggested changing to "improves my motor coordination skills". Added item \#41 to pilot study questionnaire: "Studying piano improves my coordination and motor skills."

12. Studying piano gives me a chance to be with people I enjoy spending time with.

13. Studying piano is a private activity that provides me with needed solitude.

14. Studying piano improves my understanding of music theory.

15. Studying piano helps me to feel good about myself.

16. Studying piano has helped me to improve my social status.

17. Studying piano challenges me to improve my musical skills and abilities.

18. Studying piano gives me a chance to do something that is completely different from my everyday routine.

19. Studying piano provides me with a sense of belonging.

1 reviewer was uncomfortable with the term "belonging" being too vague. Changed to:

"Studying piano provides me with a sense of belonging to a group of people that share similar values and interests."

20. Studying piano reduces the stress and tension in my life.

21. Studying piano helps me to understand more about the music that I listen to.

22. Studying piano is a playful and fun activity.

23. Studying brings me praise and recognition from others.

1 reviewer and 1 field tester noted that "piano" was missing from this item. Item was corrected for pilot study questionnaire.

24. Studying piano allows me to make good use of my imagination and creativity.

25. Studying piano increases my musical knowledge.

26. Studying piano has a positive influence on my spiritual life.

27. Studying piano improves my ability to cooperate and work with others. 
28. Studying piano improves my self-discipline and organization.

29. Studying piano exposes me to different (non-musical) ideas and philosophies.

2 reviewers felt this was a big stretch in logic. 3 out of 5 field testers agreed that this was a benefit, but with low ratings. Item was retained for pilot test but ultimately eliminated from main study questionnaire.

30. Studying piano increases my appreciation for the finer things in life.

1 reviewer suggested "appreciation for the other arts". Since item was not originally designed to be specific to just the arts, the above wording was retained for the pilot study. Item was ultimately eliminated from the main study questionnaire.

31. Studying piano improves and refines my musical skills and abilities.

32. Studying piano is rewarding and satisfying.

33. Studying piano provides me with a strong sense of community.

34. Studying piano reminds me of earlier times in my life.

35. Studying piano connects me with my cultural heritage.

36. Studying piano gives me the skills to play music that I couldn't play before.

1 reviewer felt this was unnecessary. This item was retained for the pilot test, but eliminated from the main study questionnaire.

37. Studying piano increases my appreciation for beauty in all aspects of life.

1 reviewer suggested the word all was too strong. Changed to: "Studying piano increases my appreciation for beauty in other aspects of life."

38. Studying piano brings me together with others that share a common purpose.

39. Studying piano pushes me to fulfill my highest personal potential.

40. Studying piano improves my self-confidence. 
APPENDIX B

FIELD TEST COVER SHEET AND INSTRUCTIONS 


\section{Field Test of the \\ Benefits of Adult Piano Study Questionnaire}

Thank you very much for participating in the field test of this questionnaire. Your role is extremely important - you will help determine if the questionnaire is valid, if there are any problems, if any items should be excluded, and if anything is missing.

Each item will list a potential benefit of piano study. You will be asked if this is a benefit of piano study for you personally. If you fell it is, answer yes. If you feel it isn't, answer no.

Please think only about your own experience, not about how others feel or how others expect you to feel. Your responses are confidential and anonymous, and your truthfulness is essential!

For example, if the questionnaire was about chess, it might say:

\section{Playing chess improves my ability to think strategically.}

If you disagree with this statement, circle "no". If you agree, circle "yes".

If you circle "yes", you'll be asked to rate the importance of the benefit on a scale of one to ten. Think about how important the benefit is to you. Just because you agree something is benefit, it doesn't necessarily mean that the benefit is important to you. You might agree that playing chess improves your ability to think strategically, but it may not be that important to you - you might play chess because you like spending time with your chess partners.

Please use the full range of numbers from one to ten when responding.

After the benefit items, you'll be asked a few demographic questions. All of this information is anonymous and confidential, and it's just there to help paint a picture of what adult piano students are like.

Thank you for your time and participation.

Your input is valuable!

[Benefit items from Appendix B were inserted here, with the follwing response format:]

1. Studying piano gives me the opportunity to use some of my personal talents and abilities to their fullest.

Is this a benefit of piano study for you personally? $\quad$ YES NO

If you answered yes, please rate the importance of this benefit on a scale of 1-10. 
Following the benefit items, students were provided with space to answer the following questions:

Please comment on any items that you thought were not appropriate:

Please note any benefits of piano study that you feel are missing from this questionnaire:

Please comment on any problems or difficulties you had answering or understanding any items: 
APPENDIX C

PILOT TEST QUESTIONNAIRE 


\section{Pilot Test of the \\ Benefits of Adult Piano Study Questionnaire}

Thank you very much for participating in the pilot test of this questionnaire. Your role is extremely important - you will help determine if the questionnaire is valid, if there are any problems, if any items should be excluded, and if anything is missing.

Each item will list a potential benefit of adult piano study. You will be asked if this is a benefit of piano study for you personally. If you feel it is, answer yes. If you feel it isn't, answer no.

If you do answer yes, you will then indicate how important the benefit is to you personally. You may agree that some things are benefits, but they may not be important benefits to you. If you don't think something is a benefit and answer no, then you will not rate the importance of that benefit.

Please use the full range of numbers from 1-10 when rating the importance of benefits. Please think only about your own experience, not about how others feel or how think others expect you to feel. Your responses are confidential and anonymous, and your truthfulness is essential!

Some Sample Items with their responses:

A. Exercising helps me to lose weight.

Is this a benefit of exercising for you personally? $\quad$ YES NO

If you answered yes, please rate the importance of this benefit on a scale of 1-10:

(Note: I'll answer YES and 10, because this is an important benefit to me.).

B. Exercising has led to new friendships in my life.

Is this a benefit of exercising for you personally? $\quad$ YES NO

If you answered yes, please rate the importance of this benefit on a scale of 1-10:

(Note: I'll answer YES and 1, because while I agree that I might meet new friends at the gym, this is not what I would consider to be an important benefit of my exercising.)

C. Exercising builds my vocabulary.

Is this a benefit of exercising for you personally? $\quad$ YES NO

If you answered yes, please rate the importance of this benefit on a scale of 1-10:

(Note: I'll answer NO because I don't believe that this is a benefit of exercising for me.) 


\section{Questionnaire Items}

1. Studying piano gives me the opportunity to use some of my personal talents and abilities in a unique way.

Is this a benefit of piano study for you personally? $\quad$ YES NO

If you answered yes, please rate the importance of this benefit on a scale of 1-10:

2. Studying piano gives me a satisfying sense of accomplishment.

Is this a benefit of piano study for you personally? $\quad$ YES NO

If you answered yes, please rate the importance of this benefit on a scale of 1-10:

3. Studying piano has brought new friends into my life.

Is this a benefit of piano study for you personally? $\quad$ YES NO

If you answered yes, please rate the importance of this benefit on a scale of 1-10:

4. Studying piano improves my ability to understand, interpret, and make music.

Is this a benefit of piano study for you personally? $\quad$ YES NO

If you answered yes, please rate the importance of this benefit on a scale of 1-10:

\section{Studying piano increases my self-esteem.}

Is this a benefit of piano study for you personally? $\quad$ YES NO

If you answered yes, please rate the importance of this benefit on a scale of 1-10:

6. Studying piano improves my ability to perform music for others.

Is this a benefit of piano study for you personally? $\quad$ YES NO

If you answered yes, please rate the importance of this benefit on a scale of 1-10: 
7. Studying piano improves my understanding of culture and the arts.

Is this a benefit of piano study for you personally? $\quad$ YES NO

If you answered yes, please rate the importance of this benefit on a scale of 1-10:

8. Studying piano allows me to express my inner thoughts and feelings.

Is this a benefit of piano study for you personally? $\quad$ YES NO

If you answered yes, please rate the importance of this benefit on a scale of 1-10:

9. Studying piano leads me to the discovery of new and different musical ideas and concepts.

Is this a benefit of piano study for you personally? $\quad$ YES NO

If you answered yes, please rate the importance of this benefit on a scale of 1-10:

10. Studying piano helps me to improve and grow personally.

Is this a benefit of piano study for you personally? $\quad$ YES NO

If you answered yes, please rate the importance of this benefit on a scale of 1-10:

11. Studying piano improves my technique and facility (at the piano).

Is this a benefit of piano study for you personally? $\quad$ YES NO

If you answered yes, please rate the importance of this benefit on a scale of 1-10:

12. Studying piano gives me a chance to spend time with people I enjoy.

Is this a benefit of piano study for you personally? $\quad$ YES NO

If you answered yes, please rate the importance of this benefit on a scale of 1-10: 
13. Studying piano is a private activity that provides me with needed solitude.

Is this a benefit of piano study for you personally? $\quad$ YES NO

If you answered yes, please rate the importance of this benefit on a scale of 1-10:

14. Studying piano improves my understanding of music theory.

Is this a benefit of piano study for you personally? $\quad$ YES NO

If you answered yes, please rate the importance of this benefit on a scale of 1-10:

\section{Studying piano helps me feel good about myself.}

Is this a benefit of piano study for you personally? $\quad$ YES NO

If you answered yes, please rate the importance of this benefit on a scale of 1-10:

16. Studying piano has helped me to improve my social status.

Is this a benefit of piano study for you personally? $\quad$ YES NO

If you answered yes, please rate the importance of this benefit on a scale of 1-10:

17. Studying piano challenges me to improve my musical skills and abilities.

Is this a benefit of piano study for you personally? $\quad$ YES NO

If you answered yes, please rate the importance of this benefit on a scale of 1-10:

18. Studying piano gives me a chance to do something that is completely different from my everyday routine.

Is this a benefit of piano study for you personally? $\quad$ YES NO

If you answered yes, please rate the importance of this benefit on a scale of 1-10: 
19. Studying piano provides me with a sense of belonging to a group of people who share similar values and interests.

Is this a benefit of piano study for you personally? $\quad$ YES NO

If you answered yes, please rate the importance of this benefit on a scale of 1-10:

20. Studying piano reduces stress and tension in my life.

Is this a benefit of piano study for you personally? $\quad$ YES NO

If you answered yes, please rate the importance of this benefit on a scale of 1-10:

21. Studying piano improves my ability to understand music when I am listening to music.

Is this a benefit of piano study for you personally? $\quad$ YES NO

If you answered yes, please rate the importance of this benefit on a scale of 1-10:

22. Studying piano is a playful and fun activity.

Is this a benefit of piano study for you personally? $\quad$ YES NO

If you answered yes, please rate the importance of this benefit on a scale of 1-10:

\section{Studying piano brings me praise and recognition from others.}

Is this a benefit of piano study for you personally? $\quad$ YES NO

If you answered yes, please rate the importance of this benefit on a scale of 1-10:

24. Studying piano allows me to make good use of my imagination and creativity.

$\begin{array}{lll}\text { Is this a benefit of piano study for you personally? } & \text { YES NO }\end{array}$

If you answered yes, please rate the importance of this benefit on a scale of 1-10: 


\section{Studying piano increases my musical knowledge.}

Is this a benefit of piano study for you personally? $\quad$ YES NO

If you answered yes, please rate the importance of this benefit on a scale of 1-10:

26. Studying piano has a positive influence on my spiritual life.

Is this a benefit of piano study for you personally? $\quad$ YES NO

If you answered yes, please rate the importance of this benefit on a scale of 1-10:

27. Studying piano improves my ability to cooperate and work with others.

Is this a benefit of piano study for you personally? $\quad$ YES NO

If you answered yes, please rate the importance of this benefit on a scale of 1-10:

28. Studying piano improves my self-discipline and organization.

Is this a benefit of piano study for you personally? $\quad$ YES NO

If you answered yes, please rate the importance of this benefit on a scale of 1-10:

29. Studying piano exposes me to different (non-musical) ideas and philosophies.

Is this a benefit of piano study for you personally? $\quad$ YES NO

If you answered yes, please rate the importance of this benefit on a scale of 1-10:

30. Studying piano increases my appreciation for the finer things in life.

Is this a benefit of piano study for you personally? $\quad$ YES NO

If you answered yes, please rate the importance of this benefit on a scale of 1-10: 


\section{Studying piano improves and refines my musical skills and abilities.}

Is this a benefit of piano study for you personally? $\quad$ YES NO

If you answered yes, please rate the importance of this benefit on a scale of 1-10:

\section{Studying piano is rewarding and satisfying.}

Is this a benefit of piano study for you personally?

YES NO

If you answered yes, please rate the importance of this benefit on a scale of 1-10:

33. Studying piano provides me with a strong sense of community.

Is this a benefit of piano study for you personally? $\quad$ YES NO

If you answered yes, please rate the importance of this benefit on a scale of 1-10:

34. Studying piano reminds me of earlier times in my life.

Is this a benefit of piano study for you personally? $\quad$ YES NO

If you answered yes, please rate the importance of this benefit on a scale of 1-10:

35. Studying piano connects me with my cultural heritage.

Is this a benefit of piano study for you personally? $\quad$ YES NO

If you answered yes, please rate the importance of this benefit on a scale of 1-10:

36. Studying piano gives me the skills to play more difficult music.

Is this a benefit of piano study for you personally? $\quad$ YES NO

If you answered yes, please rate the importance of this benefit on a scale of 1-10: 
37. Studying piano increases my appreciation for beauty in other aspects of life.

Is this a benefit of piano study for you personally? $\quad$ YES NO

If you answered yes, please rate the importance of this benefit on a scale of 1-10:

38. Studying piano brings me together with others who share a common purpose.

Is this a benefit of piano study for you personally? $\quad$ YES NO

If you answered yes, please rate the importance of this benefit on a scale of 1-10:

39. Studying piano challenges me to fulfill my highest personal potential.

Is this a benefit of piano study for you personally? $\quad$ YES NO

If you answered yes, please rate the importance of this benefit on a scale of 1-10:

40. Studying piano improves my self-confidence.

Is this a benefit of piano study for you personally? $\quad$ YES NO

If you answered yes, please rate the importance of this benefit on a scale of 1-10:

\section{Studying piano improves my coordination and motor skills.}

Is this a benefit of piano study for you personally? $\quad$ YES NO

If you answered yes, please rate the importance of this benefit on a scale of 1-10:

42. Studying piano fulfills a dream that I have always had.

Is this a benefit of piano study for you personally? $\quad$ YES NO

If you answered yes, please rate the importance of this benefit on a scale of 1-10: 


\section{Demographic Information}

Please tell us a little about yourself. This will help the study paint an accurate picture of the respondents. All of this information is confidential, and no one will be able to connect responses to any individual in the study.

Please circle your responses, or fill in the blank where appropriate.

Please indicate your gender: FEMALE MALE Please indicate your age:

What is the primary setting for your piano study? GROUP CLASSES PRIVATE LESSONS

How would you describe your skill level? BEGINNER INTERMEDIATE ADVANCED

About how much time do you spend practicing in an average week?

How long have you been taking piano in this setting?

years

months

How long have you taken piano as an adult student?

years

months

Did you take piano as a child?

YES

NO

If yes, how long did you study as a child?

years months

What kind of music do you primarily study? (Circle all that apply)

BEGINNING METHODS CLASSICAL JAZZ POP BROADWAY OTHER

What is your occupation? (Please indicate if retired, student, or homemaker)

What is your approximate annual income? (Circle one)

$<\$ 25,000 \quad \$ 25,000-\$ 40,000 \quad \$ 40,000-\$ 65,000 \quad \$ 65,000-\$ 100,000 \quad>\$ 100,000$

What is your highest earned degree? HIGH SCHOOL BACHELORS MASTERS DOCTORATE

About how long did it take you to complete this questionnaire? 
APPENDIX D

FACTOR ANALYSIS OF

PILOT TEST ITEMS 
Table 24.

Factor Analysis Results for Pilot Questionnaire Personal Benefit Items

\begin{tabular}{|c|c|c|c|}
\hline Item & Benefit & Factor Loading & Main Study Status \\
\hline 5 & Self Esteem & .841 & Retained \\
\hline 24 & Imagination/Creativity & .744 & Retained \\
\hline 40 & Self Confidence & .740 & Retained \\
\hline 10 & Self Growth & .702 & Retained \\
\hline 8 & Self Expression & .701 & Retained \\
\hline 15 & Self Esteem & .685 & Eliminated $^{1}$ \\
\hline 37 & Aesthetic Appreciation & .682 & Retained \\
\hline 2 & Accomplishment & .674 & Retained \\
\hline 30 & Aesthetic Appreciation & .664 & Eliminated $^{1}$ \\
\hline 39 & Self Fulfillment & .637 & Retained \\
\hline 18 & Escape from Routine & .597 & Retained \\
\hline 20 & Stress Reduction & .590 & Retained \\
\hline 28 & Self Discipline & .554 & Retained \\
\hline
\end{tabular}

(table continues)

\footnotetext{
${ }^{1}$ Item eliminated due to a lower factor loading than its corresponding alternate worded item.
} 
Table 24. (table continued)

\begin{tabular}{llcl}
\hline Item & Benefit & Factor Loading & Main Study Status \\
\hline 42 & Dream Fulfilled & .551 & Retained \\
1 & Self Fulfillment & .497 & Eliminated $^{1}$ \\
26 & Spirituality & .402 & Retained $^{1}$ \\
32 & Accomplishment & .383 & Eliminated $^{1}$ \\
13 & Solitude & .333 & Eliminated $^{2}$ \\
22 & Play/Fun & .319 & Retained $^{3}$ \\
34 & Nostalgia & $2.767 E-02$ & Eliminated $^{3}$ \\
\hline
\end{tabular}

\footnotetext{
${ }^{1}$ Item eliminated due to a lower factor loading than its corresponding alternate worded item.

${ }^{2}$ Item eliminated due to a negative impact on internal consistency.

${ }^{3}$ Item eliminated due to a factor loading below .30.
} 
Table 25.

Factor Analysis Results for Pilot Questionnaire Skill Benefit Items

\begin{tabular}{llll}
\hline Item & Benefit & Factor Loading & Main Study Status \\
\hline 4 & Musicianship & .795 & Retained \\
21 & Musical Listening & .783 & Retained \\
25 & Musical Knowledge & .780 & Retained \\
31 & Skill Refinement & .670 & Retained \\
17 & Skill Improvement & .649 & Retained \\
11 & Technique & .543 & Retained \\
9 & Musical Learning & .507 & Eliminated $^{1}$ \\
36 & Learn Difficult Music & .495 & Eliminated $^{1}$ \\
14 & Music Theory & .480 & Retained $^{2}$ \\
29 & Non-Musical Learning & .254 & Eliminated $^{2}$ \\
41 & Motor Skills & .106 & Eliminated $^{2}$ \\
& & & \\
\hline
\end{tabular}

\footnotetext{
${ }^{1}$ Item eliminated due to a negative impact on internal consistency.

${ }^{2}$ Item eliminated due to factor loading below .30 .
} 
Table 26.

Factor Analysis Results for Pilot Questionnaire Social/Cultural Benefit Items

\begin{tabular}{llll}
\hline Item & Benefit & Factor Loading & Main Study Status \\
\hline 33 & Community & .899 & Retained \\
27 & Cooperation & .886 & Retained \\
19 & Sense of Belonging & .851 & Retained \\
38 & Common Purpose & .780 & Retained \\
23 & Social Recognition & .760 & Retained \\
12 & Community & .660 & Eliminated \\
& & .576 & Retained \\
35 & Cultural Heritage & .557 & Retained \\
3 & Meet New Friends & .470 & Retained \\
16 & Social Status & .456 & Retained \\
6 & Performance for Others & .401 & Retained \\
7 & Cultural Understanding & & \\
\hline
\end{tabular}

\footnotetext{
${ }^{1}$ Item eliminated due to a lower factor loading than its corresponding alternate worded item.
} 
APPENDIX E

MAIN STUDY QUESTIONNAIRE 


\section{The Benefits of Adult Piano Study Questionnaire}

Thank you very much for participating in this research study about the benefits of adult piano study. Your role is extremely important, and your answers and opinions are valuable.

Each item will list a potential benefit of adult piano study. You will be asked if this is a benefit of piano study for you personally. If you feel it is, answer yes. If you feel it isn't, answer no.

If you do answer yes, you will then indicate how important the benefit is to you personally, on a scale of 1-10. 10 represents a most important benefit and 1 represents a least important benefit. Y You may agree that some items are benefits, but they may not be important benefits to you. If you don't think an item is a benefit, then you will not rate the importance of that benefit.

Please use the full range of numbers from 1-10 when rating the importance of benefits. Please think only about your own experience, not about how others feel or how think others expect you to feel. Your responses are confidential, and your truthfulness is essential!

Sample items with sample responses:

A. Exercising helps me to lose weight.

Is this a benefit of exercising for you personally? $\quad$ YES NO

If you answered yes, please rate the importance of this benefit on a scale of 1-10:

(Note: I'll answer YES and 10, because this is an important benefit to me.).

B. Exercising has led to new friendships in my life.

Is this a benefit of exercising for you personally? $\quad$ YES NO

If you answered yes, please rate the importance of this benefit on a scale of 1-10:

(Note: I'll answer YES and 1, because while I agree that I might meet new friends at the gym, this is not what I would consider to be an important benefit of my exercising.)

C. Exercising builds my vocabulary.

Is this a benefit of exercising for you personally? $\quad$ YES NO

If you answered yes, please rate the importance of this benefit on a scale of 1-10:

(Note: I'll answer NO because I don't believe that this is a benefit of exercising for me.)

Thank you for your time and your input!

Please begin on the following page. 


\section{Questionnaire Items}

1. Studying piano gives me a satisfying sense of accomplishment.

Is this a benefit of piano study for you personally? $\quad$ YES NO

If you answered yes, please rate the importance of this benefit on a scale of 1-10:

2. Studying piano has brought new friends into my life.

Is this a benefit of piano study for you personally? $\quad$ YES NO

If you answered yes, please rate the importance of this benefit on a scale of 1-10:

3. Studying piano improves my ability to understand, interpret, and make music.

Is this a benefit of piano study for you personally? YES NO

If you answered yes, please rate the importance of this benefit on a scale of 1-10:

\section{Studying piano increases my self-esteem.}

Is this a benefit of piano study for you personally? $\quad$ YES NO

If you answered yes, please rate the importance of this benefit on a scale of 1-10:

5. Studying piano improves my understanding of culture and the arts.

Is this a benefit of piano study for you personally? $\quad$ YES NO

If you answered yes, please rate the importance of this benefit on a scale of 1-10:

Please turn to the back of this page and continue. 


$$
10=\text { A Most Important Benefit; } 1=\text { A Least Important Benefit }
$$

6. Studying piano improves my ability to perform music for others.

Is this a benefit of piano study for you personally? $\quad$ YES NO

If you answered yes, please rate the importance of this benefit on a scale of 1-10:

7. Studying piano allows me to express my inner thoughts and feelings.

Is this a benefit of piano study for you personally? $\quad$ YES NO

If you answered yes, please rate the importance of this benefit on a scale of 1-10:

8. Studying piano gives me an opportunity to improve my social status.

Is this a benefit of piano study for you personally? $\quad$ YES NO

If you answered yes, please rate the importance of this benefit on a scale of 1-10:

9. Studying piano improves my technique and facility (at the piano).

Is this a benefit of piano study for you personally? $\quad$ YES NO

If you answered yes, please rate the importance of this benefit on a scale of 1-10:

10. Studying piano gives me a chance to do something that is completely different from my everyday routine.

Is this a benefit of piano study for you personally? $\quad$ YES NO

If you answered yes, please rate the importance of this benefit on a scale of 1-10:

11. Studying piano helps me to improve and grow personally.

Is this a benefit of piano study for you personally? $\quad$ YES NO

If you answered yes, please rate the importance of this benefit on a scale of 1-10:

Please turn to the next page and continue. 
12. Studying piano provides me with a sense of belonging to a group of people who share similar values and interests.

Is this a benefit of piano study for you personally? $\quad$ YES NO

If you answered yes, please rate the importance of this benefit on a scale of 1-10:

13. Studying piano improves my understanding of music theory.

Is this a benefit of piano study for you personally? $\quad$ YES NO

If you answered yes, please rate the importance of this benefit on a scale of 1-10:

14. Studying piano reduces stress and tension in my life.

Is this a benefit of piano study for you personally? $\quad$ YES NO

If you answered yes, please rate the importance of this benefit on a scale of 1-10:

15. Studying piano brings me praise and recognition from others.

Is this a benefit of piano study for you personally? $\quad$ YES NO

If you answered yes, please rate the importance of this benefit on a scale of 1-10:

16. Studying piano challenges me to improve my musical skills and abilities.

Is this a benefit of piano study for you personally? $\quad$ YES NO

If you answered yes, please rate the importance of this benefit on a scale of 1-10:

Please turn to the back of this page and continue. 
17. Studying piano is a playful and fun activity.

Is this a benefit of piano study for you personally? $\quad$ YES NO

If you answered yes, please rate the importance of this benefit on a scale of 1-10:

18. Studying piano improves my ability to cooperate and work with others.

Is this a benefit of piano study for you personally? $\quad$ YES NO

If you answered yes, please rate the importance of this benefit on a scale of 1-10:

19. Studying piano allows me to make good use of my imagination and creativity.

Is this a benefit of piano study for you personally? $\quad$ YES NO

If you answered yes, please rate the importance of this benefit on a scale of 1-10:

20. Studying piano has a positive influence on my spiritual life.

Is this a benefit of piano study for you personally? $\quad$ YES NO

If you answered yes, please rate the importance of this benefit on a scale of 1-10:

21. Studying piano provides me with a strong sense of community.

Is this a benefit of piano study for you personally? $\quad$ YES NO

If you answered yes, please rate the importance of this benefit on a scale of 1-10:

Please turn to the next page and continue. 
22. Studying piano improves my ability to understand music when I am listening to music.

Is this a benefit of piano study for you personally? $\quad$ YES NO

If you answered yes, please rate the importance of this benefit on a scale of 1-10:

23. Studying piano improves my self-discipline and organization.

Is this a benefit of piano study for you personally? $\quad$ YES NO

If you answered yes, please rate the importance of this benefit on a scale of 1-10:

24. Studying piano increases my appreciation for beauty in other aspects of life.

$\begin{array}{lll}\text { Is this a benefit of piano study for you personally? } & \text { YES NO }\end{array}$

If you answered yes, please rate the importance of this benefit on a scale of 1-10:

25. Studying piano connects me with my cultural heritage.

Is this a benefit of piano study for you personally? $\quad$ YES NO

If you answered yes, please rate the importance of this benefit on a scale of 1-10:

26. Studying piano increases my musical knowledge.

Is this a benefit of piano study for you personally? $\quad$ YES NO

If you answered yes, please rate the importance of this benefit on a scale of 1-10:

Please turn to the back of this page and continue. 
27. Studying piano challenges me to fulfill my highest personal potential.

Is this a benefit of piano study for you personally? $\quad$ YES NO

If you answered yes, please rate the importance of this benefit on a scale of 1-10:

28. Studying piano brings me together with others who share a common purpose.

Is this a benefit of piano study for you personally? $\quad$ YES NO

If you answered yes, please rate the importance of this benefit on a scale of 1-10:

29. Studying piano improves my self-confidence.

Is this a benefit of piano study for you personally? $\quad$ YES NO

If you answered yes, please rate the importance of this benefit on a scale of 1-10:

30. Studying piano improves and refines my musical skills and abilities.

Is this a benefit of piano study for you personally? $\quad$ YES NO

If you answered yes, please rate the importance of this benefit on a scale of 1-10:

31. Studying piano fulfills a dream that I have always had.

Is this a benefit of piano study for you personally? $\quad$ YES NO

If you answered yes, please rate the importance of this benefit on a scale of 1-10:

Thank you for your time and your responses.

Please complete the final page of the survey, which contains some demographic questions. All of your responses are anonymous and confidential. 


\section{Demographic Information}

Please tell us a little about yourself. This will help the study paint an accurate picture of the respondents. All of this information is confidential, and no one will be able to connect responses to any individual in the study.

Please circle your responses, or fill in the blank where appropriate.

Please indicate your gender: FEMALE MALE Please indicate your age:

What is the primary setting for your piano study? GROUP CLASSES PRIVATE LESSONS

How would you describe your skill level? BEGINNER INTERMEDIATE ADVANCED

About how much time do you spend practicing in an average week?

How long have you been taking piano in this setting?

years months

How long have you taken piano as an adult student?

years months

Did you take piano as a child?

YES

NO

If yes, how long did you study as a child?

years months

What kind of music do you primarily study? (Circle all that apply)

BEGINNING METHODS CLASSICAL JAZZ POP BROADWAY OTHER

What is your occupation? (Please indicate if retired, student, or homemaker)

What is your approximate annual income as an individual (not household or family)? (Circle one)

$$
\begin{aligned}
& \text { less than } \$ 25,000 \\
& \$ 25,000-\$ 34,999 \\
& \$ 35,000-\$ 49,999 \\
& \$ 50,000-\$ 74,999
\end{aligned}
$$

What is your highest earned degree?
$\$ 75,000$ - $\$ 99,999$

$\$ 100,000$ - \$149,999

$\$ 150,000$ or more

\section{HIGH SCHOOL BACHELORS MASTERS DOCTORATE}


APPENDIX F

COVER LETTER, INSTRUCTIONS,

RESPONSE SHEET, AND

FOLLOW-UP LETTER 


\section{COVER LETTER}

Dear...,

Thank you for agreeing to participate in this research study on the benefits of adult piano study. Very little research has been conducted on adult piano students, and it is my hope that your participation in this study will help us learn more about adults who choose to invest time, energy, and money into piano study.

I have enclosed ( ) surveys per your request, and I have included ( ) additional copies of the survey should you need them. If you require any additional copies, please contact me as soon as possible. There is also an instruction sheet for the administration of the questionnaires and a sheet for you to notate the number of questionnaires distributed and collected.

I would greatly appreciate your assistance in distributing these questionnaires to your adult piano students as soon as possible. Based on the pilot study, I would expect that your students could complete the survey in 15 minutes or less. Please follow the points on the enclosed instruction sheet when you distribute the questionnaires.

If you would prefer not to use instructional time for completion of the survey, you may ask that the students return the survey at their next lesson or class. It is important, however, that all of the surveys be collected in a timely fashion.

I have also enclosed return postage and a mailer for the return of the surveys to me. I would greatly appreciate it if you could return the completed surveys no later than May $1^{\text {st }}, 2002$. If you anticipate any problems meeting this deadline, please contact me.

In appreciation for your participation in this study, I will be happy to send you a copy of the results. Please indicate your desire for this, along with the number of surveys distributed and collected, on the enclosed sheet.

Thank you very much for your time and cooperation in this important project.

Sincerely,

Peter Jutras 


\section{INSTRUCTIONS FOR ADMINISTRATION OF THE QUESTIONNAIRE}

Thank you very much for your help in this study. To make this process as clear and easy as possible, please take the following steps when administering the questionnaire.

1. Note the number of questionnaires distributed.

2. Briefly explain the purpose of the questionnaire to the students (to study the benefits of adult piano study).

3. Please read the sample items aloud to the students, noting the different types of responses.

4. Remind the students to consider their own experience, not what they might be "expected" to think. Their opinions and responses, whether positive or negative, are valuable.

5. Remind the students that if they answer no to the existence of a benefit, they do not rate its importance.

6. Encourage students to use the full range of numbers from 1-10 when rating the importance of benefits.

7. Remind the students that all information is anonymous and confidential.

8. Outline a clear time and place for the collection of the questionnaires. 


\section{BENEFITS OF ADULT PIANO STUDY \\ TEACHER RESPONSE SHEET}

Thank you very much for your participation in this research study. Please complete the following sheet to be returned with the completed surveys.

Teacher Name:

Surveys Distributed:

Surveys Collected:

Yes, I would like to receive a copy of the results when the study is completed.

I do not wish to receive a copy of the results at this time. 


\section{FOLLOW-UP LETTER}

Dear...,

Recently you received some surveys to distribute to adult piano students. You were mailed these surveys based on your willingness to participate in a research study examining the benefits of adult piano study.

To date ( ) \% of the surveys have been returned. Since your surveys are not among them, it is possible that you did not receive my original correspondence, or that they are currently on their way in the mail to me. I have enclosed duplicate copies of the materials mailed earlier. If you have already mailed your completed surveys, please disregard this letter, and thank you for your participation.

In order to paint an accurate picture of the adult piano student, it is essential that all of the surveys in this study be returned. If you are experiencing any problems distributing or collecting the survey, please do not hesitate to contact me.

Your assistance in this research study is greatly appreciated.

Sincerely,

Peter Jutras 


\section{REFERENCES}

Adams, N. (1996). Piano lessons: Music, love, and true adventures. New York: Delta Publishing.

Allen, L. R. (1991). Benefits of leisure services to community satisfaction. In B. L. Driver, P. J. Brown, \& G. L. Peterson (Eds.). Benefits of leisure (pp. 331-350). State College, PA: Venture Publishing, Inc.

Andrews (1970). Goals and objectives for music education. Music Educators Journal, 57(4), 23-26.

Beder, H. (1989). Purposes and philosophies of adult education. In S. Merriam \& P. Cunningham (Eds.)., Handbook of adult and continuing education (pp. 37-50). San-Francisco: Jossey Bass.

Belanger, P. \& Valdivielso, S. (Eds.). (1997). The emergence of learning societies: Who participates in adult learning? Oxford: Pergamon and UNESCO Institute for Education.

Black, M.F. (1997). Beginning/Intermediate concert band programs for mature adults a national survey. Journal of Band Research, 34, 40-50.

Blakslee, M. (Ed.). (1992). Special focus: Music for lifelong learning [Special issue]. Music Educators Journal, 79(4).

Boyle, J. D. \& Radocy, R. E. (1987). Measurement and evaluation of musical experiences. New York: Schirmer Books. 
Boshier, R. \& Collins, J. B. (1985). The Houle typology after twenty-two years: A large scale empirical test. Adult Education Quarterly, 35(3), 113-130.

Bowles C. L. (1988). An assessment of self-expressed music education interests and music experiences by adult audiences: Implications for music education. (Doctoral dissertation, The University of Texas at Austin, 1988), Dissertation Abstracts International,49 (11), 3295. (UMI No. 8901277).

Casey, D. E. (1992). Descriptive research: Techniques and procedures. In R. Colwell (Ed.). Handbook of research on music teaching and learning (pp. 115-123). New York: Schirmer Books.

Chiodo, P. A. (1997). The development of lifelong commitment: A qualitative study of adult music participation. (Doctoral dissertation, The State University of New York at Buffalo, 1997). Dissertation Abstracts International, 58 (07), 2578. (UMI No. 9801280).

Coffman, D. D. (1996). Musical backgrounds and interests of active older adult band members. Dialogue in Instrumental Music Education, 20(1), 25-34.

Conda, J. M. (1997). The Late Bloomer's Piano Club: A case study of a group in progress. (Doctoral dissertation, The University of Oklahoma, 1997). Dissertation Abstracts International, 58 (02), 409. (UMI No. 9721060).

Cooper, T. L. (1996). Adults' perceptions of piano study: Achievements, experiences, and interests. (Doctoral dissertation, The University of Texas at Austin, 1996). Dissertation Abstracts International, 57 (09), 3736. (UMI No. 9705996). 
Cooper, W. (1999). Some philosophical aspects of leisure theory. In E. L. Jackson \& T. L. Burton (Eds.), Leisure studies: Prospects for the twenty-first century (pp. 3-15). State College, PA: Venture Publishing, Inc.

Courtney, B. (1994). Are psychological models of adult development still important for the practice of adult education? Adult Education Quarterly, 44(3), 145-153.

Csikszentmihalyi, M. (1990). Flow: The psychology of optimal experience. New York: Harper Collins.

Csikszentmihalyi, M., \& Csikszentmihaly, I. (Eds.). (1988). Optimal experience:

Psychological studies of flow in consciousness: New York: Cambridge University Press.

Csikszentmihalyi, M., \& Kleiber, D. A. (1991). Leisure and self-actualization. In B. L.

Driver, P. J. Brown, \& G. L. Peterson (Eds.). Benefits of leisure (pp. 91-102). State College, PA: Venture Publishing, Inc.

Darrough, G. P. (1990). Older participants in selected retirement community choruses. (Doctoral dissertation, Arizona State University, 1990). Dissertation Abstracts International, 51 (08), 2559. (UMI No. 910869).

Dillon, B. (1998). How important is technique for adult leisure students? Keyboard Companion, 9(4), 40-43.

Dillon, B. (1999). What technology do you use with your adult and teenage students? Keyboard Companion, 10(1), 32-35.

Driver, B. L. \& Brown, P. J. (1986). Probable personal benefits of outdoor recreation. In A literature review: President's Commission on Americans Outdoors. (pp. "Values" - 63-70.) Washington, D. C.: Government Printing Office. 
Driver, B. L., Brown, P. J., \& Peterson, G. L. (Eds.). (1991). Benefits of lesiure. State College, PA: Venture Publishing, Inc.

Driver, B. L. \& Bruns, D. H. (1999). Concepts and uses of the benefits approach to leisure. In E. L. Jackson \& T. L. Burton (Eds.), Leisure studies: Prospects for the twenty-first century (pp. 349-369). State College, PA: Venture Publishing, Inc.

Driver, B. L., Tinsley, H. E. A., \& Manfredo, M. J. (1991). The Paragraphs about Leisure and Recreation Experience Preference Scales: Results from two inventories designed to assess the breadth of the perceived psychological benefits of leisure. In B. L. Driver, P. J. Brown, \& G. L. Peterson (Eds.). Benefits of leisure (pp. 263-286). State College, PA: Venture Publishing, Inc.

Easley, A. T. (1991). Programmed, nonclinical skill development benefits of leisure activities. In B. L. Driver, P. J. Brown, \& G. L. Peterson (Eds.). Benefits of leisure (pp. 145-160). State College, PA: Venture Publishing, Inc.

Edwards, A. L. (1957). Techniques of attitude scale construction. New York: Appleton Century Crofts.

Fowler, F. J. (1988). Survey research methods. Newbury Park, CA: Sage Publications

Fraenkel, J. R., \& Wallen, N. E. (1993). How to design and evaluate research in education (2nd. Ed.). New York: McGraw-Hill.

Gay, L. R. (1992). Educational research. Competencies for analysis and application. New York: Merrill. 
Goodale, T. L., \& Cooper, W. (1991). Philosophical perspectives on leisure in Englishspeaking countries. In B. L. Driver, P. J. Brown, \& G. L. Peterson (Eds.). Benefits of leisure (pp. 25-35). State College, PA: Venture Publishing, Inc.

Graefe, A. R., Ditton, R. B., Roggenbuck, J. W., \& Schreyer, R. (1981). Notes on the stability of the factor structure of leisure meanings. Leisure Sciences, 4(1), 51-65.

Haggard, L. M., \& Williams, D. R. (1991). Self identity benefits of leisure activities. In B. L. Driver, P. J. Brown, \& G. L. Peterson (Eds.). Benefits of leisure (pp. 103119). State College, PA: Venture Publishing, Inc.

Heintzelman, T. D. (1989). Adult concert band participation in the United States. (Doctoral dissertation, Indiana University, 1989). Dissertation Abstracts International, 50 (02), 381. (UMI No. 8909091).

Henry, G. T., \& Basile, K. C. (1994). Understanding the decision to participate in formal adult education. Adult Education Quarterly, 44(2), 64-82.

Hinkle, L. B. (1988). The meaning of choral experience to the adult membership of the German singing societies comprising the United Singers Federation of Pennsylvania. (Doctoral dissertation, Pennsylvania State University, 1988). Dissertation Abstracts International,48 (10), 2568. (UMI No. 8728017).

Holland, S. (1999). Sunday evening adult recitals. Clavier, 27(2) 33.

Holt, J. (1978). Never too late: My musical life story. New York: Delta Publishing. International Society for Music Education. (1994). Declaration of beliefs for worldwide promotion of music education. International Journal of Music Education, 24, 49. 
Isaac, S. \& Michael, W. B. (1997). Handbook in research and evaluation for education and the behavioral sciences. San Diego, CA: Educational and Industrial Testing Services.

Iso-Ahola, S. E. (1980). The social psychology of leisure and recreation. Dubuque, IA: Wm. C. Brown Company.

Iso-Ahola, S. E. (1999). Motivational foundations of leisure. In E. L. Jackson \& T. L. Burton (Eds.), Leisure studies: Prospects for the twenty-first century (pp. 35-51). State College, PA: Venture Publishing, Inc.

Ivry, B. (2002, February 1). Giving amateurs a chance to grow. The Christian Science Monitor, p. 20.

Jackson, E. L. \& Burton, T. L. (Eds.). (1999). Leisure studies: Prospects for the twentyfirst century. State College, PA: Venture Publishing, Inc.

Johnson, R. G. (1982). An investigation of the initiating interests of two sub-groups of beginning pianists participating in a class piano teaching environment. (Doctoral dissertation, Ohio State University, 1982). Dissertation Abstracts International, 43 (08), 2589. (UMI No. 8300280).

Kaltoft, G. (1990). Music and emancipatory learning in three community education programs. (Doctoral dissertation, Columbia University Teacher's College, 1990). Dissertation Abstracts International, 51 (07), 2239. (UMI No. 9033861).

Kelly, J. R. (1999). Leisure and society: A dialectical analysis. In E. L. Jackson \& T. L. Burton (Eds.), Leisure studies: Prospects for the twenty-first century (pp. 53-68). State College, PA: Venture Publishing, Inc. 
Knowles, M. (1990). The adult learner: A neglected species (4 ${ }^{\text {th }}$ Ed.). Houston, TX: Gulf Publishing.

Larson, P. S. (1983). An exploratory study of lifelong musical interest and activity: Case study of twelve retired adults. (Doctoral dissertation, Temple University, 1983). Dissertation Abstracts International, 44 (01), 100. (UMI No. 8311646).

Levy, J. (2000). Leisure education, quality of life, and community development: Toward a systematic and holistic coping and resilient model for the third millennium. In A. Sivan and H. Ruskin (Eds.). Leisure education, community development, and populations with special needs. (pp. 43-54). New York: CABI Publishing.

London, M., Crandall, R., \& Fitzgibbons, D. (1977). The psychological structure of leisure: activities, needs, people. Journal of Leisure Research, 9, 252-263.

MacDonald, R. P. (1985). Factor analysis and related methods. Hillsdale, NJ: Lawrence Erlbaum Associates.

Mannell, R. C., \& Stynes, D. J. (1991). A retrospective: The benefits of leisure. In B. L. Driver, P. J. Brown, \& G. L. Peterson (Eds.). Benefits of leisure (pp. 461473). State College, PA: Venture Publishing, Inc.

Maris, B. E. (2001). Making music at the piano: Learning strategies for adult students. New York: Oxford University Press.

Mark, M. L., \& Gary, C. L. (1992). A history of American music education. New York: Schirmer Books.

Mark, M. L. (1995). Music education history as prologue to the future: Practicioners and researchers. Bulletin of Historical Research in Music Education, 16 (2), 98-121. 
Mark, M. L. (1996). Informal learning and adult music activities. Bulletin for the Council of Research in Music Education, 130, 119-122.

Maslow, A. H. (1968). Toward a psychology of being $\left(2^{\text {nd }}\right.$ Ed. $)$. Princeton, NJ: D. Van Nostrand Company, Inc.

Maslow, A. H. (1970). Motivation and personality ( $2^{\text {nd }}$ Ed.). New York: Harper and Row.

McDonald, B. L., \& Schreyer, R. (1991). Spiritual benefits of leisure participation and leisure settings. In B. L. Driver, P. J. Brown, \& G. L. Peterson (Eds.). Benefits of leisure (pp. 179-194). State College, PA: Venture Publishing, Inc.

Merriam, S. B., \& Brockett, R. G. (1997). The profession and practice of adult education: An introduction. San Francisco: Jossey-Bass.

Merriam, S. B., \& Caffarella, R. S. (1999a). Learning in adulthood $\left(2^{\text {nd }}\right.$ ed.). San Francisco: Jossey-Bass.

Merrriam, S. B., \& Caffarella, R. S. (1999b). Perspectives on adult learning: Framing our research. In: Proceedings of the Annual Adult Education Research Conference, Northern Illinois University, (pp. 62-67).

Mueller, J. H. (1958). Music and education: A sociological approach. In N. B. Henry (Ed.). Basic concepts in music education: The fifty-seventh yearbook of the National Society for the Study of Education (pp. 88-122). Chicago: University of Chicago Press.

Murphy, J. \& Sullivan, G. (1968). Music in American society: An interpretive report of the Tanglewood Symposium. Reston, VA: Music Educators National Conference. 
Music Educators National Conference (1974). The school music program: Descriptions and standards. Reston, VA: Music Educators National Conference.

National Endowment for the Arts. (1997). 1997 Survey of public participation in the arts. Retrieved February 23, 2003, from http://arts.endow.gov/pub/Survey/Survey.pdf.

Orthner, D. K. (1975). Leisure activity patterns and marital satisfaction over the marital career. Journal of Marriage and the Family, 37, 91-102.

Orthner, D. K., \& Mancini, J. A. (1991). Benefits of leisure for family bonding. In B. L. Driver, P. J. Brown, \& G. L. Peterson (Eds.). Benefits of leisure (pp. 289-301). State College, PA: Venture Publishing, Inc.

Palisi, B. J. (1984). Marriage companionship and marriage well-being: A comparison of metropolitan areas in three countries. Journal of Comparative Family Studies, $15,43-56$.

Patterson, F. C. (1985). Motivational factors contributing to participation in community bands of the Montachusett region of north central Massachusetts. (Doctoral dissertation, The University of Connecticut, 1985). Dissertation Abstracts International, 46 (07), 1776. (UMI No. 8520664).

Price, L. (2001, January 20). Striking a chord: It's never too late to learn to play music. The Dallas Morning News, pp. C1-C2.

Rainbow, E. L., \& Froehlich, H. C. (1987). Research in music education: An introduction to systematic inquiry. New York: Schirmer Books.

Rencher, A. C. (1995). Methods of multivariate analysis. New York: John Wiley \& Sons. 
Roggenbuck, J. W., Loomis, R. J., \& Dagostino, J. V. (1991). The learning benefits of leisure. In B. L. Driver, P. J. Brown, \& G. L. Peterson (Eds.). Benefits of leisure (pp. 195-213). State College, PA: Venture Publishing, Inc.

Rosenthal, D. H., Driver, B. L., \& Waldman, D. (1982). Construct validity of instruments measuring recreationists' preferences. Leisure Sciences, 5(2), 89-108.

Rossman, B. B., \& Ulehla, Z. J. (1977). Psychological reward values associated with wilderness use: a functional-reinforcement approach. Environment and Behavior, 9(1), 41-65.

Rybak, C. A. (1995). Older adults and Flow: Investigating optimal experience in selected music leisure activities. (Doctoral dissertation, Arizona State University, 1995). Dissertation Abstracts International, 56 (12), 4695. (UMI No. 9611711).

Seago, T. (1993). Motvational factors influencing participation in selected Southern Baptist church choirs. (Doctoral dissertation, The University of Houston, 1993). Dissertation Abstracts International, 54 (05), 1718. (UMI No. 9320319).

Spell, G. M. (1989). Motivational factors and selected socio-demographic characteristics of Georgia community chorus participation as measured by the education participation scale, the community chorus participation scale, and the personal inventory form. (Doctoral dissertation, The University of Georgia, 1989). Dissertation Abstracts International, 51 (02). (UMI No. 9018368).

Spencer, W. D. (1996). An attitude assessment of amateur musicians in adult community bands. Unpublished doctoral dissertation, The University of North Texas. 
Spreitzer, E. \& Snyder, E. E. (1975). The psychosocial functions of sport as perceived by the general population. International Review of Sport Sociology, 10(3-4), 87-95.

Stebbins, R. A. (1992). Costs and rewards in barbershop singing. Leisure Studies, 11, 123-133.

Stebbins, R. A. (2001). New directions in the theory and research of serious leisure. Lewiston, NY. Edwin Mellen Press.

Tinsley, H. E. A., Barrett, T. C., \& Kass, R. A. (1977). Leisure activities and need satisfaction. Journal of Leisure Research, 9, 110-120.

Tinsley, H. E. A., \& Bowman, S. L. (1986). Discriminant validity of the Paragraphs about Leisure for expert and naïve respondents. Educational and Psychological Measurement, 46, 461-465.

Tinsley, H. E. A., Driver, B. L., \& Kass, R. A. (1982). Reliability and concurrent validity of the recreation experience preference scales. Journal of Educational and Psychological Measurement, 41(3), 897-907.

Tinsley, H. E. A., \& Johnson, T. L. (1984). A preliminary taxonomy of leisure activities. Journal of Leisure Research, 16, 234-244.

Tinsley, H. E. A., \& Kass, R. A. (1978). Leisure activities and need satisfaction: A replication and extension. Journal of Leisure Research, 10, 191-202.

Tinsley, H. E. A., \& Kass, R. A. (1979). The latent structure of the need-satisfying properties of leisure activities. Journal of Leisure Research, 11, 278-291. 
Tinsley, H. E. A., \& Kass, R. A. (1980a). The construct validity of the Leisure Activities Questionnaire and of the Paragraphs about Leisure. Educational and Psychological Measurement, 40, 219-226.

Tinsley, H. E. A., \& Kass, R. A. (1980b). Discriminant validity of the Leisure Activities Questionnaire and the Paragraphs about Leisure. Educational and Psychological Measurement, 40, 227-233.

Tinsley, H. E. A., Teaff, J. D., Colbs, S. L., \& Kaufman, N. (1985). A system of classifying leisure activities in terms of the psychological benefits of participation reported by older persons. Journal of Gerentology, 49, 172-178.

Tuijnman, A. C. (Ed.). (1996). International encyclopedia of adult education. Oxford: Pergamon.

U. S. Census Bureau. (1999). Statistical abstract of the United States: $1999\left(119^{\text {th }}\right.$ ed.). Washington, D.C.: U.S. Census Bureau.

U.S. Census Bureau. (2001) Census 2000 summary file 1 (SF-1) 100 percent data. GTC-PH1: Population, housing units, area, and density, 2000. Retrieved March 2, 2003, from http://factfinder.census.gov.

U.S. Department of Commerce. (2003). Bureau of Economic Analysis: National income and product accounts tables: Table 2.9. Personal income and its disposition. Retrieved February 15, 2003, from http://www.bea.doc.gov/bea/dn/nipaweb/index.asp. 
Valentine, T. (1997). The United States of America: The current predominance of learning for the job. In P. Belanger \& S. Valdivielso (Eds.), The emergence of learning societies: Who participates in adult learning? (pp. 95-108). Oxford: Pergamon and UNESCO Institute for Education.

Veal, A. J. (1997). Research methods for leisure and tourism: A practical guide. Great Britain: Pittman Publishing.

Veblen, T. (1899). The theory of the leisure class. New York: Macmillan Company. Vincent, P. M. (1997). A study of community choruses in Kentucky and implications for music education. (Doctoral dissertation, The University of Kentucky, 1997). Dissertation Abstracts International, 58 (06), 1982. (UMI No. 9735637).

Wlodkowski, R. J. (1999). Enhancing adult motivation to learn (Rev. ed.). San Francisco: Jossey-Bass.

Wankel, L. M., \& Berger, B. G. (1991). The personal and social benefits of sport and physical activity. In B. L. Driver, P. J. Brown, \& G. L. Peterson (Eds.). Benefits of leisure (pp. 121-144). State College, PA: Venture Publishing, Inc. 